\title{
Should We Cooperate? Game Theory Insights for Servitization.
}

DOI:

10.1108/JOSM-11-2020-0430

\section{Document Version}

Accepted author manuscript

Link to publication record in Manchester Research Explorer

\section{Citation for published version (APA):}

Wagstaff, S., Burton, J., \& Zolkiewski, J. (2021). Should We Cooperate? Game Theory Insights for Servitization. Journal of Service Management. https://doi.org/10.1108/JOSM-11-2020-0430

\section{Published in:}

Journal of Service Management

\section{Citing this paper}

Please note that where the full-text provided on Manchester Research Explorer is the Author Accepted Manuscript or Proof version this may differ from the final Published version. If citing, it is advised that you check and use the publisher's definitive version.

\section{General rights}

Copyright and moral rights for the publications made accessible in the Research Explorer are retained by the authors and/or other copyright owners and it is a condition of accessing publications that users recognise and abide by the legal requirements associated with these rights.

\section{Takedown policy}

If you believe that this document breaches copyright please refer to the University of Manchester's Takedown Procedures [http://man.ac.uk/04Y6Bo] or contact uml.scholarlycommunications@manchester.ac.uk providing relevant details, so we can investigate your claim.

\section{OPEN ACCESS}




\section{Should We Cooperate? Game Theory Insights for Servitization.}

\begin{tabular}{|r|l|}
\hline Journal: & Journal of Service Management \\
\hline Manuscript ID & JOSM-11-2020-0430.R2 \\
\hline Manuscript Type: & Research Paper \\
\hline Keywords: & $\begin{array}{l}\text { Servitization, Game Theory, Oil Industry, Servitization Dynamics, } \\
\text { Business Relationships, Mixed Methods }\end{array}$ \\
\hline \multicolumn{2}{|l}{} \\
\hline
\end{tabular}

\section{SCHOLARONE ${ }^{m}$ \\ Manuscripts}




\title{
Should We Cooperate? Game Theory Insights for Servitization
}

\begin{abstract}
Purpose: An abundance of literature suggests that organisations adopting a cooperative approach achieve greater rewards than those that act in opposition or isolation. An emerging body of work also highlights the multiple actors involved in servitization. Despite this, in some contexts, the benefits of servitization are not apparent. This paper examines business relationships in the oil industry and how they affect levels of servitization.
\end{abstract}

Design/Methodology/Approach: A mixed method study employing qualitative and quantitative methods was used to fully explore the context. In the quantitative phase, 48 oil industry specialists responded to a scenario based on game theory. This aimed to determine if the relationships between their respective organisations are cooperative or adversarial. Abduction drove a second qualitative phase. This consisted of a series of semi-structured interviews that were used to explore the servitization level and influence of servitization on relationships and vice versa.

Findings: The statistical results suggest all parties used adversarial strategies despite the publicised intent to work cooperatively. The interviews suggested that increasing (decreasing) servitization could increase (decrease) cooperation and, in turn, value cocreation but revealed nuances to this effect. It also adds to our understanding of the darker side of servitization by illustrating the impact of mimetic isomorphism.

Originality/Value: The findings add to understanding of the complex dynamics around servitization by showing that it is only at advanced levels of servitization that cooperative behaviour is observed, and base and intermediate levels result in non-cooperative behaviour and thus illustrate the importance of adopting a multi-actor lens to explore servitization.

KEYWORDS: Servitization Dynamics, Game Theory, Oil Industry, Business Relationships, Mixed Methods

\section{Introduction}

The extant literature tends to focus on success stories, e.g., IBM, Rolls Royce and Xerox (Ng et al., 2012) and suggests a steady progression from supply of base services through intermediate, to provision of advanced services (Baines and Lightfoot, 2013). However, there is growing recognition that not all organizations follow a smooth transition journey, with reports of a service paradox (Gebauer et al., 2005), service failure and deservitization 
(Kowalkowski et al., 2017, Valtakoski, 2017). Researchers are beginning to explore why this is so. Factors such as tensions (Burton et al., 2016), servitzation intent (Crowley et al. 2018), the challenges of developing appropriate service strategies, (Raddats and Kowalkowski, 2014; Raddats et al., 2018), and the paradoxical nature of servitization (Kohtamaki et al., 2020) illustrate the complexities of the challenges facing an organization that embarks on a servitization journey.

Hence, this research uses a relational lens to explore servitization that has not progressed to an advanced level and to understand what prevents servitization from being perceived as beneficial by both parties. Thus, we have identified a context where progression to advanced services has not been fully realized. Moving to a multi-actor perspective necessitates recognition of the complex network of relationships any organization is embedded in (Håkansson \& Snehota, 2017). These networks and the individual relationships within them are often cooperative (Dyer \& Nobeoka, 2000) and require trust and commitment (Morgan \& Hunt, 1994). However, the impact of changes, such as introducing advanced services, on individual relationships remains under-explored. This motivated our research questions: 1) How does cooperation within a relationship affect the transition to advanced services? 2) What are the strategies adopted by both actors in a relationship when faced with the introduction of more advanced levels of service? 3) how do changes in servitization level impact on cooperation?

This paper provides a novel perspective and contribution to servitization by exploring how game theory (Lima et al., 2018) can enhance our understanding of an area where servitization appears to be stalled at the intermediate level: the oil industry. Game theory provides a robust method to analyse strategy in business relationships in comparison to analysing intended or stated strategies. In order to improve the robustness of our findings, a qualitative phase of research was then used to explore the potential for servitization to influence the adversarial or cooperative nature of business relationships. Drawing on this, our contribution is to show that it is only high levels of servitization (advanced services) that facilitate cooperative behaviour. This illustrates the paradoxical, non-linear and complex relationship between service provision and cooperative behaviour and the strategies that drive this in a servitization context.

The remainder of this paper is structured as follows, first we review relevant literature and develop our conceptual framework. We then describe the methods employed, present our findings, discuss the implications and propose future areas of investigation.

\section{Literature Review}

\subsection{Servitization}

Traditionally, servitization is described as the process a manufacturing organisation undergoes to increase their competitive advantage by developing the services they offer to their customers (Baines et al., 2009; Kamp and Parry, 2017). Servitization achieves this advantage by creating additional revenue streams that change the existing business focus 
from product-centricity to service-centricity and, in doing so, differentiates the manufacturer and customer from their peers within the network (Raddats et al., 2015). This change of focus often requires transformation (Kowalkowski et al., 2017) and more recently the processes that garner this change are being explored (Baines et al., 2020). Much extant research takes a focal manufacturer perspective (Raddats et al., 2019) and fails to address the complex network/service ecosystem of manufacturers and customers involved in servitization (Ferreira et al., 2013; Story et al., 2017). Additionally, the provision of advanced services remains difficult and, if they are to become more than tools to enhance competitiveness, they must be exploited fully by both manufacturers and customers (Salonen et al., 2017).

$\mathrm{Ng}$ et al., (2012) argue that transformation from an entrenched goods-dominant logic to a service-dominant logic mindset is a significant challenge and critical to the success of servitization. However, recent literature argues that this dichotomous 'either-or' thinking should be replaced by a recognition of hybrid approaches (Burton et al., 2017) and 'both-and' thinking (Kohtamäki et al., 2020). Goods and services are interdependent and, therefore, organisations cannot simply choose between a service-dominant logic and a goods-dominant logic mindset, instead, they should embrace a paradoxical 'both-and' approach.

Although servitization is gaining traction and many manufacturers are adding a variety of services to their portfolios (Baines et al., 2020), this pattern is not uniform. Some companies are deservitizing (Kowalkowski et al., 2017). Others appear not to fully embrace or implement service-focussed strategies (Raddats et al., 2018) or possess the capabilities needed to effectively make the transition (Reim et al., 2019). Digital technologies, e.g., big data, cloud computing and the internet of things (IoT), can enable, drive and shape the application of servitization (Kohtamäki et al., 2019; Tronvoll et al., 2020). However, it is the strategy and not the technology which should drive the servitization process (Peillon and Dubruc, 2019) and the broad range of factors that influence this means that successful servitization is not always guaranteed (Lexutt, 2020). Barriers to success may be due to employees' general lack of understanding about their organisation's current level of servitization, which in turn is related to their level of education in the process of servitization, rather than a failing of servitization itself (Shi et al.,2017; Salonen et al., 2017). It has also been suggested that the lack of a servitization strategy can lead to fragmentation of the organisation, which may result in a reduced return on the investment in servitization or, in extreme circumstances, complete deservitization (Gebauer and Kowalkowski, 2012; Kowalkowski et al., 2015). This suggests more understanding of such strategic decisionmaking processes is needed.

\subsection{Game Theory (Exploring Strategic Decision Making)}

Game theory is traditionally used to explore, guide and interpret the strategic decisionmaking of rational parties (Lima et al., 2018). It is used as a tool to simultaneously find the optimum balance of maximum payoff and minimal risk for a given situation (Tadelis, 2013). There are two strategies in game theory: cooperative and non-cooperative. In a noncooperative strategy, each party attempts to get the best payoff for themselves by employing 
a strategy which includes the unknown strategies and counterstrategies of the other parties. In contrast to this, in a cooperative strategy, the parties are free to make agreements and alliances to increase the likelihood of a fair outcome for each party (Peleg and Sudhölter, 2007).

A central tenet in cooperative game theory is the Shapley value (Shapley, 1953). It is used in cooperative game theory to calculate a fair distribution of rewards or costs based upon the contributions of each participant (Calleja and Llerena, 2020). The Shapley value was intended to model the interactions of participants who choose to cooperate, unlike participants in a non-cooperative scenario (Winter, 2002). Therefore, if the results of an interaction resemble the Shapley value prediction, it can be posited that the participants were playing a cooperative game strategy (Algaba et al., 2019). Hence, using the Shapley value can distinguish between a cooperative and non-cooperative strategy in an interaction between two or more participants (Algaba et al., 2019).

Due to the recent introduction of modern mathematical tools, game theory is now widely accessible to scholars and the general public (Ross, 2019) with the majority of applications employed in financial strategies (Chatterjee and Samuelson, 2014). However, new managerial applications of game theory have grown considerably, especially in the interpretation of 'big data' for predictive analysis. Here, game theory uses past information to predict future events, reduce risk, and maximise returns (Hammoudi, 2018).

Despite this, the use of game theory in conjunction with servitization is limited (Zhong, 2014). One notable exception is a paper written by Gao (2019), which uses game theory to show the equilibrium positions of an organisation's servitization evolution. Gao (2019) concludes that for the successful adoption of servitization the net servitization revenue must be positive and is also contingent upon the servitization position of the manufacturer's counterpart. Additionally, although with a slightly different focus, an evolutionary game approach has been adopted to explore outsourcing as part of servitization; this research highlights the importance of collaborative approaches when it is difficult to provide highquality services (Ma et al., 2020). On the other hand, there are several papers written about the unrelated subject of gamification and servitization (Hezarkhani, 2017; Lee et al., 2016; Süße and Wilkens, 2014). Gamification is a teaching and learning tool which reflects the growing popularity of games in everyday life (Koivisto and Hamari, 2019; Shi et al., 2013; Welbers et al., 2019), rather than game theory, which is a method to understand and guide strategic decisions (Lima et al., 2018).

\subsection{Research Gap and Conceptual Framework}

Business relationships and their dimensions, e.g., trust, commitment, cooperation, coordination are discussed extensively in the supply chain, business-to-business marketing and organizational behaviour literature (e.g. Dyer \& Nobeoka, 2000, Håkansson \& Snehota, 2017). However, this discussion is only now beginning to be introduced into the servitization context as focus moves away from the manufacturer as the focal actor and towards a multi- 
actor perspective (e.g. Story et al., 2017) network (e.g. Huikkola et al., 2020), and relational perspectives (e.g. Kamalaldin et al., 2020). Digital servitization research focuses on the servitization ecosystem, which involves relationships that are focused on mutual value creation and shared goals (Kohtamäki et al., 2019; Lusch and Nambisan, 2015; Sklyar et al., 2019; Story et al., 2020) and are essential to the servitization process and continued success of the servitized ecosystem (Opresnik and Taisch, 2015). Much of the extant literature views servitization as process undertaken by manufacturers in isolation (Raddats et al., 2019). The literature which discusses the customer or intermediaries tend to regard servitization as an intra-company process (Raddats et al., 2017) or from the perspective of the manufacturer or the customer and neglect the collaborative perspective of servitization (Finne and Holmström, 2013; Polova, 2020). However, the benefits and rewards of collaboration are beginning to be acknowledged in the discussion around digital servitization (Tronvoll et al., 2020).

Scholars agree that collaboration between actors is required for the application and development of advanced services and servitization (Story et al., 2017; Polova, 2020). This collaboration relies upon the shared interests and knowledge each party brings to the table (Burton et al., 2016; Polova, 2020) and aligning these attributes to the mutual benefit and value co-creation of all parties (Finne and Holmström, 2013; Raddats et al., 2017). Research has shown that organisations that collaborate are more successful than those that do not (Raddats et al., 2019). However, it is also noted that servitization collaboration is a difficult undertaking that requires the sharing of trust and commitment during the entire process (Polova, 2020). Additionally, the review of the literature suggests more understanding of servitization strategies and the associated decision making is needed. Using the lens of game theory to examine the nature of the relationship between oil industry organisations provides a mechanism with which to view these interactions and involves a novel mechanism for this exploration.

Table I suggests that advanced levels of servitization produce more cooperative relationships where risk and reward are more likely to be shared between the manufacturer and customer (Baines and Lightfoot, 2013). Simply stated, a manufacturer cannot work in isolation from their customer and cooperation is required for collaboration and servitization (Kohtamäki et al., 2019). Similarly, when servitization levels are at a base level the provision of services are much reduced and the need for advanced levels of cooperation are not observed (Kremer et al., 2016). As such, at the intermediate level the relationship is more complex with potential for some cooperative behaviour to emerge. Therefore, if the level of servitization can be determined, this will provide insight into the level of cooperation that exists in the given relationship, and vice versa.

***Insert Table I here****

However, it is difficult to know if this claim is a reality and carried out in practice at all levels within organisations. Game theory focuses on the employed strategy and not the intent (Elkind and Rothe, 2016; Peleckis, 2015). Therefore, by analysing the strategy used in the 
relationship between two actors, we can compare the intended and actual strategies used by either party. Thus, the following research questions were created:

1. How does cooperation within a relationship affect the transition to advanced services?

2. What are the strategies adopted by both actors in a relationship when faced with the introduction of more advanced levels of service?

3. How do changes in servitization level impact on cooperation?

\section{Methodology}

The research questions provide an opportunity to employ a mix of quantitative and qualitative insight in order to understand the phenomena. A mixed methods approach that combines complimentary qualitative and quantitative methods is adopted; thereby benefiting from the relative strengths and reducing the individual weaknesses of each method (Brewer and Hunter, 1989). This is in-line with the definition proposed by Johnson et al., (2007, pg. 123) whereby "a researcher or team of researchers combines elements of qualitative and quantitative research approaches (e.g., use of qualitative and quantitative viewpoints, data collection, analysis, inference techniques) for the broad purposes of breadth and depth of understanding and corroboration. Using a mixed method allows triangulation of the findings (Denzin, 1978) whereby observations can be verified using more than one method, thereby "increase[ing] their scope, depth and consistency" (Flick, 2009, p. 445). A sequential explanatory design was adopted (Creswell et al., 2003) as illustrated in Figure 1.

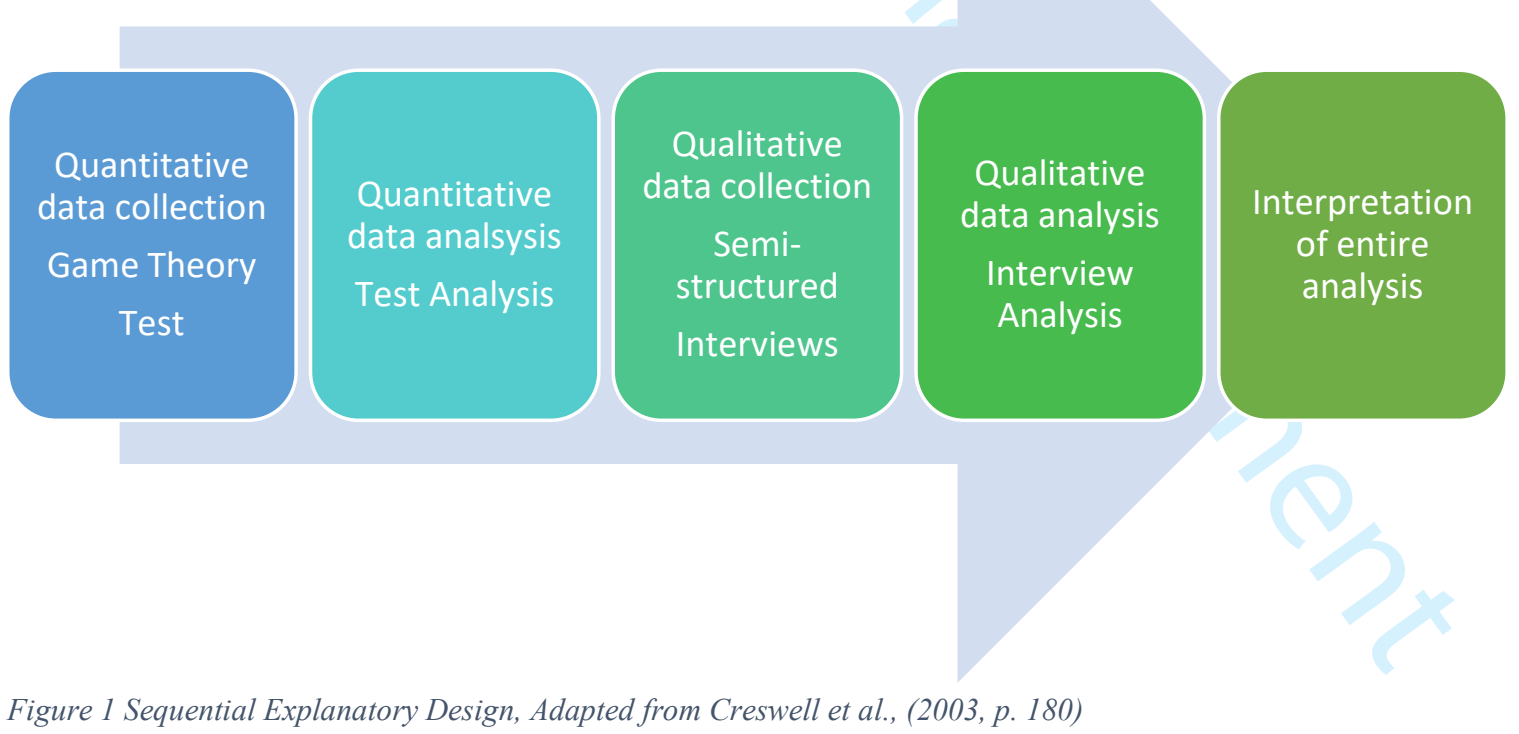

The different phases, their analysis and the research context chosen for the research are described in the sections below. The procedures outlined by Harrison et al., (2020) to ensure rigour in mixed methods research have been used to guide this process, e.g., reporting the different data collection and analysis procedures and illustrating how the different data 
strands contribute to the discussion and conclusions. The research uses the interorganisational relationships between Operators (OP) (the users of these services and equipment) and Service Companies (SC) (suppliers of equipment and technical services in the industry), as the unit of analysis. These relationships are explored from the perspectives of the employees working for these organisations.

\subsection{Research Context}

The research context necessary to explore these questions needed to be one in which high levels of servitization are not evident. Generally, studies considering the topic of servitization within the oil industry are sparse. However, the available literature highlights that most organisations lack a definitive servitization strategy (Bandinelli and Gamberi, 2011; Kumar and Markeset, 2007). This suggests that the oil industry could provide a suitable research context. Oil is a volatile global commodity and an important export for many nations (Kesicki, 2010) making it a highly political product (Parra, 2004). Additionally, the extraction, transportation and combustion of oil and its derivatives can have detrimental effects on the natural environment. Currently, standard extraction practices mean that only $20 \%-34 \%$ of the oil in a reservoir can be recovered with the remaining oil being permanently lost (Bentley, 2002; Zitha et al., 2008). However, with pre-planning, advanced procedures and new technologies this can, in some instances, be increased to $35 \%-45 \%$ (Bentley, 2002; Zitha et al., 2008). Cooperation between all stakeholders is needed to realise the associated political, environmental and financial gains achieved by increasing the recovery factor (Alvarado and Manrique, 2010; Åm and Heiberg, 2014). Servitization would be a potential route to achieve this. Despite SC showcasing such promises in their promotional material, e.g. ("Mission, Vision, Values", 2020; "Who We Are", 2020), there is limited evidence of cooperation in practice. Additionally, the OP seem reluctant to either engage in cooperative practices or accept the benefits servitization can provide. Thus, our research attempts to determine the prevalence of advanced levels of servitization within this industry. This conflicting focus within the OP and SC relationship highlights an interesting research area and, thus, the purpose of this research is to explore the relationship between servitization and the strategies that are in play in this context. To this effect, game theory is used to examine these relationships in practice to determine if they are adversarial or cooperative in nature and to identify the actual strategies being used. Building on this, a semi-structured interview process was used to develop understanding and context of the cooperative/non-cooperative processes identified in the test (Korstjens and Moser, 2017).

\subsection{Game Theory Test}

Figure 2 below shows the conceptual framework for the Game Theory Test. Starting from the left, it is proposed that if the servitization level between two actors is at a base level (Baines and Lightfoot, 2013) their relationship is likely to be adversarial (Kemp and Stephen, 1999). Similarly, if the servitization relationship is advanced, then their relationship is likely to be cooperative. This paper seeks to investigate if changing the servitization level, indicated by the double-headed arrows below, can change a relationship from adversarial to cooperative and vice versa. 


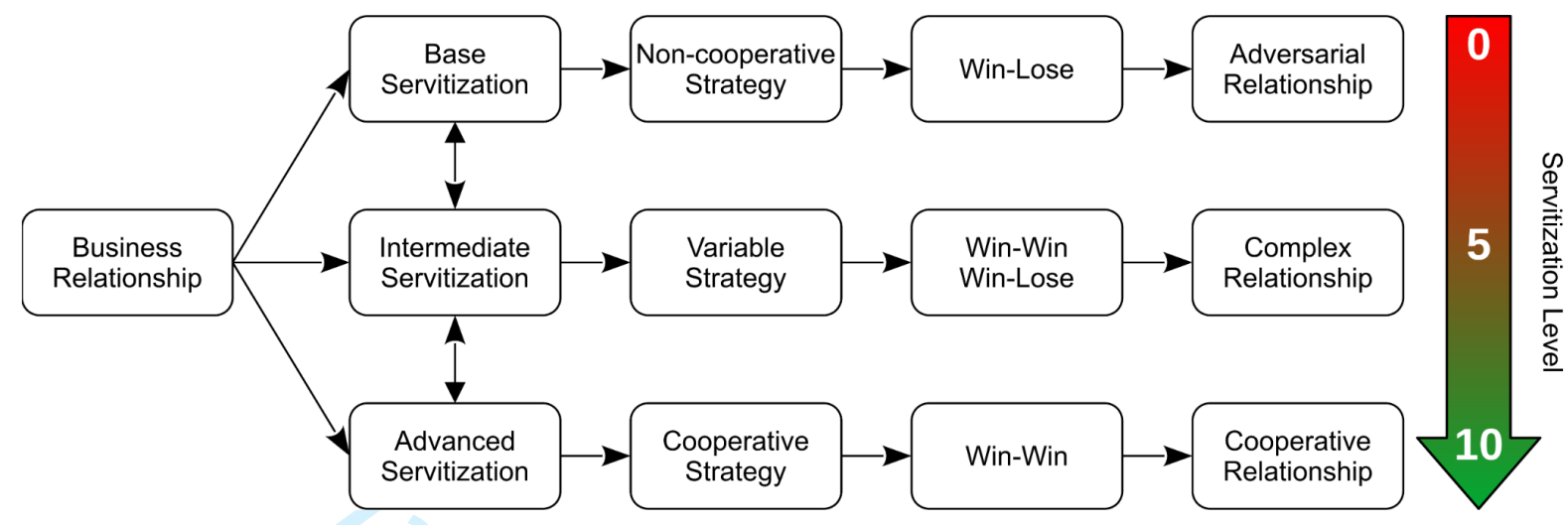

Figure 2 Hypothesised relationship between servitization level and game type

For this test, a sample size of 48 was deemed appropriate, see Table II below. The age of the subjects ranged from 25 to 51 with a median age of 43.0 years. The experience levels range from 12 to 39 years with a median value of 23.0 years. The nationalities were diverse and included: Europe, North and South America, the Middle East, Asia and Australasia. All of those questioned had experience in several geographic locations and had worked with several organisations. This combination offers a rich breadth of experience and knowledge and enables the provision of a comprehensive data set. The subjects were identified using a selective strategy (Easterby-Smith et al., 2012) to ensure that they possessed the knowledge and experience of the oil industry needed to produce reliable data. Criticism is often made of such convenience sampling methods as not producing generalizable findings (Bryman, 2012). However, this paper is specifically focused on the oil industry, therefore, a selective sampling method enabled the selection of a group that was sufficiently diverse and representative by ensuring diversity in organisation type, experience levels and geographic locations. Post-hoc analysis confirms that the effects were sufficiently pronounced that the sample size of 48 produced a statistical power $>0.8$, see Table III. All respondents were contacted in advance and gave their consent to undertake the test and take part in a subsequent interview if randomly selected.

Departing from the traditional methodological application of game theory, this paper takes a novel approach to this research by using a game theory lens to investigate servitization strategy. This determination is achieved by inverting the typical game theory approach to use the outcomes of the game to understand the strategy being employed by each player, unlike typical applications which use game theory to develop the best strategy for a given situation. Game theory was selected as it provides an insight into the strategy being employed by each 'player' and allows the researcher to understand the actual strategy being used in a realistic representative scenario, and if a contradiction exists between this and the intended or expressed strategy of the player. Game theory is an established method used to work with game strategy, and so will produce robust findings (Peleg and Sudhölter, 2007; Tadelis, 2013). Other methods of analysis were unlikely to sufficiently address the strategy element of 
the interorganisational relationships in a format that is as established and accessible as game theory. The test is based on the classic game theory prisoners' dilemma (Dixit and Nalebuff, 2010).

\section{***Insert Table II here***}

\subsection{Strategy Testing}

A game theory test was selected to investigate the expressed strategy used by employees within the oil industry. Game theory, unlike other methods, focuses on strategy and therefore has the virtue of discovering the actual conscious or subconscious strategy used and not the expressed strategy of the player. Game theory is also a modern, but well-established, method for determining strategy and strategic outcomes of scenarios like the one presented to the test participants and can, therefore, be relied upon to provide robust findings. The participants were directed to complete a test to determine if they elected to use a cooperative or adversarial strategy when they were dealing with their regular day-to-day business partners. The test consisted of a version of the established prisoners' dilemma (Dixit and Nalebuff, 2010) modified with a realistic oilfield scenario where the Service Company (SC) provided a new tool generating a saving for the Operator (OP). The test used an inverted version of the prisoners' dilemma where the aim of the test was not to determine the outcome, which was already known, instead it was to use the outcome to determine the type of game strategy being employed by each actor, specifically competitive or non-competitive. One version (High reward) of the test examined a saving of $\$ 1,025,000$ and the other version (Low reward) a lesser saving of $\$ 350,000$. The difference in values between the two tests determined if value was a factor in the strategy of either party, the tests were otherwise identical.

During the test, the participants were asked to allocate a percentage share of the saving to the $\mathrm{SC}$ responsible for creating the saving. Each participant was asked to allocate the saving value based on what they thought was fair. The same participant was then asked to reconsider the realistic saving value based upon their experience and expectation if the event occurred in their current organisation, both these values were recorded.

\subsection{Semi-structured Interviews}

After the analysis of the Game Theory test, semi-structured interviews were carried out on a subset of the original forty-eight test participants. All test participants were contacted; three or four of each of the groups (high reward service company [HS], high reward operator [HO], low reward service company [LS] and low reward operator [LO]) were interviewed. Analysis of the interviews took place alongside the interviews; after interview nine no additional themes emerged, i.e. thematic saturation was achieved (Galvin, 2015). However, a total of thirteen interviews were conducted to balance the representation from each of the four groups used in the game theory test shown in Table II. Each interview was conducted one-to-one, via Skype or in-person depending on the interviewee's location and lasted between 45 and 60 minutes. 
In the interviews, interviewees were first asked to identify the level of servitization of their current organisation based on the scale, shown in Table I, created by Baines and Lightfoot (2013) which has three levels: base, intermediate and advanced. There are many scales available such as Fang et al. (2008) who base their assessment on service revenue, or Homburg et al. (2002) who use the number of services as a measurement. Unlike these, which focus on a single parameter, the Baines and Lightfoot (2013) scale uses a broad range of factors to identify servitization levels. The scale does not require a lengthy analysis of data, for example, company accounts, and is written in a format that practitioners can easily understand and in subject areas they were familiar with without lengthy instruction. This scale was ideally suited for the relatively short interview sessions with subjects that were not familiar with servitization at a detailed academic level.

After the servitization level of the interviewee's organisation was identified, each of the interviewees was then interviewed about their experience of value co-creation and servitization levels in relation to cooperative and adversarial relationships. This part of the research process was designed to expand further on the initial results of the quantitative research, adding context and clarification. In order to understand the effect of base, intermediate or advanced levels of servitization the interviewees were also asked, via multiple questions, to comment if these servitization levels were more or less conducive to adversarial or cooperative relationships based on experience from their prior working history and experiences.

\subsection{Qualitative Analysis}

Each interview was then transcribed and analysed using the NVivo 12 software platform. An abductive approach was adopted for the qualitative analysis (Dubois and Gadde, 2002), which aligns with the method proposed by Gioia et al. (2013) who advise changing the research questions to progress the research in new directions. Initially 5 themes and 15 subthemes were identified through discussion amongst the three coders to determine the servitization level and the influence of servitization on cooperation or non-cooperation. These first and second order themes increased to 7 themes and 28 sub-themes due to the abductive discursive process; a detailed summary is provided in the findings section. Gioia et al. (2013) state that qualitative rigor begins with defining first and second order categories, or themes to be used during qualitative research, this is represented in figure 3 below for this research. 


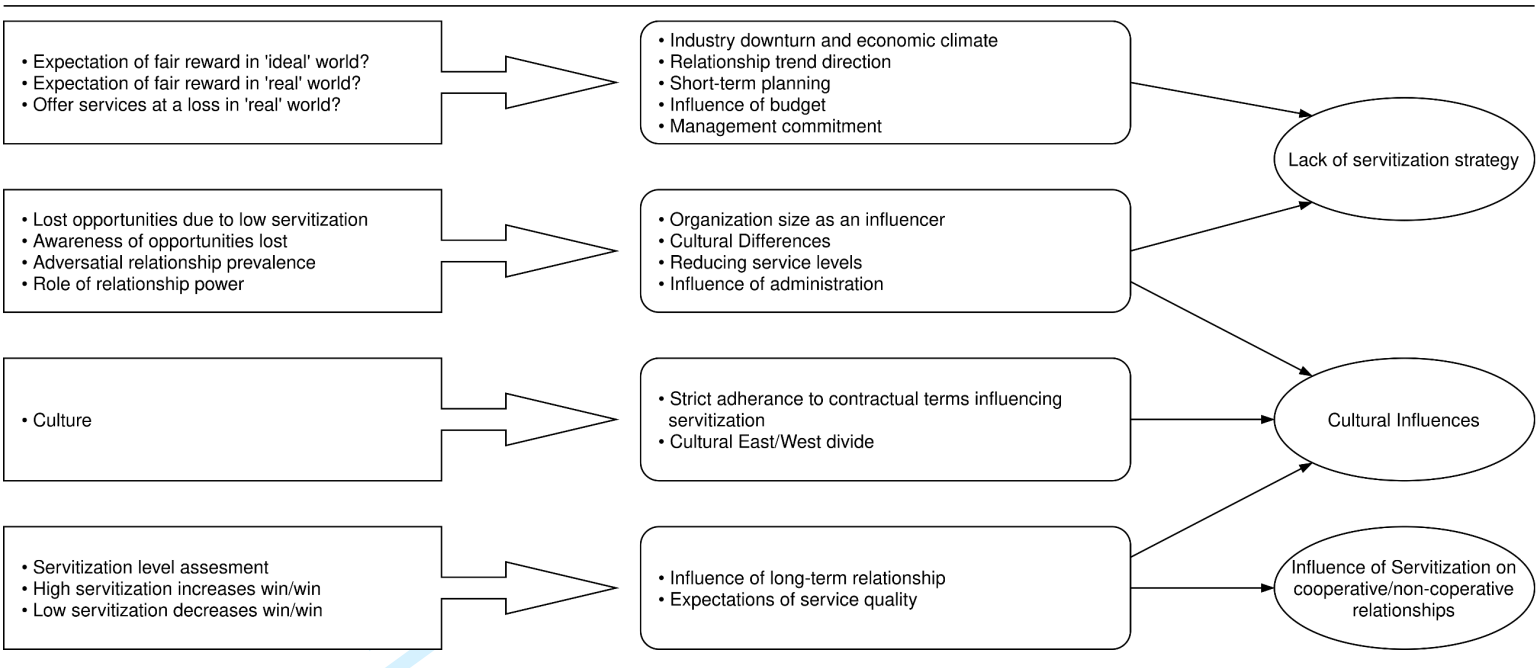

Figure 3: Data Structure, Adapted from Corley and Gioia (2004, p. 184)

\section{Findings}

\subsection{Fairness and Strategy}

The Shapley value states that each participant receives a reward that is fair in relation to their investment. This is characterized by the 'null player property' which states that if a participant contributes zero, then their reward should be zero (Calleja and Llerena, 2020). Thus, the Shapley value was used to indicate if the strategies being displayed during the test and the outcome of the interaction were cooperative or non-cooperative. If the test found that a reward distribution approximated the Shapley value, this would indicate that all parties are acting cooperatively. If the value differs from the Shapley value, this indicates that they acted with a non-cooperative or adversarial strategy.

To determine if the participants in the test were cognisant of their cooperative or noncooperative position, the value of their fair and realistic awards were compared. If the values were dissimilar, then each party was cognisant that the award they had offered was unfair, and they were, therefore, knowingly acting in a non-cooperative way. If the values were similar, this indicated the intention to act fairly and cooperatively. However, if the values were appreciably different from the Shapley value, then they were not behaving cooperatively, but were not cognisant of it. This is represented in Figure 4 below: 


\section{Figure 4: Fairness Analysis Flow Chart}

The following charts show the award to the SC for making high (Graph 1) and low (Graph 2) savings during the oilfield dilemma test. It is interesting to observe that in all cases the proposed reward is substantially lower than the Shapley value. In addition to this, and in all cases, there is a significant difference between the fair award and the realistic award, signifying that both parties were aware that the award was not fair. Median values and interquartile ranges (IQR) were used to represent central tendency rather than the mean, which can present a skewed representation based upon the recommendation of Murphy et al. (1998) and Hartwig et al. (2020).

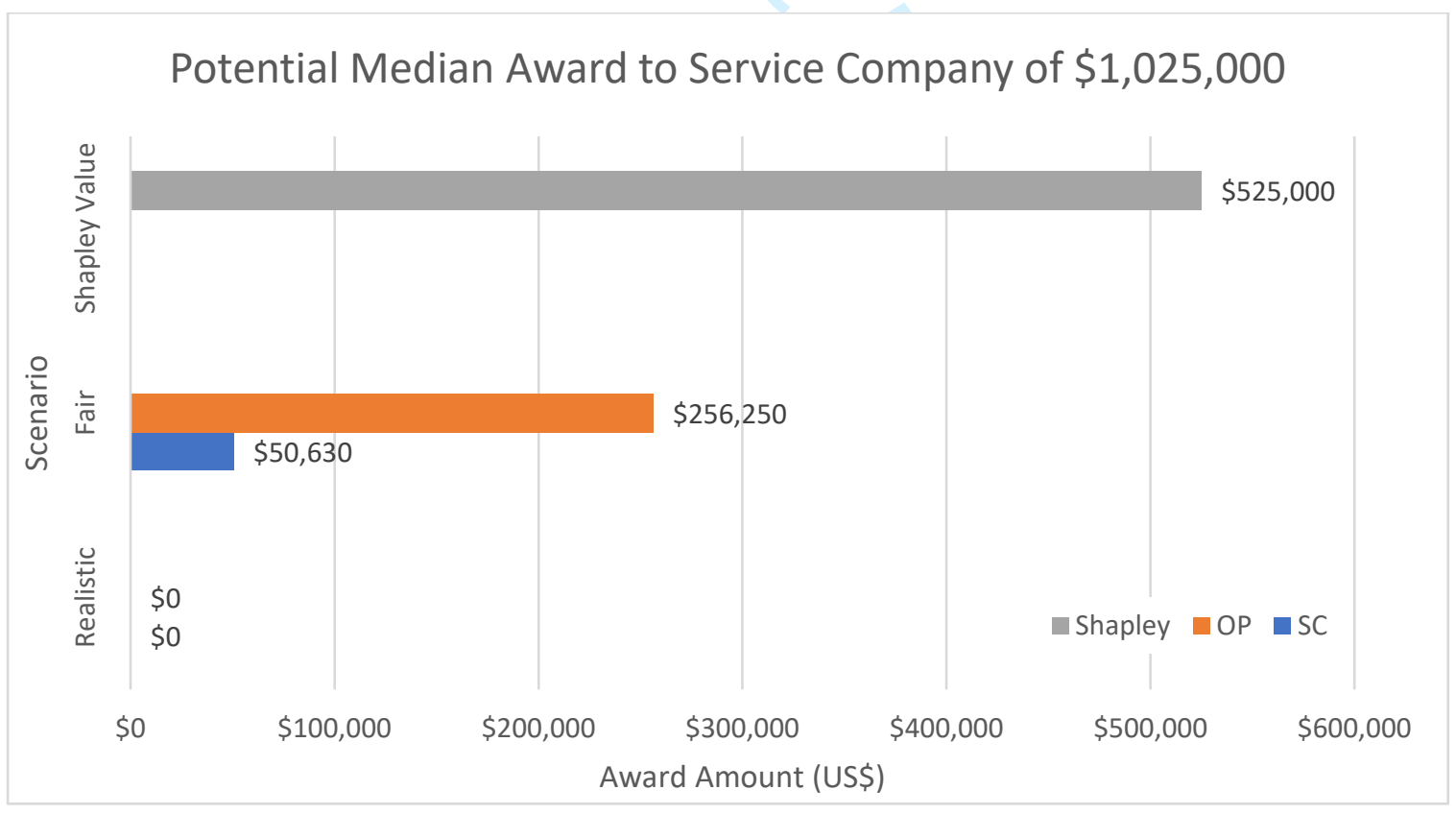

Graph 1: Median award to $S C$ when value $=\$ 1,025,000 . n=24$

Graph 1 shows that there is a significant difference between all the proposed rewards and the Shapley value. In addition to the above findings, a set of t-tests, see Table III below, were 
carried out which show that the difference between SC fair and realistic values were statistically significantly different $(\mathrm{p}=0.004)$. Similarly, the OP fair and realistic values were statistically significantly different $(\mathrm{p}<0.001)$. Using the Fairness Analysis Chart, Figure 4, we can determine that all parties were not working cooperatively, and all parties were cognisant of this.

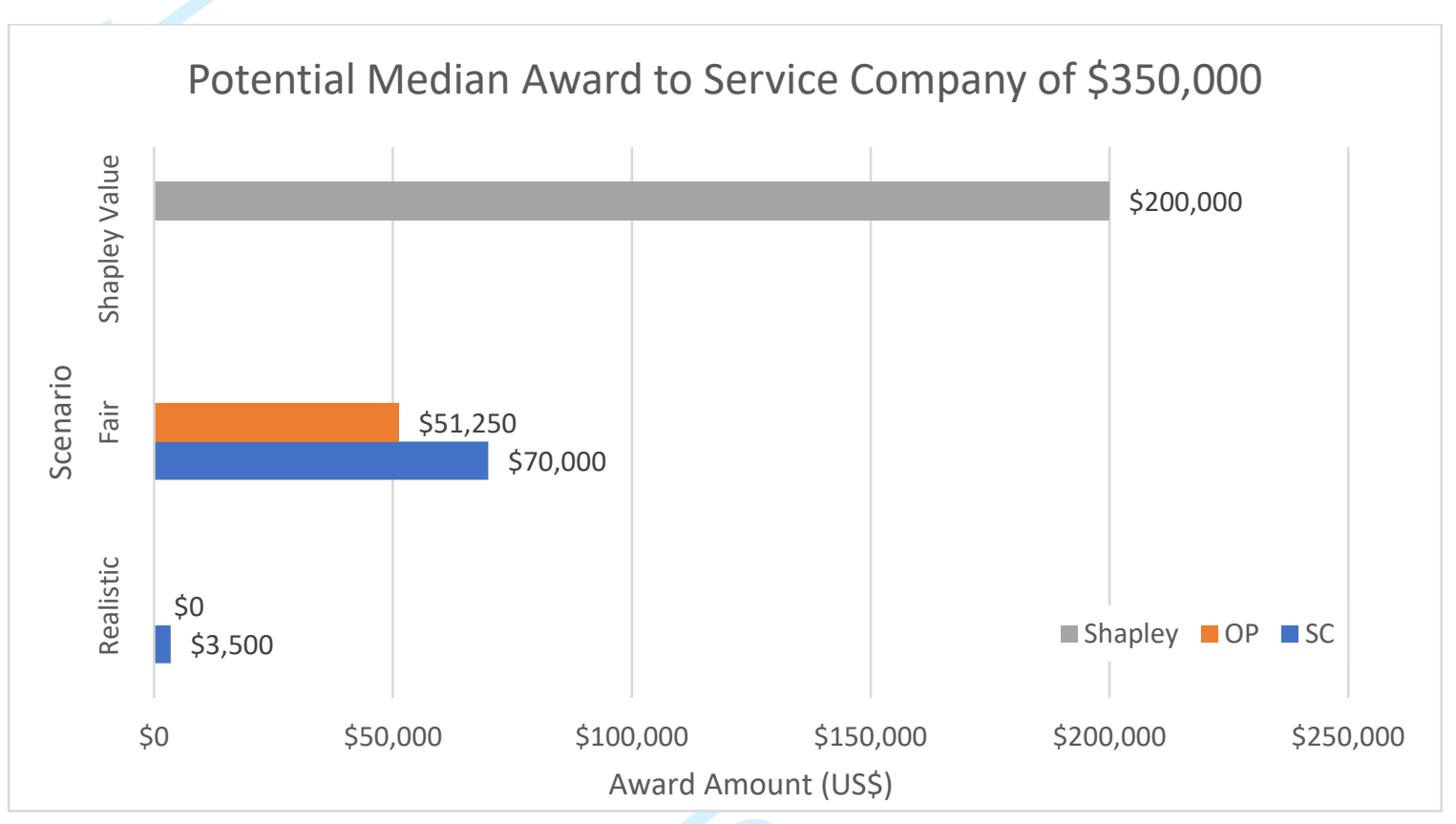

Graph 2: Median award to $S C$ when value $=\$ 350,000 . n=24$

Graph 2 shows that there is also a significant difference between all the proposed rewards and the Shapley value, even for a lesser reward. T-tests, see Table III below, were carried out which show that the difference between SC fair and realistic values were statistically significantly different $(\mathrm{p}<0.001)$. Similarly, the OP fair and realistic values were statistically significantly different $(\mathrm{p}=0.008)$. Referring to Figure 4 , we can determine that, again, all parties were not working cooperatively, and all parties were cognisant of this.

***Insert Table III here***

The servitization levels, as perceived by the respondents, within each organisation were also collected and it was found that the median servitization level claimed by OP employees was 5.0 , or intermediate, with an IQR of 1.5. However, the SCs claimed a median servitization level of 6.5 which is slightly above intermediate, with an IQR of 5.0. The OP has a small IQR which indicates that there is general agreement amongst this group that the servitization level is 5.0. However, the larger IQR of the SC would seem to indicate that there is less agreement within the group on servitization level.

\subsection{A Deeper Understanding of the Situation}

Table IV shows the final coding framework developed in this research. Themes and subthemes are listed, and the references attributed to each are shown in parentheses. The 
emergent themes are identified by an asterisk (*). Appendix 1 provides a list and explanation of all themes and sub-themes.

***Insert Table IV here****

The interview sessions were designed to deepen the understanding of the findings of the fairness analysis, which found that the relationship is knowingly unfair but acceptable to both SC and OP. One significant finding effect noted was the economic downturn in the oil industry, this lead to tightening of contractual terms and budget constraints and increased the likelihood of adversarial relationships. Many of the interviewees also noted that they had experience of organisations where advanced servitization levels created a more cooperative environment. Several senior SC and OP managers from various locations reported that organisations with higher levels of servitization were more cooperative, and vice versa.

\subsubsection{The Relationship Between Servitization and Cooperation}

The interviewees reported many examples of the necessity of collaboration between all actors for advanced levels of servitization (supporting Story et al., 2017; Polova and Thomas, 2020). For example:

A senior SC Middle East account manager who identifies that greater levels of cooperation (servitization) will lead to more cooperative relationships:

To build a relationship with your client and to maintain that, you've got to service a client and he's got to service you as well. Once you build up trust and respect, the business will just continue to grow.

Likewise, a SC product champion in the US also states that greater levels of collaboration (servitization) create a balance of benefits for both parties compared to non-cooperative behaviour:

The collaborative environment makes a huge difference, ... work[ing] together to explain ... the benefits of both rather than thinking ... you're going to squeeze more money out of me. So instead of this...more collaborative and open discussions..., interactions and collaborations help the situation to be a win-win; ... is very essential... high servitization is a win-win ... there has to be a very good balance from both sides.

Finally, the quote below from a senior OP confirms that cooperation and trust lead to successful business relationships and win-win outcomes for both parties:

If you have ... trust and partnership ..., it will almost always result in a winwin .. the operator then goes out of their way [to] find other ways to compensate you ... I've experienced that in multiple locations around the world. 
The three quotes above not only confirm that collaboration is required for servitization, but also indicate that this collaboration is a universal requirement. The three individuals quoted come from manufacturers (SC), customers (OP) and represent different cultural and geographical regions.

\subsubsection{Resistance to Change and Industry Norms.}

The influence of organisational culture was brought up extensively during the semi-structured interviews. Additionally, resistance to change was found to be universal, which indicates this is likely to be an 'industry norm' rather than a geographic or social cultural effect (Gordon, 1991). The oil industry is notorious for having a culture of change resistance as highlighted in their continued resistance to gender diversity (Miller, 2004). The example below, from a sales manager in the US confirms that there is an industry-wide culture of resistance to change impeding the application of servitization:

The organisational culture barrier... some organisations which are culturally very... laggard in a sense where they just don't like changes.

A similar observation was made by an OP manager in the Middle East, but this time referring to individuals exhibiting resistance to change and that this was a result of the effect of an industry norm:

The biggest barrier is people and the mindset and opening up organisations to work collaboratively. So there's still a lot of resistance. There's still a lot of 'them and us' in oil ... and that's probably the biggest thing which is holding people back.

During the semi-structured interviews, a number of interviewees attributed the resistance to change and adversarial attitude to an East-West cultural difference. However, these reports were inconsistent, even between interviewees with experience of working in multiple cultures. An East-West cultural difference would conflict with literature on this subject (Salacuse, 1998), therefore, we posit that this is not a social or geographical cultural difference but a result of an industry norm. An example of such a quote gathered during the semi-structured interviews by a SC Country Manager in the Middle East is presented below:

If you're talking low-cost areas invariably they're [Middle East] just looking at the price and they may have old fashioned attitudes in terms of service companies... it's definitely the old fashioned attitude that wins.

As discussed above an adversarial business culture was identified in many interviews. This was reported universally, from $\mathrm{OP}, \mathrm{SC}$ and different regions. The quotation below serves as an example taken from a SC country manager who explains that there is a high occurrence of a win/lose culture and employees who naturally prefer to play a win/lose strategy: 


\begin{abstract}
People who've got certain chips on their shoulders and think they're better than other people at their jobs when they're clearly not. And the jumping to rash decisions.
\end{abstract}

These findings provide evidence that the oil industry has a universal industry norm, which cuts across geographical cultures, and instils an industry norm that encourages an aversion to change. The evidence also suggests that the same industry norm promotes an adversarial working relationship between all parties.

\title{
4.2.3 Servitization Planning and Resources
}

There were many observations on the effect of servitization strategy on the implementation of servitization, both from an organisational and personal perspective. The findings suggest that such planning is ubiquitously absent from all of the organizations represented in this research, instead, they rely upon a process of organic growth or, as Ruis-Alba et al., (2019, p.629) phrase it, "flying blind". Lack of planning can starve the servitization process of resources and the necessary management support required for the lengthy and difficult servitization process (Baines and Lightfoot, 2013). In addition to this it is recognised that some organisations may be unaware of the benefits of servitization, preferring to "buy hardware instead of outcomes" (Kohtamäki et al., 2019, p. 381). This point is made by an account manager in the US who describes how companies are unwilling to undertake new strategies, such as servitization:

It was getting better but then again with the downturn, it has also gone down significantly... Deep down they probably are aware, but they're missing out on the opportunity and at the same time justifying with the fact that what they're doing is already working so let's not change with bigger promises which may not even happen.

\subsubsection{Environmental Influences}

During the semi-structured interviews, the impact of the recent oil price decline and general environment within the oil industry was expressed as a potential cause for the problems in implementing servitization. The interviews provided support to show that there are significant internal (strict application of contractual and financial terms) and external influences which prevent the formation of mutually beneficial relationships between the relevant actors. The inhibition of these natural business relationships hinders the introduction of servitization within the oil industry. This point is made by a senior OP engineer from the Middle-East:

I just think in the last three to five years with the ... there's been a huge culling of specialty service staff. It was pretty brutal the way people had careers ripped away from them, and forced redundancies, ... in that environment you can't afford to have much leeway... the working relationships are far more brutal.

This observation was echoed by a SC engineer, also in the Middle East: 
The base problem is the people that control the money make the biggest decisions. And it's all based on cost and reducing costs, whereas they don't look at the big picture, the value of it.

These findings compliment the findings of the game theory analysis and together provide a robust set of data which can be used to interpret the observable and underlying motivations of the strategies towards the observed inter and intra company relationships. Strong evidence has been provided relating to the stagnation of servitization and deservitization within the oil industry.

\section{Discussion}

The quantitative analysis has shown, with a high degree of statistical significance, that both the OP and SC are using an adversarial or non-cooperative strategy in their interactions. This finding was also confirmed in the interviews. Furthermore, the interviews revealed that the relationships appear to be becoming more adversarial and suggest that a cost-cutting environment, brought about by a prolonged industry downturn, may be responsible. Thus, illustrating how business relationships impact upon servitization strategies and outcomes; this finding is congruent with Kowalkowski et al., (2015). Interestingly, this finding illustrates the complexity of the relationship that exists in a servitization ecosystem where goals and strategies are not always shared equally and value creation is not distributed fairly (Kohtamäki et al., 2019; Lusch and Nambisan, 2015; Opresnik and Taisch, 2015; Sklyar et al., 2019; Story et al., 2020).

The use of game theory and the test administered allowed the underlying nature of the relationship to be observed and could, therefore, differentiate between intent and action. When comparing the proposed awards from the test, the findings show that both parties were cognisant that their behaviour was unfair and non-cooperative, or adversarial. One could therefore suggest that not only a base, but an intermediate level of servitization is likely to create an environment where an adversarial relationship is prominent, see Figure 5 below. This finding is congruent with a form of mimetic isomorphism as described in institutional theory where the actors within the oil industry change or have changed their behaviour to become increasingly similar to each other (Haveman, 1993); in this case their preference for a non-cooperative strategy. Generally, the assumption of Institutional Theory and specifically isomorphism is that the process elevates these organisations to a more harmonious sameness (Martínez-Ferrero and García-Sánchez, 2017). However, in this research the isomorphism takes a darker form of a common, or shared, noncooperative sameness.

All parties expressed that they had experienced greater levels of cooperation in organisations with higher levels of servitization. Similarly, they also stated that they had experienced more adversarial behaviour when working for organisations with low levels of servitization within the oil industry. It was suggested that taking steps to increase or decrease servitization could therefore influence the development of an adversarial relationship into a cooperative relationship and vice versa. This shows that the servitization process is dynamic, complex and is not always one-directional (Valtakoski, 2017) and affected by the relationships of the 
actors involved, i.e., actors are both impacted by and influence the relationships they are involved in (Håkansson and Ford, 2002).

Figure 5 below shows the revised relationship between servitization level and game type. In the initial conceptualisation (see Figure 2) intermediate servitization was connected to a variable strategy which eventually led to a complex relationship. However, the findings of this research have shown that an intermediate level of servitization does not lead to a variable strategy, but instead leads to a non-cooperative strategy, as seen below in Figure 5. Therefore, the findings of this research indicate that both base and intermediate servitization levels result in an adversarial relationship and a win-lose strategy.

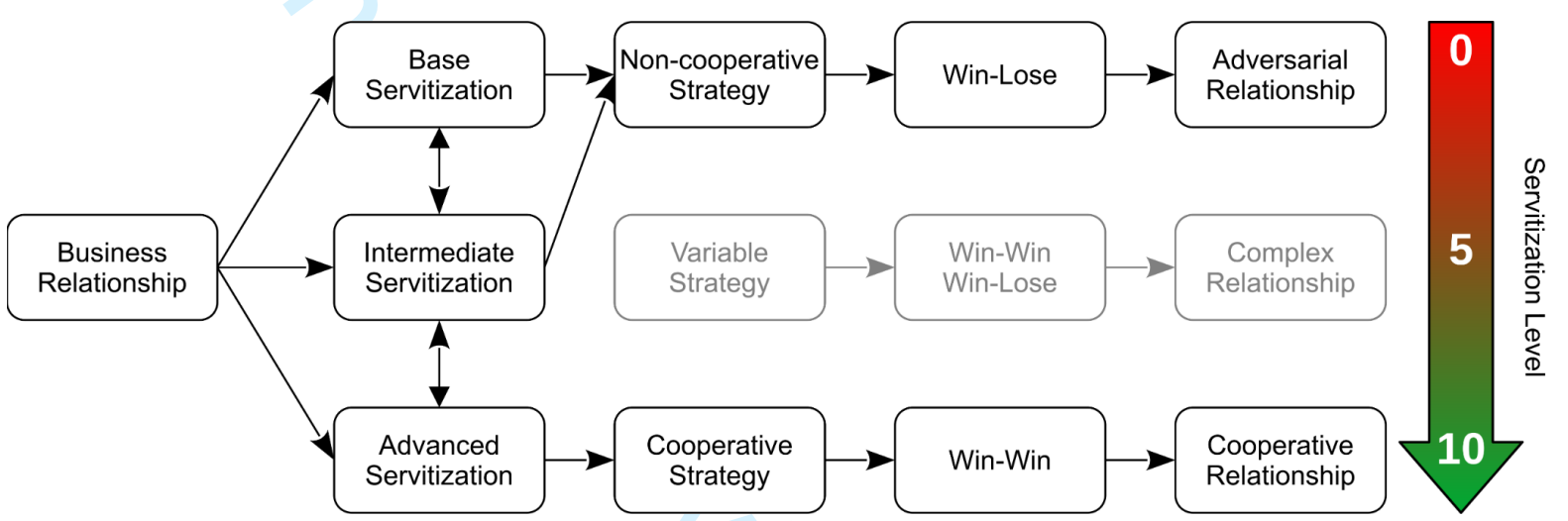

Figure 5: Proposed relationship between servitization level and game type

The findings have indicated that servitization at a base or intermediate level can produce the same outcome, i.e., a win-lose adversarial relationship. In order for servitization to become a game-changer it, therefore, needs to be implemented at an advanced level. However, given the difficult and often non-linear progression of the servitization process and the absence of results on its progression through the basic and intermediate phases, it is questionable if it will receive the required management support and allocation of resources to reach the advanced level and provide a return on the investment. This may explain the apparent stagnation of the servitization process observed in the oil industry and similar organisations and industries observed in the academic literature (Andrews et al., 2018; Raddats et al., 2019).

\section{Conclusion}

\subsection{Theoretical Contributions}

Little literature exists on the use of game theory and servitization (Zhong, 2014). Therefore, this research provides an opportunity to make a methodological contribution. In this section we identify three theoretical contributions to existing servitization theory derived from this research.

The first theoretical contribution shows that whilst there is acknowledgement that servitization is a dynamic process (Andrews et al., 2018; Raddats et al., 2019) and subject to deservitization (Brax, 2005), by using game theory we can add to existing theory by showing that cooperative relationships are only achievable in this context when advanced services are 
involved. This contribution was made possible by combining the methods used within this research and opens a new area of theoretical interest and research opportunities. This finding challenges the tacit assumption that the benefits of servitization improve linearly with an increase in servitization level, instead suggesting that there may be a parabolic relationship, as shown in Figure 6 below.

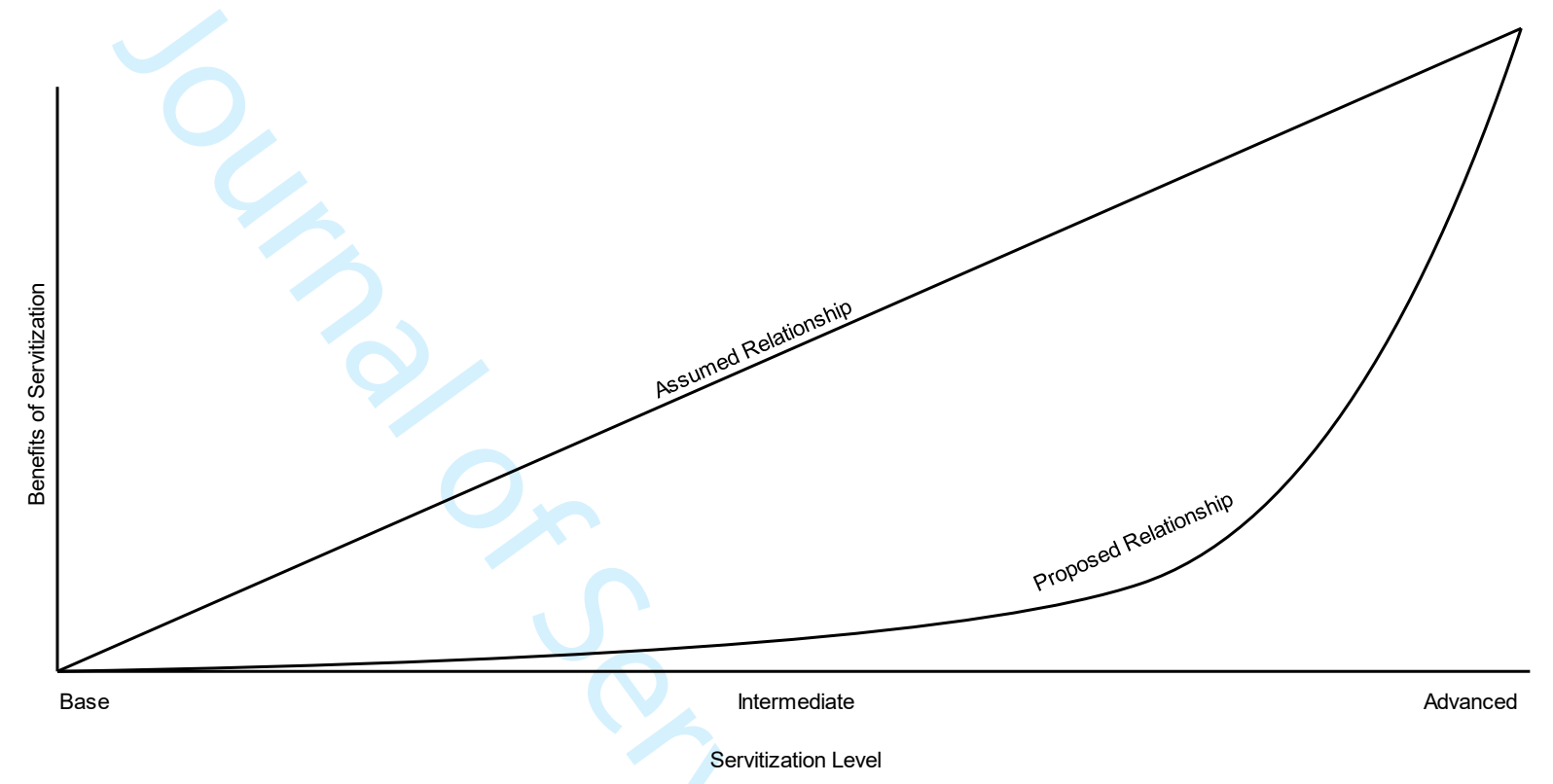

Figure 6: Sketch Showing Assumed and Proposed Relationship Between Servitization Level and Servitization Benefits

Secondly, our research shows how both industry and macro-level factors influence servitization strategies. A darker side of mimetic isomorphism (Haveman, 1993) appeared with respect to how employees of each organisation type were behaving in their business dealings. The research identified that this unfair behaviour was a conscious decision that both sides were aware of and, in the case of many of the SC, self-imposed. By exploring this from a multi-actor perspective, this extends understanding of the darker side of servitization.

Finally, the link proposed by many of the interviewees between servitization, deservitization, and the economic environment reminds us that servitization is impacted by macroenvironmental factors. Specifically, that an economic downturn may increase strict adherence to contractual terms and in so doing reduce the ability of employees to form cooperative relationships, and inevitably impedes the servitization process. These findings illustrate the insight that arises from adopting a relational lens for servitization research and how it provides additional insight into the theoretical understanding of servitization and the servitization paradox process.

\subsection{Management and Practical Implications}

This research provides practical insights for management teams wishing to implement a servitization strategy within their organisation. These relate to:

- The nonlinear application and return of servitization

- Criticality of management strategy and the effect of downturns 
- The role of individual, organisational and geographical culture

- The motivators for management to implement servitization and reflection on unilateral application within networks

It has been suggested that the application of servitization is not a linear process (Andrews et al., 2018; Raddats et al., 2019). This research supports this position and goes further to propose that the return on servitization, especially in the interim stages of servitization, are also not linear. Specifically, that the cooperative relationships derived from servitization may not become evident until advanced levels of servitization have been achieved. Therefore, if an organisation wishes to take advantage of increased cooperation and the benefits of closer working relationships, the management team and organisational structure needs to be committed to achieving advanced levels of servitization.

The transition to servitization is a difficult and prolonged process, requiring management commitment to change within an organisation (Raddats et al., 2018; Ulaga and Reinartz, 2011) and provision of suitable resources (Baines and Lightfoot, 2013; Lenka et al., 2018). A lack of management commitment was mentioned by the interviewees as a significant factor in the failure of the servitization process to reach advanced levels. Therefore, this research advocates that management should prioritise the preparation of a robust servitization strategy. Failure to prepare such a strategy may incur the detrimental effects of deservitization and failure to achieve the rewards if servitization is abandoned or stalled before advanced levels are achieved (Benedettini et al., 2015). Management commitment is especially important during the many industry specific downturns, such as the ongoing oil price crash of 2014 (England, 2020), and the more widespread global economic recessions. This research has shown that there is a tendency for management to reduce costs by strict enforcement contracts or introducing tighter constraints within new contracts, and it is not uncommon for servitization to stall or revert to an earlier incarnation due to these restrictions, an observation also made by Andrews et al. (2018).

This research has shown that there is a resistance to change both at an organizational and individual levels within both OP and SC, which may slow the implementation of servitization. Both the $\mathrm{OP}$ and $\mathrm{SC}$ are aware that an adversarial relationship exists within the oil industry. It has been shown in this research that there is a propensity for a win-lose culture. However, this may be more a factor of industry norms (Blake and Mouton, 1961; Bülow and Kumar, 2011) than East-West cultural differences (Salacuse, 1998). Failure to address these aspects within the servitization strategy may slow or completely derail the servitization process.

The findings suggest that increasing servitization to advanced levels increases the likelihood of cooperation and in turn increases value co-creation. Similarly, reducing or maintaining servitization levels at a base or even intermediate levels is likely to result in adversarial relationships and reduce the likelihood of value co-creation. Therefore, one can posit that management should endeavour to increase servitization levels in order to maximise the potential value co-creation possibilities. However, it must be recognised that these 
organisations exist within a highly complex service ecosystem and a unilateral change is unlikely to be successful. Therefore, a paradigm change within the entire ecosystem may be required (potentially requiring political or regulatory action) to realise the financial and environmental advantages that servitization can access from value co-creation and the efficient use of existing and new resources.

This research is of importance to many stakeholders as it may reduce the need to develop new oil reserves by increasing efficient use of existing reserves. It should therefore benefit the natural environment and economic and political stability of the nations which hold these reserves.

\subsection{Limitations and Future Research}

This research was undertaken in the oil industry and, therefore, further research is needed to explore if the findings are generalisable to other contexts. However, there is no reason to suspect that advanced servitization may not promote cooperative relationships in other industries. Game theory provides an avenue to explore this further and also to investigate if there are other factors that impact on the level of servitization achieved.

The test taken by the participants was relevant to their industry and factored in elements such as the size of award, however, there is a possibility that the subjects could have responded differently to a different scenario or group of scenarios. Therefore, it would be prudent to confirm these findings with a greater range of tests across a wider range of industries. Due to the inherently complex and sometimes counterintuitive nature of game theory, the format of the test in this research was somewhat complex, especially for those not familiar with game theory. This complexity required an explanation of the test scenario and an opportunity for the person being tested to ask questions and seek clarification, removing the option of a selfadministered electronic survey. This personal interaction limited the number of tests taken due to time constraints and other logistical issues. In order to increase the quantity of responses and apply this test to other industries, perhaps a version of the test could be administered simultaneously to a larger group with individual responses collected on paper or some form of electronic voting system. Such an approach could also work for a range of tests and applied to other industries, where the subject matter could be modified, but the underlying concept remained intact.

The research has identified that there is a statistically significant difference in servitization level within the SC when compared with the OP. It may be beneficial to perform additional research, perhaps with a larger sample group and using a more advanced method of assessing servitization level, to understand the reasons for this discrepancy and if this has any influence on the servitization process.

It has been mentioned that industry downturn appears to increase the likelihood for adversarial relationships, and the findings seem to suggest that cost cutting, and strict contract enforcement may be, at least in part, responsible for this. However, focusing on this financial and contractual aspect is warranted to identify the causal link between cost cutting, contractual enforcement and its impact on the servitization process. Furthermore, the 
acceptance of adversarial relationships by both SC and OP at the expense of servitization and value co-creation warrants further investigation.

Future game theory research could be conducted via researcher collaboration with practitioners. A servitizing company with a relatively large number of customers could offer two levels of new service value sharing with two separate groups of randomly allocated customers: low and high. The value created and volume of service activities could then be measured over time to identify the potential impact of different applied servitization strategies. 


\section{References}

Algaba, E., Fragnelli, V. and Sánchez-Soriano, J. (Eds.). (2019), Handbook of the Shapley Value, 1st ed., Chapman \& Hall, Boca Raton.

Alvarado, V. and Manrique, E. (2010), "Enhanced Oil Recovery: An Update Review”, Energies, Vol. 3 No. 9, pp. 1529-1575.

Åm, K. and Heiberg, S. (2014), "Public-private partnership for improved hydrocarbon recovery - Lessons from Norway's major development programs", Energy Strategy Reviews, Vol. 3, pp. 30-48.

Andrews, D., Dmitrijeva, J., Bigdeli, A.Z. and Baines, T. (2018), "Snakes and Ladders in Servitization: Using a Game to Capture Inhibitors and Enablers of Transformation", Research-Technology Management, Vol. 61 No. 6, pp. 37-47.

Baines, T., Bigdeli, A.Z., Sousa, R. \& Schroeder, A. 2020. Framing the servitization transformation process: A model to understand and facilitate the servitization journey. International Journal of Production Economics, 221, 107463, pp 1-16.

Baines, T. and Lightfoot, H. (2013), Made to Serve, 1st ed., John Wiley \& Sons, Inc., Chichester, available at:https://doi.org/10.1002/9781119207955.

Baines, T.S., Lightfoot, H.W., Benedettini, O. and Kay, J.M. (2009), “The servitization of manufacturing", Journal of Manufacturing Technology Management, Vol. 20 No. 5, pp. 547567.

Bandinelli, R. and Gamberi, V. (2011), "Servitization in oil and gas sector: outcomes of a case study research", Journal of Manufacturing Technology Management, Vol. 23 No. 1, pp. 87-102.

Benedettini, O., Neely, A. and Swink, M. (2015), "Why do servitized firms fail? A risk-based explanation", International Journal of Operations \& Production Management, Vol. 35 No. 6, pp. $946-979$.

Bentley, R.W. (2002), “Global oil \& gas depletion: an overview”, Energy Policy, Vol. 30 No. 3, pp. 189-205.

Blake, R.R. and Mouton, J.S. (1961), "Reactions to Intergroup Competition under Win-Lose Conditions", Management Science, INFORMS, Vol. 7 No. 4, pp. 420-435.

Brax, S. (2005), "A manufacturer becoming service provider - challenges and a paradox", edited by Gustafsson, A.Managing Service Quality: An International Journal, Vol. 15 No. 2, pp. 142-155.

Brewer, J. and Hunter, A. (1989), Multimethod Research: A Synthesis of Styles., 1st ed., Sage, Thousand Oaks.

Bryman, A. (2012), Social Research Methods, 4th ed., Oxford University Press, Oxford.

Bülow, A.M. and Kumar, R. (2011), “Culture and Negotiation”, International Negotiation, Vol. 16 No. 3, pp. 349-359.

Burton, J., Story, V.M., Raddats, C. and Zolkiewski, J. (2017), “Overcoming the challenges that hinder new service development by manufacturers with diverse services strategies", International Journal of Production Economics, Vol. 192 No. October 2017, pp. 29-39. 
Burton, J., Story, V., Zolkiewski, J., Raddats, C., Baines, T.S. and Medway, D (2016) " Identifying Tensions in the Servitized Value Chain", Research-Technology Management, Vol. 59, No. 5; pp. 38-47.

Calleja, P. and Llerena, F. (2020), "Consistency, weak fairness, and the Shapley value", Mathematical Social Sciences, Vol. 105, pp. 28-33.

Chatterjee, K. and Samuelson, W. (2014), Game Theory and Business Applications, 2nd ed., Springer, Boston.

Corley, K.G. and Gioia, D.A. (2004), "Identity Ambiguity and Change in the Wake of a Corporate Spin-off”, Administrative Science Quarterly, Vol. 49 No. 2, pp. 173-208.

Creswell, J.W., Plano Clark, V.L., Gutmann, M., and Hanson, W. (2003), Advanced mixed methods research designs. In A. Tashakkori \& C. Teddlie (Eds.), Handbook of mixed methods in social and behavioral research (pp. 209-240). Thousand Oaks, CA: Sage.

Crowley, E., Burton, J. and Zolkiewski, J. (2018), "Servitization intent as a factor in the servitization process", Journal of Business \& Industrial Marketing, Vol. 33 Issue: 8, pp.11251140.

Denzin, N.K. (1978), The Research Act, 1st ed., Aldine, Chicago.

Dixit, A.K. and Nalebuff, B.J. (2010), The Art of Strategy: A Game Theorist's Guide to Success in Business and Life, 1st ed., W. W. Norton \& Company, London.

Dubois, A. and Gadde, L.-E. (2002), "Systematic combining: an abductive approach to case research", Journal of Business Research, Vol. 55 No. 7, pp. 553-560.

Dyer, J.H. and Nobeoka, K. (2000), "Creating and Managing a High-Performance Knowledge-Sharing Network: The Toyota Case", Strategic Management Journal, Vol. 21 No. 3, pp. 345-367.

Easterby-Smith, M., Horpe, R. and Jackson, P.R. (2012), Management Research, 4th ed., SAGE, London.

Elkind, E. and Rothe, J. (2016), "Cooperative Game Theory”, Economics and Computation: An Introduction to Algorithmic Game Theory, Computational Social Choice, and Fair Division, Springer, Berlin, Heidelberg, pp. 135-193.

England, J. (2020), "Lower for Longer and the Risk of Oil and Gas Underinvestment", Deloitte United States, available at: https://www2.deloitte.com/us/en/pages/energy-andresources/articles/lower-for-longer-risk-oil-gas-underinvestment.html (accessed $2 \mathrm{March}$ 2020).

Fang, E. (Er), Palmatier, R.W. and Steenkamp, J.-B.E.M. (2008), "Effect of Service Transition Strategies on Firm Value", Journal of Marketing, Vol. 72 No. 5, pp. 1-14.

Ferreira, F.N.H., Proença, J.F., Spencer, R. and Cova, B. (2013), "The transition from products to solutions: External business model fit and dynamics", Industrial Marketing Management, Vol. 42 No. 7, pp. 1093-1101.

Finne, M. and Holmström, J. (2013) 'A manufacturer moving upstream: triadic collaboration for service delivery', Supply Chain Management: An International Journal, 18(1), pp. 21-33. Flick, U. (2009), An Introduction to Qualitative Reaearch, 4th ed., SAGE, Los Angeles.

Galvin, R. (2015), "How many interviews are enough? Do qualitative interviews in building energy consumption research produce reliable knowledge?", Journal of Building Engineering, Vol. 1, pp. 2-12. 
Gao, L. (2019), "Evolutionary game analysis of servitization transformation in manufacturing enterprises", presented at the 2019 5th International Conference on Green Power, Materials and Manufacturing Technology and Applications (GPMMTA 2019), Taiyuan, China, pp. 16.

Gebauer, H., Fleisch, E. and Friedli, T. (2005) " Overcoming the service paradox in manufacturing companies", European Management Journal, Vol. 23, No. 1, pp. 14-26.

Gebauer, H. and Kowalkowski, C. (2012), "Customer-focused and service-focused orientation in organizational structures", Journal of Business \& Industrial Marketing, Vol. 27 No. 7, pp. 527-537.

Gioia, D.A., Corley, K.G. and Hamilton, A.L. (2013), "Seeking Qualitative Rigor in Inductive Research", Organizational Research Methods, Vol. 16 No. 1, pp. 15-31.

Gordon, G. G. (1991) 'Industry Determinants of Organizational Culture', The Academy of Management Review, 16(2), pp. 396-415.

Håkansson, H. and Ford, D. (2002) "How Should Companies Interact in Business Networks?", Journal of Business Research, Vol. 55, No. 2, pp. 133-139.

Håkansson, H. and Snehota, I. (eds.) (2017), No Business Is An Island: Making Sense of the Interactive Business World, Emerald Publishing Ltd., Bingley, UK

Hammoudi, A. (2018), Game Theory Approach to Managerial Strategies and Value Creation, 1st ed., Vol. 3, John Wiley and Sons Inc, Hoboken.

Harrison, R. L., Reilly, T. M. and Creswell, J. W. (2020) 'Methodological Rigor in Mixed Methods: An Application in Management Studies', Journal of Mixed Methods Research, 14(4), pp. 473-495

Hartwig, F.P., Smith, G.D., Schmidt, A.F., Sterne, J.A.C., Higgins, J.P.T. and Bowden, J. (2020), "The median and the mode as robust meta-analysis estimators in the presence of small-study effects and outliers", Research Synthesis Methods, Vol. 11 No. 3, pp. 397-412.

Haveman, H.A. (1993), "Follow the Leader: Mimetic Isomorphism and Entry Into New Markets”, Administrative Science Quarterly, Vol. 38 No. 4, pp. 593-627.

Hezarkhani, B. (2017), "Optimal design of uptime-guarantee contracts under IGFR valuations and convex costs", European Journal of Operational Research, Vol. 256 No. 2, pp. 556-566.

Homburg, C., Hoyer, W.D. and Fassnacht, M. (2002), "Service Orientation of a Retailer's Business Strategy: Dimensions, Antecedents, and Performance Outcomes", Journal of Marketing, Vol. 66 No. 4, pp. 86-101.

Huikkola, T., Rabetino, R., Kohtamäki, M. and Gebauer, H. (2020) " Firm boundaries in servitization: Interplay and repositioning practices", Industrial Marketing Management, Vol. 90, pp. 90-105.

Johnson, R.B, Onwuegbuzie, A.J. and Turner, L.A. (2007), "Towards a definition of mixed methods research", Journal of Mixed Methods Research, Vol. 1, No.2, pp. 112-133.

Kamalaldin, A. Linde, L., Sjödin, D. and Parida, V. (2020) "Transforming provider-customer relationships in digital servitization: A relational view on digitalization", Industrial Marketing Management, Vol. 89, pp. 306-325.

Kamp, B. and Parry, G. (2017), "Servitization and advanced business services as levers for competitiveness", Industrial Marketing Management, Vol. 60, pp. 11-16. 
Kemp, A.G. and Stephen, L. (1999), "Risk:reward sharing contracts in the oil industry: the effects of bonus:penalty schemes”, Energy Policy, Vol. 27 No. 2, pp. 111-120.

Kesicki, F. (2010), “The third oil price surge - What's different this time?", Energy Policy, Vol. 38 No. 3, pp. 1596-1606.

King, Nigel., Horrocks, C. and Brooks, J. (2010), Interviews in Qualitative Research, 2nd ed., Sage Publications Ltd, Los Angeles.

Kohtamäki, M., Einola, S. and Rabetino, R. (2020), "Exploring servitization through the paradox lens: Coping practices in servitization", International Journal of Production Economics, Vol. 226, 107619, pp.1-15.

Kohtamäki, M., Parida, V., Oghazi, P., Gebauer, H. and Baines, T. (2019), "Digital servitization business models in ecosystems: A theory of the firm", Journal of Business Research, Vol. 104, pp. 380-392.

Koivisto, J. and Hamari, J. (2019), "The rise of motivational information systems: A review of gamification research", International Journal of Information Management, Vol. 45, pp. 191-210.

Korstjens, I. and Moser, A. (2017) 'Series: Practical guidance to qualitative research. Part 2: Context, research questions and designs', European Journal of General Practice, 23(1), pp. 274-279. doi: 10.1080/13814788.2017.1375090.

Kowalkowski, C., Gebauer, H., Kamp B. and Parry, G. (2017) "Servitization and deservitization: Overview, concepts, and definitions", Industrial Marketing Management, Vol. 60 (January), pp. 4-10.

Kowalkowski, C., Windahl, C., Kindström, D. and Gebauer, H. (2015), “What service transition? Rethinking established assumptions about manufacturers' service-led growth strategies", Industrial Marketing Management, Vol. 45 No. 1, pp. 59-69.

Kremer, D., Seregni, M., Canepa, A., Zanetti, C. and Gusmeroli, S. (2016), “The Focusactivity Framework for Evaluating PSS Cooperation Readiness of Manufacturing Firms", Procedia CIRP, Vol. 47, pp. 132-137.

Kumar, R. and Markeset, T. (2007), "Development of performance-based service strategies for the oil and gas industry: a case study", Journal of Business \& Industrial Marketing, Vol. 22 No. 4, pp. 272-280.

Lee, S., Yoo, S. and Kim, D. (2016), "When is servitization a profitable competitive strategy?", International Journal of Production Economics, Vol. 173, pp. 43-53.

Lenka, S., Parida, V., Sjödin, D.R. and Wincent, J. (2018), “Towards a multi-level servitization framework", International Journal of Operations \& Production Management, Vol. 38 No. 3, pp. 810-827.

Lexutt, E. (2020), "Different roads to servitization success - A configurational analysis of financial and non-financial service performance", Industrial Marketing Management, Vol., 84, pp.105-125.

Lima, B.B. de, Câmara, S.F., Mota, T.L.N. da G., Silva, A.L. e and Padilha, P. (2018), "Management of Innovation Networks: a choice for collaboration considering the game theory”, Business and Management Studies, Vol. 4 No. 2, p. 24.

Lusch, R. F. and Nambisan, S. (2015) 'Service Innovation: A Service-Dominant Logic Perspective’, MIS Quarterly, 39(1), pp. 155-175. 
Ma R., Feng C., Jiang L. (2020) "Evolutionary Game Analysis of Service Outsourcing Strategy for Manufacturing Enterprises Based on Servitization", In: Zhang J., Dresner M., Zhang R., Hua G., Shang X. (eds) LISS2019. Springer, Singapore.

https://doi.org/10.1007/978-981-15-5682-1_19

Martínez-Ferrero, J. and García-Sánchez, I.-M. (2017), “Coercive, normative and mimetic isomorphism as determinants of the voluntary assurance of sustainability reports", International Business Review, Vol. 26 No. 1, pp. 102-118.

Miller, G. E. (2004) 'Frontier Masculinity in the Oil Industry: The Experience of Women Engineers', Gender, Work \& Organization, 11(1), pp. 47-73.

"Mission, Vision, Values". (2020), Halliburton, available at: https://www.halliburton.com/en-US/about-us/corporate-profile/mission-visionvalues.html?node-id=ijzrw073 (accessed 5 November 2020).

Morgan, R.M. and Hunt, S.D. (1994), "The Commitment-Trust Theory Of Relationship Marketing", Journal of Marketing, Vol. 58 (July 1994), pp. 20 -38.

Murphy, M.K., Black, N.A., Lamping, D.L., McKee, C.M., Sanderson, C.F., Askham, J. and Marteau, T. (1998), "Consensus development methods, and their use in clinical guideline development.", Health Technology Assessment, Vol. 2 No. 3, pp. 1-88.

Ng, I., Parry, G., Smith, L., Maull, R. and Briscoe, G. (2012), “Transitioning from a goodsdominant to a service-dominant logic: Visualising the value proposition of Rolls-Royce", Journal of Service Management, Vol. 23 No. 3, pp. 416-439.

Opresnik, D. and Taisch, M. (2015) 'The value of Big Data in servitization', International Journal of Production Economics, 165, pp. 174-184.

Parra, F. (2004), Oil Politics - A Modern History of Petroleum, Vol. 25, L. B. Tauris \& Co. Ltd., New York, available at:https://doi.org/10.2307/41323035.

Peillon, S. and Dubruc, N. (2019), "Barriers to digital servitization in French manufacturing SMEs", Procedia CIRP, Vol. 83, pp. 146-150.

Peleckis, K. (2015), "The Use of Game Theory for Making Rational Decisions in Business Negations: A Conceptual Model”, Entrepreneurial Business and Economics Review, Vol. 3 No. 4, pp. 105-121.

Peleg, B. and Sudhölter, P. (2007), Introduction to the Theory of Cooperative Games, 2nd ed., Springer, Berlin, available at:https://doi.org/10.1007/978-3-540-72945-7.

Polova, O. and Thomas, C. (2020) 'How to perform collaborative servitization innovation projects: the role of servitization maturity', Industrial Marketing Management, 90, pp. 231251.

Raddats, C., Burton, J. and Ashman, R. (2015), "Resource configurations for services success in manufacturing companies", Journal of Service Management, Vol. 26 No. 1, pp. 97-116.

Raddats, C., Burton, J., Zolkiewski, J. and Story, V. (2018), "Overcoming the Challenges of Servitisation: Aligning Responses to Service Strategy", Practices and Tools for Servitization, Springer International Publishing, Cham, pp. 171-184.

Raddats, C. and Kowalkowski, C. (2014) "A Reconceptualization of Manufacturers' Service Strategies", Journal of Business-to-Business Marketing, Vol. 21, No. 1, pp. 19-34. 
Raddats, C., Kowalkowski, C., Benedettini, O., Burton, J. and Gebauer, H. (2019), "Servitization: A contemporary thematic review of four major research streams", Industrial Marketing Management, Vol. 83, pp. 207-223.

Raddats, C., Zolkiewski, J., Story, V. M., Burton, J., Baines, T. and Ziaee Bigdeli, A. (2017) 'Interactively developed capabilities: evidence from dyadic servitization relationships', International Journal of Operations \& Production Management, 37(3), pp. 382-400.

Reim, W., Sjödin, D.R. and Parida, V. (2019) "Servitization of global service network actorsA contingency framework for matching challenges and strategies in service transition", Journal of Business Research, 104, pp.461-471.

Ross, D. (2019), "Game Theory”, The Stanford Encyclopedia of Philosophy, Metaphysics Research Lab, Stanford University.

Ruiz-Alba, J. L., Soares, A., Rodríguez-Molina, M. A. and Frías-Jamilena, D. M. (2019) 'Servitization strategies from customers' perspective: the moderating role of co-creation', Journal of Business \& Industrial Marketing, 34(3), pp. 628-642.

Salacuse, J.W. (1998), “Ten Ways that Culture Affects Negotiating Style: Some Survey Results", Negotiation Journal, Vol. 14 No. 3, pp. 221-240.

Salonen, A., Saglam, O. and Hacklin, F. (2017), "Servitization as reinforcement, not transformation", Journal of Service Management, Vol. 28, reim

No. 4, pp. 662-686.

Shapley, L.S. (1953), "A value for n-person games", Contributions to the Theory of Games II, 1st ed., Princeton University Press, Princeton, pp. 307-317.

Shi, V.G., Baines, T., Baldwin, J., Ridgway, K., Petridis, P., Bigdeli, A.Z., Uren, V., et al. (2017), "Using gamification to transform the adoption of servitization", Industrial Marketing Management, Vol. 63, pp. 82-91.

Shi, V.G., Baldwin, J., Ridgway, K. and Scott, R. (2013), "Gamification for servitization a conceptual paper", Frameworks and Analysis, p. 114.

Sklyar, A., Kowalkowski, C., Tronvoll, B. and Sörhammar, D. (2019) 'Organizing for digital servitization: A service ecosystem perspective', Journal of Business Research, 104, pp. 450460.

Story, V.M., Raddats, C., Burton, J., Zolkiewski, J. and Baines, T. (2017), "Capabilities for advanced services: A multi-actor perspective”, Industrial Marketing Management, Vol. 60 No. May, pp. 54-68.

Story, V., Zolkiewski, J., Verleye, K., Nazifi, A., Hannibal, C., Grimes, A. and Abboud, L. (2020) 'Stepping out of the shadows: Supporting actors' strategies for managing end-user experiences in service ecosystems', Journal of Business Research, 116, pp. 401-411.

Süße, T. and Wilkens, U. (2014), "Preparing Individuals for the Demands of PSS Work Environments through a Game-based Community Approach - Design and Evaluation of a Learning Scenario", Procedia CIRP, Vol. 16, pp. 271-276.

Tadelis, S. (2013), Game Theory: An Introduction, 1st ed., Princeton University Press, Oxford.

Tronvoll, B., Sklyar, A., Sörhammar, D. and Kowalkowski, C. (2020), "Transformational shifts through digital servitization", Industrial Marketing Management, Vol. 89, pp. 293-305. 
Ulaga, W. and Reinartz, W.J. (2011), "Hybrid Offerings: How Manufacturing Firms Combine Goods and Services Successfully", Journal of Marketing, Vol. 75 No. 6, pp. 5-23.

Valtakoski, A. (2017) "Explaining servitization failure and deservitization: A knowledgebased perspective", Industrial Marketing Management, Vol. 60, January, pp. 138-150.

Welbers, K., Konijn, E.A., Burgers, C., de Vaate, A.B., Eden, A. and Brugman, B.C. (2019), "Gamification as a tool for engaging student learning: A field experiment with a gamified app", E-Learning and Digital Media, Vol. 16 No. 2, pp. 92-109.

"Who We Are". (2020), Schlumberger, available at: https://www.slb.com/who-we-are (accessed 11 April 2020).

Winter, E. (2002), “The shapley value”, Handbook of Game Theory with Economic Applications, Vol. 3, Elsevier, London, pp. 2025-2054.

Zhong, H. (2014), “Game analysis of product-service integration”, Journal of Industrial Engineering and Management, Vol. 7 No. 5, pp. 1447-1467.

Zitha, P., Felder, R., Zornes, D., Brown, K. and Mohanty, K. (2008), “Increasing Hydrocarbon Recovery Factors”, Society of Petroleum Engineers, pp. 1-9. 


\section{Appendix 1}

\begin{tabular}{|c|c|c|}
\hline Theme & Sub-theme & Description \\
\hline \multirow[t]{7}{*}{$\begin{array}{l}\text { Oilfield dilemma } \\
\text { discussion }\end{array}$} & \multicolumn{2}{|c|}{$\begin{array}{c}\text { The level of awareness of both personal and organisational attitudes } \\
\text { to servitization. }\end{array}$} \\
\hline & Offer reward in Ideal World & $\begin{array}{l}\text { Expectation of a reward in an ideal } \\
\text { world scenario and what is a fair } \\
\text { reward }\end{array}$ \\
\hline & Offer reward in Real World & $\begin{array}{l}\text { Expectation of a reward in a real-world } \\
\text { scenario and what is a realistic reward }\end{array}$ \\
\hline & Offer Tool & $\begin{array}{l}\text { Attitudes of SC and OP to win-lose } \\
\text { relationships and if these relationships } \\
\text { are common within the setting }\end{array}$ \\
\hline & Long term relationship & $\begin{array}{l}\text { How the intention to maintain long } \\
\text { term relationships influences business } \\
\text { decisions }\end{array}$ \\
\hline & Expected service & $\begin{array}{l}\text { How the expectation of service is } \\
\text { expressed as a business differentiator }\end{array}$ \\
\hline & $\begin{array}{l}\text { Contractual or procurement } \\
\text { block }\end{array}$ & $\begin{array}{l}\text { The impact of contractual or } \\
\text { procurement restrictions on the ability } \\
\text { to participate in a win-win scenario }\end{array}$ \\
\hline \multirow{5}{*}{$\begin{array}{l}\text { Servitization } \\
\text { Level }\end{array}$} & \multicolumn{2}{|c|}{ Perceptions of levels of servitization } \\
\hline & Level & $\begin{array}{l}\text { Servitization level of different } \\
\text { organisations and what constitutes the } \\
\text { level }\end{array}$ \\
\hline & $\begin{array}{l}\text { High servitization }= \\
\text { increased chance of win/win }\end{array}$ & $\begin{array}{l}\text { Advanced levels of servitization and its } \\
\text { contribution to a win/win culture. }\end{array}$ \\
\hline & $\begin{array}{l}\text { Low servitization }=\text { reduced } \\
\text { chance of win/win }\end{array}$ & $\begin{array}{l}\text { Base levels of servitization and its } \\
\text { influence on a win/win culture }\end{array}$ \\
\hline & Contracts and procurement & $\begin{array}{l}\text { Contracts and procurement procedures } \\
\text { removing the ability to form close } \\
\text { relationships with their business } \\
\text { partners }\end{array}$ \\
\hline \multirow{6}{*}{$\begin{array}{l}\text { Servitization } \\
\text { Application }\end{array}$} & \multicolumn{2}{|c|}{ How servitization impacts the health of a business } \\
\hline & $\begin{array}{l}\text { Opportunities lost due to } \\
\text { lack of servitization }\end{array}$ & $\begin{array}{l}\text { Lost/sacrificed servitization } \\
\text { opportunities }\end{array}$ \\
\hline & $\begin{array}{l}\text { Awareness of opportunities } \\
\text { lost due to lack of } \\
\text { servitization }\end{array}$ & $\begin{array}{l}\text { Awareness of lost servitization } \\
\text { opportunities }\end{array}$ \\
\hline & Power & $\begin{array}{l}\text { Interorganisational power and its } \\
\text { impact on servitization and/or } \\
\text { cooperation strategy. }\end{array}$ \\
\hline & Organisation size & $\begin{array}{l}\text { How the size of the organisation, with } \\
\text { respect to its counterparts or } \\
\text { irrespective of its counterparts' size } \\
\text { impact servitization }\end{array}$ \\
\hline & Culture & $\begin{array}{l}\text { How organisational culture impacts } \\
\text { servitization }\end{array}$ \\
\hline
\end{tabular}




\begin{tabular}{|c|c|c|}
\hline Theme & Sub-theme & Description \\
\hline & Fading service levels & $\begin{array}{l}\text { Impact of diminishing levels of service } \\
\text { on the business relationship and the } \\
\text { servitization process }\end{array}$ \\
\hline & $\begin{array}{l}\text { Inter-organisational } \\
\text { administration block }\end{array}$ & $\begin{array}{l}\text { Barriers to servitization caused by the } \\
\text { rigidity of intracompany administration }\end{array}$ \\
\hline \multirow{7}{*}{$\begin{array}{l}\text { Antecedent } \\
\text { Factors }\end{array}$} & \multicolumn{2}{|c|}{ Antecedents to servitization } \\
\hline & Culture & $\begin{array}{l}\text { Culture in the context of personal } \\
\text { attitudes to relationships }\end{array}$ \\
\hline & $\begin{array}{l}\text { Industry downturn and } \\
\text { environment }\end{array}$ & $\begin{array}{l}\text { Impact of wider environmental factors } \\
\text { on the servitization process }\end{array}$ \\
\hline & Trend & $\begin{array}{l}\text { Trends with respect to servitization and } \\
\text { relationship type }\end{array}$ \\
\hline & Revenue and budget driven & $\begin{array}{l}\text { Impact of resource availability on the } \\
\text { application of servitization }\end{array}$ \\
\hline & Management Commitment & $\begin{array}{l}\text { Differences in managerial intent, e.g., } \\
\text { where senior managers appear to be } \\
\text { more committed to servitization than } \\
\text { less senior managers }\end{array}$ \\
\hline & $\begin{array}{l}\text { Internal administration } \\
\text { block }\end{array}$ & $\begin{array}{l}\text { Business practices of organisations } \\
\text { which restrict the implementation of } \\
\text { servitization }\end{array}$ \\
\hline \multirow{5}{*}{$\begin{array}{l}\text { Servitization as a } \\
\text { solution }\end{array}$} & \multicolumn{2}{|c|}{ Perceptions of different levels of servitization } \\
\hline & $\begin{array}{l}\text { Increasing servitization }= \\
\text { win/win }\end{array}$ & $\begin{array}{l}\text { How increasing servitization results in } \\
\text { a win/win outcome }\end{array}$ \\
\hline & $\begin{array}{l}\text { Increasing servitization } \neq \\
\text { win/win }\end{array}$ & $\begin{array}{l}\text { How increasing servitization does not } \\
\text { result in a win/win outcome }\end{array}$ \\
\hline & $\begin{array}{l}\text { Decreasing servitization }= \\
\text { win/win }\end{array}$ & $\begin{array}{l}\text { How decreasing servitization results in } \\
\text { an increased possibility of a win/win } \\
\text { outcome }\end{array}$ \\
\hline & $\begin{array}{l}\text { Decreasing servitization } \neq \\
\text { win/win }\end{array}$ & $\begin{array}{l}\text { How decreasing servitization decreases } \\
\text { the possibility of a win/win outcome }\end{array}$ \\
\hline East/West divide & & $\begin{array}{l}\text { Differences between Eastern and } \\
\text { Western cultures }\end{array}$ \\
\hline $\begin{array}{l}\text { Short term } \\
\text { planning }\end{array}$ & & $\begin{array}{l}\text { Management commitment not being } \\
\text { forward looking enough to see a } \\
\text { servitization plan through to fruition }\end{array}$ \\
\hline
\end{tabular}




\title{
Should We Cooperate? Game Theory Insights for Servitization
}

\begin{abstract}
Purpose: An abundance of literature suggests that organisations adopting a cooperative approach achieve greater rewards than those that act in opposition or isolation. An emerging body of work also highlights the multiple actors involved in servitization. Despite this, in some contexts, the benefits of servitization are not apparent. This paper examines business relationships in the oil industry and how they affect levels of servitization.
\end{abstract}

Design/Methodology/Approach: A mixed method study employing qualitative and quantitative methods was used to fully explore the context. In the quantitative phase, 48 oil industry specialists responded to a scenario based on game theory. This aimed to determine if the relationships between their respective organisations are cooperative or adversarial. Abduction drove a second qualitative phase. This consisted of a series of semi-structured interviews that were used to explore the servitization level and influence of servitization on relationships and vice versa.

Findings: The statistical results suggest all parties used adversarial strategies despite the publicised intent to work cooperatively. The interviews suggested that increasing (decreasing) servitization could increase (decrease) cooperation and, in turn, value cocreation but revealed nuances to this effect. It also adds to our understanding of the darker side of servitization by illustrating the impact of mimetic isomorphism.

Originality/Value: The findings add to understanding of the complex dynamics around servitization by showing that it is only at advanced levels of servitization that cooperative behaviour is observed, and base and intermediate levels result in non-cooperative behaviour and thus illustrate the importance of adopting a multi-actor lens to explore servitization.

KEYWORDS: Servitization Dynamics, Game Theory, Oil Industry, Business Relationships, Mixed Methods

\section{Introduction}

The extant literature tends to focus on success stories, e.g., IBM, Rolls Royce and Xerox ( $\mathrm{Ng}$ et al., 2012) and suggests a steady progression from supply of base services through intermediate, to provision of advanced services (Baines and Lightfoot, 2013). However, there is growing recognition that not all organizations follow a smooth transition journey, with reports of a service paradox (Gebauer et al., 2005), service failure and deservitization 
(Kowalkowski et al., 2017, Valtakoski, 2017). Researchers are beginning to explore why this is so. Factors such as tensions (Burton et al., 2016), servitzation intent (Crowley et al. 2018), the challenges of developing appropriate service strategies, (Raddats and Kowalkowski, 2014; Raddats et al., 2018), and the paradoxical nature of servitization (Kohtamaki et al., 2020) illustrate the complexities of the challenges facing an organization that embarks on a servitization journey.

Hence, this research uses a relational lens to explore servitization that has not progressed to an advanced level and to understand what prevents servitization from being perceived as beneficial by both parties. Thus, we have identified a context where progression to advanced services has not been fully realized. Moving to a multi-actor perspective necessitates recognition of the complex network of relationships any organization is embedded in (Håkansson \& Snehota, 2017). These networks and the individual relationships within them are often cooperative (Dyer \& Nobeoka, 2000) and require trust and commitment (Morgan \& Hunt, 1994). However, the impact of changes, such as introducing advanced services, on individual relationships remains under-explored. This motivated our research questions: 1) How does cooperation within a relationship affect the transition to advanced services? 2) What are the strategies adopted by both actors in a relationship when faced with the introduction of more advanced levels of service? 3) how do changes in servitization level impact on cooperation?

This paper provides a novel perspective and contribution to servitization by exploring how game theory (Lima et al., 2018) can enhance our understanding of an area where servitization appears to be stalled at the intermediate level: the oil industry. Game theory provides a robust method to analyse strategy in business relationships in comparison to analysing intended or stated strategies. In order to improve the robustness of our findings, a qualitative phase of research was then used to explore the potential for servitization to influence the adversarial or cooperative nature of business relationships. Drawing on this, our contribution is to show that it is only high levels of servitization (advanced services) that facilitate cooperative behaviour. This illustrates the paradoxical, non-linear and complex relationship between service provision and cooperative behaviour and the strategies that drive this in a servitization context.

The remainder of this paper is structured as follows, first we review relevant literature and develop our conceptual framework. We then describe the methods employed, present our findings, discuss the implications and propose future areas of investigation.

\section{Literature Review}

\subsection{Servitization}

Traditionally, servitization is described as the process a manufacturing organisation undergoes to increase their competitive advantage by developing the services they offer to their customers (Baines et al., 2009; Kamp and Parry, 2017). Servitization achieves this advantage by creating additional revenue streams that change the existing business focus 
from product-centricity to service-centricity and, in doing so, differentiates the manufacturer and customer from their peers within the network (Raddats et al., 2015). This change of focus often requires transformation (Kowalkowski et al., 2017) and more recently the processes that garner this change are being explored (Baines et al., 2020). Much extant research takes a focal manufacturer perspective (Raddats et al., 2019) and fails to address the complex network/service ecosystem of manufacturers and customers involved in servitization (Ferreira et al., 2013; Story et al., 2017). Additionally, the provision of advanced services remains difficult and, if they are to become more than tools to enhance competitiveness, they must be exploited fully by both manufacturers and customers (Salonen et al., 2017).

$\mathrm{Ng}$ et al., (2012) argue that transformation from an entrenched goods-dominant logic to a service-dominant logic mindset is a significant challenge and critical to the success of servitization. However, recent literature argues that this dichotomous 'either-or' thinking should be replaced by a recognition of hybrid approaches (Burton et al., 2017) and 'both-and' thinking (Kohtamäki et al., 2020). Goods and services are interdependent and, therefore, organisations cannot simply choose between a service-dominant logic and a goods-dominant logic mindset, instead, they should embrace a paradoxical 'both-and' approach.

Although servitization is gaining traction and many manufacturers are adding a variety of services to their portfolios (Baines et al., 2020), this pattern is not uniform. Some companies are deservitizing (Kowalkowski et al., 2017). Others appear not to fully embrace or implement service-focussed strategies (Raddats et al., 2018) or possess the capabilities needed to effectively make the transition (Reim et al., 2019). Digital technologies, e.g., big data, cloud computing and the internet of things (IoT), can enable, drive and shape the application of servitization (Kohtamäki et al., 2019; Tronvoll et al., 2020). However, it is the strategy and not the technology which should drive the servitization process (Peillon and Dubruc, 2019) and the broad range of factors that influence this means that successful servitization is not always guaranteed (Lexutt, 2020). Barriers to success may be due to employees' general lack of understanding about their organisation's current level of servitization, which in turn is related to their level of education in the process of servitization, rather than a failing of servitization itself (Shi et al.,2017; Salonen et al., 2017). It has also been suggested that the lack of a servitization strategy can lead to fragmentation of the organisation, which may result in a reduced return on the investment in servitization or, in extreme circumstances, complete deservitization (Gebauer and Kowalkowski, 2012; Kowalkowski et al., 2015). This suggests more understanding of such strategic decisionmaking processes is needed.

\subsection{Game Theory (Exploring Strategic Decision Making)}

Game theory is traditionally used to explore, guide and interpret the strategic decisionmaking of rational parties (Lima et al., 2018). It is used as a tool to simultaneously find the optimum balance of maximum payoff and minimal risk for a given situation (Tadelis, 2013). There are two strategies in game theory: cooperative and non-cooperative. In a noncooperative strategy, each party attempts to get the best payoff for themselves by employing 
a strategy which includes the unknown strategies and counterstrategies of the other parties. In contrast to this, in a cooperative strategy, the parties are free to make agreements and alliances to increase the likelihood of a fair outcome for each party (Peleg and Sudhölter, 2007).

A central tenet in cooperative game theory is the Shapley value (Shapley, 1953). It is used in cooperative game theory to calculate a fair distribution of rewards or costs based upon the contributions of each participant (Calleja and Llerena, 2020). The Shapley value was intended to model the interactions of participants who choose to cooperate, unlike participants in a non-cooperative scenario (Winter, 2002). Therefore, if the results of an interaction resemble the Shapley value prediction, it can be posited that the participants were playing a cooperative game strategy (Algaba et al., 2019). Hence, using the Shapley value can distinguish between a cooperative and non-cooperative strategy in an interaction between two or more participants (Algaba et al., 2019).

Due to the recent introduction of modern mathematical tools, game theory is now widely accessible to scholars and the general public (Ross, 2019) with the majority of applications employed in financial strategies (Chatterjee and Samuelson, 2014). However, new managerial applications of game theory have grown considerably, especially in the interpretation of 'big data' for predictive analysis. Here, game theory uses past information to predict future events, reduce risk, and maximise returns (Hammoudi, 2018).

Despite this, the use of game theory in conjunction with servitization is limited (Zhong, 2014). One notable exception is a paper written by Gao (2019), which uses game theory to show the equilibrium positions of an organisation's servitization evolution. Gao (2019) concludes that for the successful adoption of servitization the net servitization revenue must be positive and is also contingent upon the servitization position of the manufacturer's counterpart. Additionally, although with a slightly different focus, an evolutionary game approach has been adopted to explore outsourcing as part of servitization; this research highlights the importance of collaborative approaches when it is difficult to provide highquality services (Ma et al., 2020). On the other hand, there are several papers written about the unrelated subject of gamification and servitization (Hezarkhani, 2017; Lee et al., 2016; Süße and Wilkens, 2014). Gamification is a teaching and learning tool which reflects the growing popularity of games in everyday life (Koivisto and Hamari, 2019; Shi et al., 2013; Welbers et al., 2019), rather than game theory, which is a method to understand and guide strategic decisions (Lima et al., 2018).

\subsection{Research Gap and Conceptual Framework}

Business relationships and their dimensions, e.g., trust, commitment, cooperation, coordination are discussed extensively in the supply chain, business-to-business marketing and organizational behaviour literature (e.g. Dyer \& Nobeoka, 2000, Håkansson \& Snehota, 2017). However, this discussion is only now beginning to be introduced into the servitization context as focus moves away from the manufacturer as the focal actor and towards a multi- 
actor perspective (e.g. Story et al., 2017) network (e.g. Huikkola et al., 2020), and relational perspectives (e.g. Kamalaldin et al., 2020). Digital servitization research focuses on the servitization ecosystem, which involves relationships that are focused on mutual value creation and shared goals (Kohtamäki et al., 2019; Lusch and Nambisan, 2015; Sklyar et al., 2019; Story et al., 2020) and are essential to the servitization process and continued success of the servitized ecosystem (Opresnik and Taisch, 2015). Much of the extant literature views servitization as process undertaken by manufacturers in isolation (Raddats et al., 2019). The literature which discusses the customer or intermediaries tend to regard servitization as an intra-company process (Raddats et al., 2017) or from the perspective of the manufacturer or the customer and neglect the collaborative perspective of servitization (Finne and Holmström, 2013; Polova, 2020). However, the benefits and rewards of collaboration are beginning to be acknowledged in the discussion around digital servitization (Tronvoll et al., 2020).

Scholars agree that collaboration between actors is required for the application and development of advanced services and servitization (Story et al., 2017; Polova, 2020). This collaboration relies upon the shared interests and knowledge each party brings to the table (Burton et al., 2016; Polova, 2020) and aligning these attributes to the mutual benefit and value co-creation of all parties (Finne and Holmström, 2013; Raddats et al., 2017). Research has shown that organisations that collaborate are more successful than those that do not (Raddats et al., 2019). However, it is also noted that servitization collaboration is a difficult undertaking that requires the sharing of trust and commitment during the entire process (Polova, 2020). Additionally, the review of the literature suggests more understanding of servitization strategies and the associated decision making is needed. Using the lens of game theory to examine the nature of the relationship between oil industry organisations provides a mechanism with which to view these interactions and involves a novel mechanism for this exploration.

Table I suggests that advanced levels of servitization produce more cooperative relationships where risk and reward are more likely to be shared between the manufacturer and customer (Baines and Lightfoot, 2013). Simply stated, a manufacturer cannot work in isolation from their customer and cooperation is required for collaboration and servitization (Kohtamäki et al., 2019). Similarly, when servitization levels are at a base level the provision of services are much reduced and the need for advanced levels of cooperation are not observed (Kremer et al., 2016). As such, at the intermediate level the relationship is more complex with potential for some cooperative behaviour to emerge. Therefore, if the level of servitization can be determined, this will provide insight into the level of cooperation that exists in the given relationship, and vice versa.

***Insert Table I here****

However, it is difficult to know if this claim is a reality and carried out in practice at all levels within organisations. Game theory focuses on the employed strategy and not the intent (Elkind and Rothe, 2016; Peleckis, 2015). Therefore, by analysing the strategy used in the 
relationship between two actors, we can compare the intended and actual strategies used by either party. Thus, the following research questions were created:

1. How does cooperation within a relationship affect the transition to advanced services?

2. What are the strategies adopted by both actors in a relationship when faced with the introduction of more advanced levels of service?

3. How do changes in servitization level impact on cooperation?

\section{Methodology}

The research questions provide an opportunity to employ a mix of quantitative and qualitative insight in order to understand the phenomena. A mixed methods approach that combines complimentary qualitative and quantitative methods is adopted; thereby benefiting from the relative strengths and reducing the individual weaknesses of each method (Brewer and Hunter, 1989). This is in-line with the definition proposed by Johnson et al., (2007, pg. 123) whereby "a researcher or team of researchers combines elements of qualitative and quantitative research approaches (e.g., use of qualitative and quantitative viewpoints, data collection, analysis, inference techniques) for the broad purposes of breadth and depth of understanding and corroboration. Using a mixed method allows triangulation of the findings (Denzin, 1978) whereby observations can be verified using more than one method, thereby "increase[ing] their scope, depth and consistency" (Flick, 2009, p. 445). A sequential explanatory design was adopted (Creswell et al., 2003) as illustrated in Figure 1.

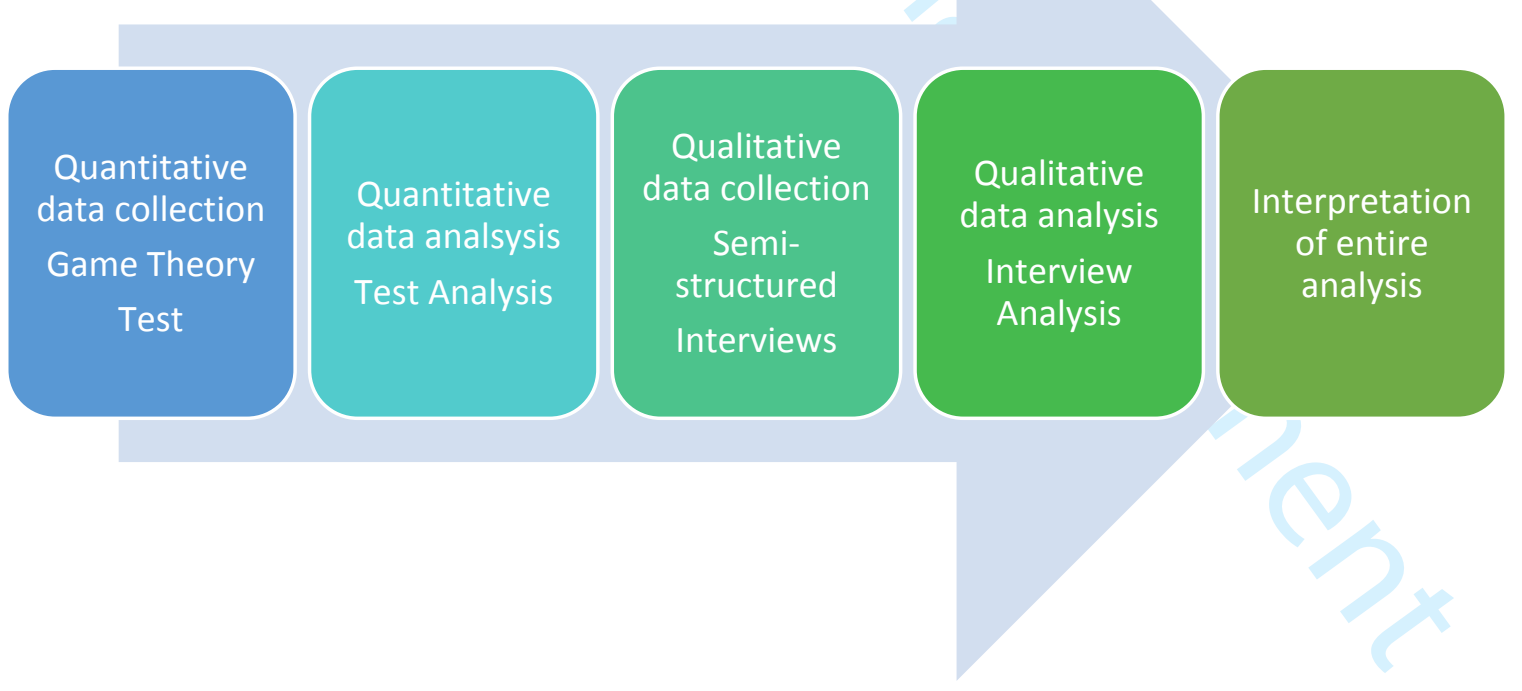

Figure 1 Sequential Explanatory Design, Adapted from Creswell et al., (2003, p. 180)

The different phases, their analysis and the research context chosen for the research are described in the sections below. The procedures outlined by Harrison et al., (2020) to ensure rigour in mixed methods research have been used to guide this process, e.g., reporting the different data collection and analysis procedures and illustrating how the different data 
strands contribute to the discussion and conclusions. The research uses the interorganisational relationships between Operators (OP) (the users of these services and equipment) and Service Companies (SC) (suppliers of equipment and technical services in the industry), as the unit of analysis. These relationships are explored from the perspectives of the employees working for these organisations.

\subsection{Research Context}

The research context necessary to explore these questions needed to be one in which high levels of servitization are not evident. Generally, studies considering the topic of servitization within the oil industry are sparse. However, the available literature highlights that most organisations lack a definitive servitization strategy (Bandinelli and Gamberi, 2011; Kumar and Markeset, 2007). This suggests that the oil industry could provide a suitable research context. Oil is a volatile global commodity and an important export for many nations (Kesicki, 2010) making it a highly political product (Parra, 2004). Additionally, the extraction, transportation and combustion of oil and its derivatives can have detrimental effects on the natural environment. Currently, standard extraction practices mean that only $20 \%-34 \%$ of the oil in a reservoir can be recovered with the remaining oil being permanently lost (Bentley, 2002; Zitha et al., 2008). However, with pre-planning, advanced procedures and new technologies this can, in some instances, be increased to $35 \%-45 \%$ (Bentley, 2002; Zitha et al., 2008). Cooperation between all stakeholders is needed to realise the associated political, environmental and financial gains achieved by increasing the recovery factor (Alvarado and Manrique, 2010; Åm and Heiberg, 2014). Servitization would be a potential route to achieve this. Despite SC showcasing such promises in their promotional material, e.g. ("Mission, Vision, Values", 2020; "Who We Are", 2020), there is limited evidence of cooperation in practice. Additionally, the OP seem reluctant to either engage in cooperative practices or accept the benefits servitization can provide. Thus, our research attempts to determine the prevalence of advanced levels of servitization within this industry. This conflicting focus within the OP and SC relationship highlights an interesting research area and, thus, the purpose of this research is to explore the relationship between servitization and the strategies that are in play in this context. To this effect, game theory is used to examine these relationships in practice to determine if they are adversarial or cooperative in nature and to identify the actual strategies being used. Building on this, a semi-structured interview process was used to develop understanding and context of the cooperative/non-cooperative processes identified in the test (Korstjens and Moser, 2017).

\subsection{Game Theory Test}

Figure 2 below shows the conceptual framework for the Game Theory Test. Starting from the left, it is proposed that if the servitization level between two actors is at a base level (Baines and Lightfoot, 2013) their relationship is likely to be adversarial (Kemp and Stephen, 1999). Similarly, if the servitization relationship is advanced, then their relationship is likely to be cooperative. This paper seeks to investigate if changing the servitization level, indicated by the double-headed arrows below, can change a relationship from adversarial to cooperative and vice versa. 
For this test, a sample size of 48 was deemed appropriate, see Table II below. The age of the subjects ranged from 25 to 51 with a median age of 43.0 years. The experience levels range from 12 to 39 years with a median value of 23.0 years. The nationalities were diverse and included: Europe, North and South America, the Middle East, Asia and Australasia. All of those questioned had experience in several geographic locations and had worked with several organisations. This combination offers a rich breadth of experience and knowledge and enables the provision of a comprehensive data set. The subjects were identified using a selective strategy (Easterby-Smith et al., 2012) to ensure that they possessed the knowledge and experience of the oil industry needed to produce reliable data. Criticism is often made of such convenience sampling methods as not producing generalizable findings (Bryman, 2012). However, this paper is specifically focused on the oil industry, therefore, a selective sampling method enabled the selection of a group that was sufficiently diverse and representative by ensuring diversity in organisation type, experience levels and geographic locations. Post-hoc analysis confirms that the effects were sufficiently pronounced that the sample size of 48 produced a statistical power $>0.8$, see Table III. All respondents were contacted in advance and gave their consent to undertake the test and take part in a subsequent interview if randomly selected.

Departing from the traditional methodological application of game theory, this paper takes a novel approach to this research by using a game theory lens to investigate servitization strategy. This determination is achieved by inverting the typical game theory approach to use the outcomes of the game to understand the strategy being employed by each player, unlike typical applications which use game theory to develop the best strategy for a given situation. Game theory was selected as it provides an insight into the strategy being employed by each 'player' and allows the researcher to understand the actual strategy being used in a realistic representative scenario, and if a contradiction exists between this and the intended or expressed strategy of the player. Game theory is an established method used to work with game strategy, and so will produce robust findings (Peleg and Sudhölter, 2007; Tadelis, 2013). Other methods of analysis were unlikely to sufficiently address the strategy element of 
the interorganisational relationships in a format that is as established and accessible as game theory. The test is based on the classic game theory prisoners' dilemma (Dixit and Nalebuff, 2010).

*** Insert Table II here***

\subsection{Strategy Testing}

A game theory test was selected to investigate the expressed strategy used by employees within the oil industry. Game theory, unlike other methods, focuses on strategy and therefore has the virtue of discovering the actual conscious or subconscious strategy used and not the expressed strategy of the player. Game theory is also a modern, but well-established, method for determining strategy and strategic outcomes of scenarios like the one presented to the test participants and can, therefore, be relied upon to provide robust findings. The participants were directed to complete a test to determine if they elected to use a cooperative or adversarial strategy when they were dealing with their regular day-to-day business partners. The test consisted of a version of the established prisoners' dilemma (Dixit and Nalebuff, 2010) modified with a realistic oilfield scenario where the Service Company (SC) provided a new tool generating a saving for the Operator (OP). The test used an inverted version of the prisoners' dilemma where the aim of the test was not to determine the outcome, which was already known, instead it was to use the outcome to determine the type of game strategy being employed by each actor, specifically competitive or non-competitive. One version (High reward) of the test examined a saving of $\$ 1,025,000$ and the other version (Low reward) a lesser saving of $\$ 350,000$. The difference in values between the two tests determined if value was a factor in the strategy of either party, the tests were otherwise identical.

During the test, the participants were asked to allocate a percentage share of the saving to the SC responsible for creating the saving. Each participant was asked to allocate the saving value based on what they thought was fair. The same participant was then asked to reconsider the realistic saving value based upon their experience and expectation if the event occurred in their current organisation, both these values were recorded.

\subsection{Semi-structured Interviews}

After the analysis of the Game Theory test, semi-structured interviews were carried out on a subset of the original forty-eight test participants. All test participants were contacted; three or four of each of the groups (high reward service company [HS], high reward operator [HO], low reward service company [LS] and low reward operator [LO]) were interviewed. Analysis of the interviews took place alongside the interviews; after interview nine no additional themes emerged, i.e. thematic saturation was achieved (Galvin, 2015). However, a total of thirteen interviews were conducted to balance the representation from each of the four groups used in the game theory test shown in Table II. Each interview was conducted one-to-one, via Skype or in-person depending on the interviewee's location and lasted between 45 and 60 minutes. 
In the interviews, interviewees were first asked to identify the level of servitization of their current organisation based on the scale, shown in Table I, created by Baines and Lightfoot (2013) which has three levels: base, intermediate and advanced. There are many scales available such as Fang et al. (2008) who base their assessment on service revenue, or Homburg et al. (2002) who use the number of services as a measurement. Unlike these, which focus on a single parameter, the Baines and Lightfoot (2013) scale uses a broad range of factors to identify servitization levels. The scale does not require a lengthy analysis of data, for example, company accounts, and is written in a format that practitioners can easily understand and in subject areas they were familiar with without lengthy instruction. This scale was ideally suited for the relatively short interview sessions with subjects that were not familiar with servitization at a detailed academic level.

After the servitization level of the interviewee's organisation was identified, each of the interviewees was then interviewed about their experience of value co-creation and servitization levels in relation to cooperative and adversarial relationships. This part of the research process was designed to expand further on the initial results of the quantitative research, adding context and clarification. In order to understand the effect of base, intermediate or advanced levels of servitization the interviewees were also asked, via multiple questions, to comment if these servitization levels were more or less conducive to adversarial or cooperative relationships based on experience from their prior working history and experiences.

\subsection{Qualitative Analysis}

Each interview was then transcribed and analysed using the NVivo 12 software platform. An abductive approach was adopted for the qualitative analysis (Dubois and Gadde, 2002), which aligns with the method proposed by Gioia et al. (2013) who advise changing the research questions to progress the research in new directions. Initially 5 themes and 15 subthemes were identified through discussion amongst the three coders to determine the servitization level and the influence of servitization on cooperation or non-cooperation. These first and second order themes increased to 7 themes and 28 sub-themes due to the abductive discursive process; a detailed summary is provided in the findings section. Gioia et al. (2013) state that qualitative rigor begins with defining first and second order categories, or themes to be used during qualitative research, this is represented in figure 3 below for this research. 


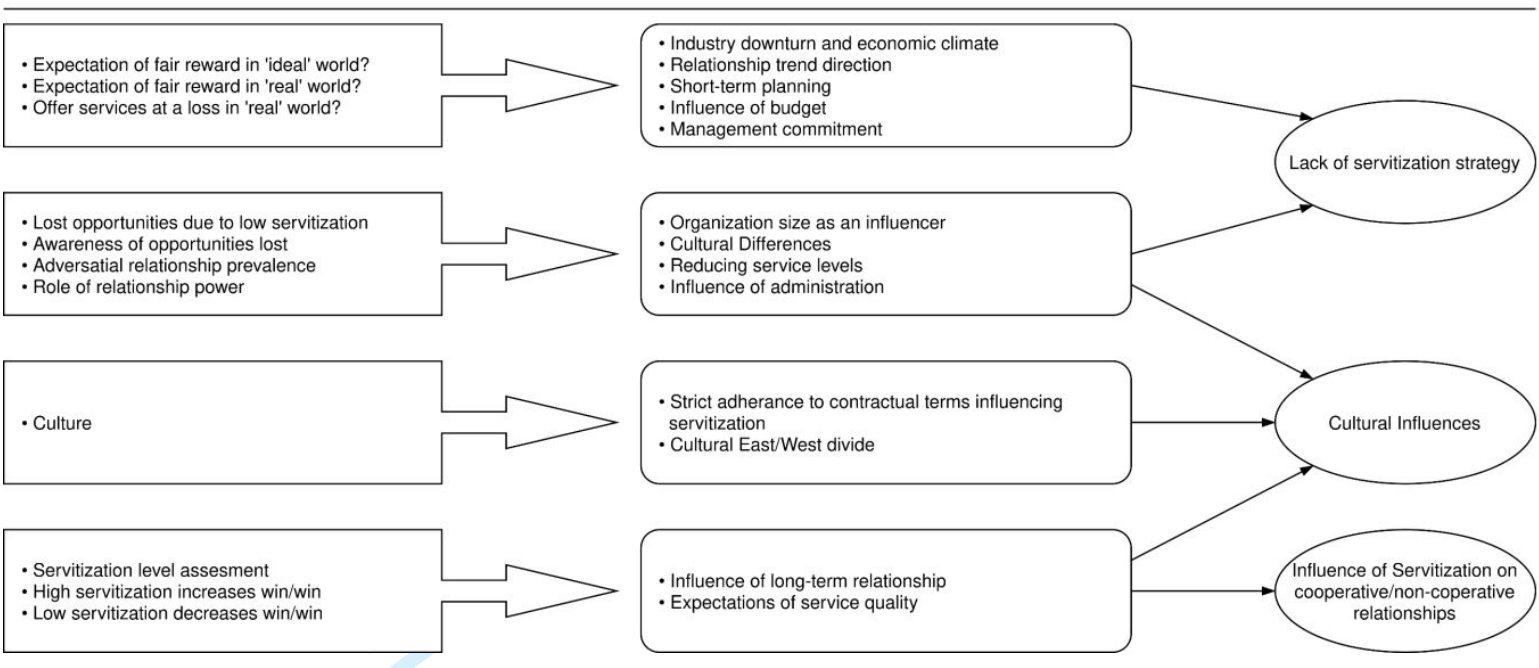

Figure 3: Data Structure, Adapted from Corley and Gioia (2004, p. 184)

\section{$4 \quad$ Findings}

\subsection{Fairness and Strategy}

The Shapley value states that each participant receives a reward that is fair in relation to their investment. This is characterized by the 'null player property' which states that if a participant contributes zero, then their reward should be zero (Calleja and Llerena, 2020). Thus, the Shapley value was used to indicate if the strategies being displayed during the test and the outcome of the interaction were cooperative or non-cooperative. If the test found that a reward distribution approximated the Shapley value, this would indicate that all parties are acting cooperatively. If the value differs from the Shapley value, this indicates that they acted with a non-cooperative or adversarial strategy.

To determine if the participants in the test were cognisant of their cooperative or noncooperative position, the value of their fair and realistic awards were compared. If the values were dissimilar, then each party was cognisant that the award they had offered was unfair, and they were, therefore, knowingly acting in a non-cooperative way. If the values were similar, this indicated the intention to act fairly and cooperatively. However, if the values were appreciably different from the Shapley value, then they were not behaving cooperatively, but were not cognisant of it. This is represented in Figure 4 below: 


\section{Figure 4: Fairness Analysis Flow Chart}

The following charts show the award to the SC for making high (Graph 1) and low (Graph 2) savings during the oilfield dilemma test. It is interesting to observe that in all cases the proposed reward is substantially lower than the Shapley value. In addition to this, and in all cases, there is a significant difference between the fair award and the realistic award, signifying that both parties were aware that the award was not fair. Median values and interquartile ranges (IQR) were used to represent central tendency rather than the mean, which can present a skewed representation based upon the recommendation of Murphy et al. (1998) and Hartwig et al. (2020).

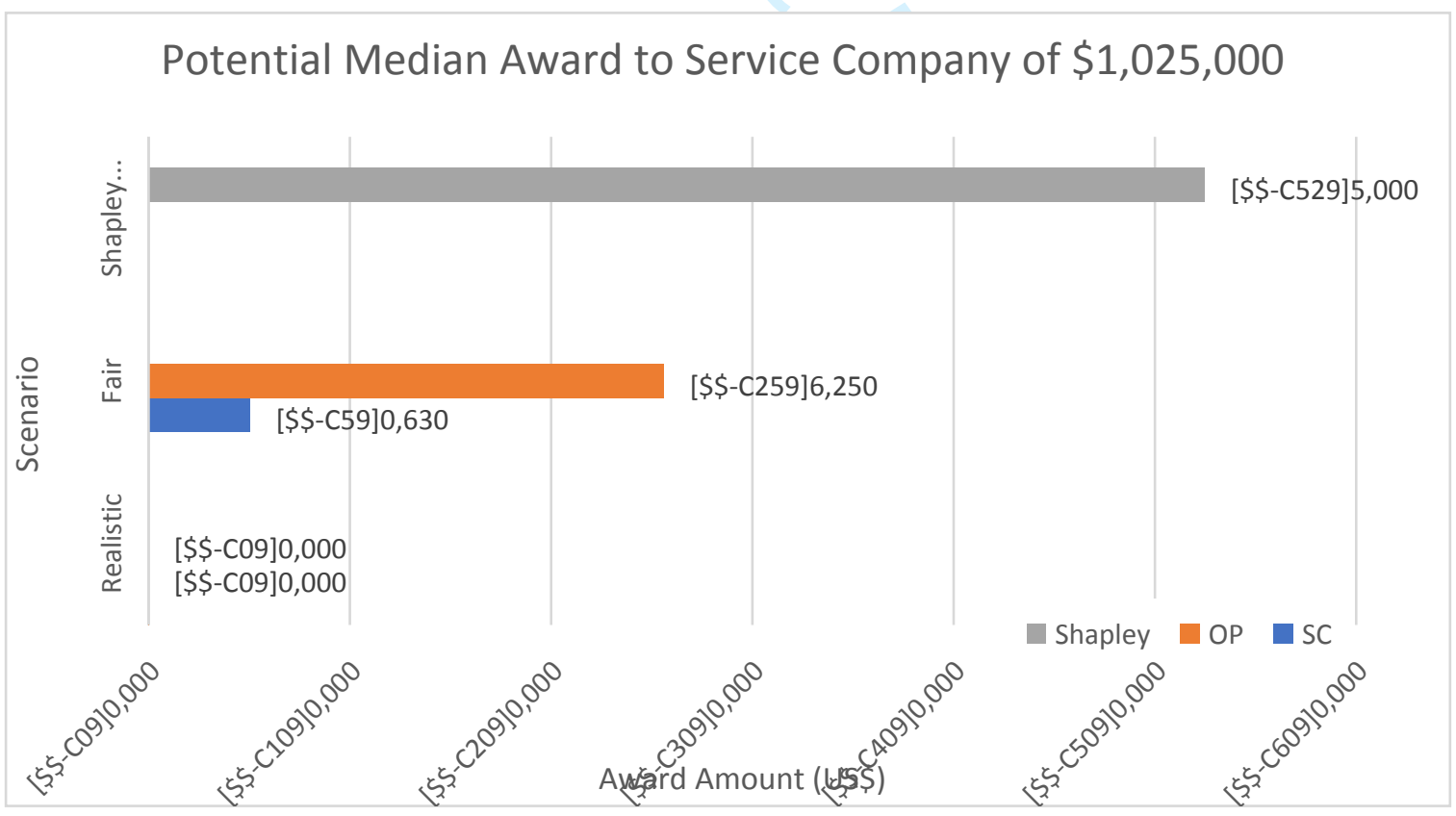

Graph 1: Median award to $S C$ when value $=\$ 1,025,000 . n=24$

Graph 1 shows that there is a significant difference between all the proposed rewards and the Shapley value. In addition to the above findings, a set of t-tests, see Table III below, were 
carried out which show that the difference between SC fair and realistic values were statistically significantly different $(\mathrm{p}=0.004)$. Similarly, the OP fair and realistic values were statistically significantly different $(\mathrm{p}<0.001)$. Using the Fairness Analysis Chart, Figure 4, we can determine that all parties were not working cooperatively, and all parties were cognisant of this.

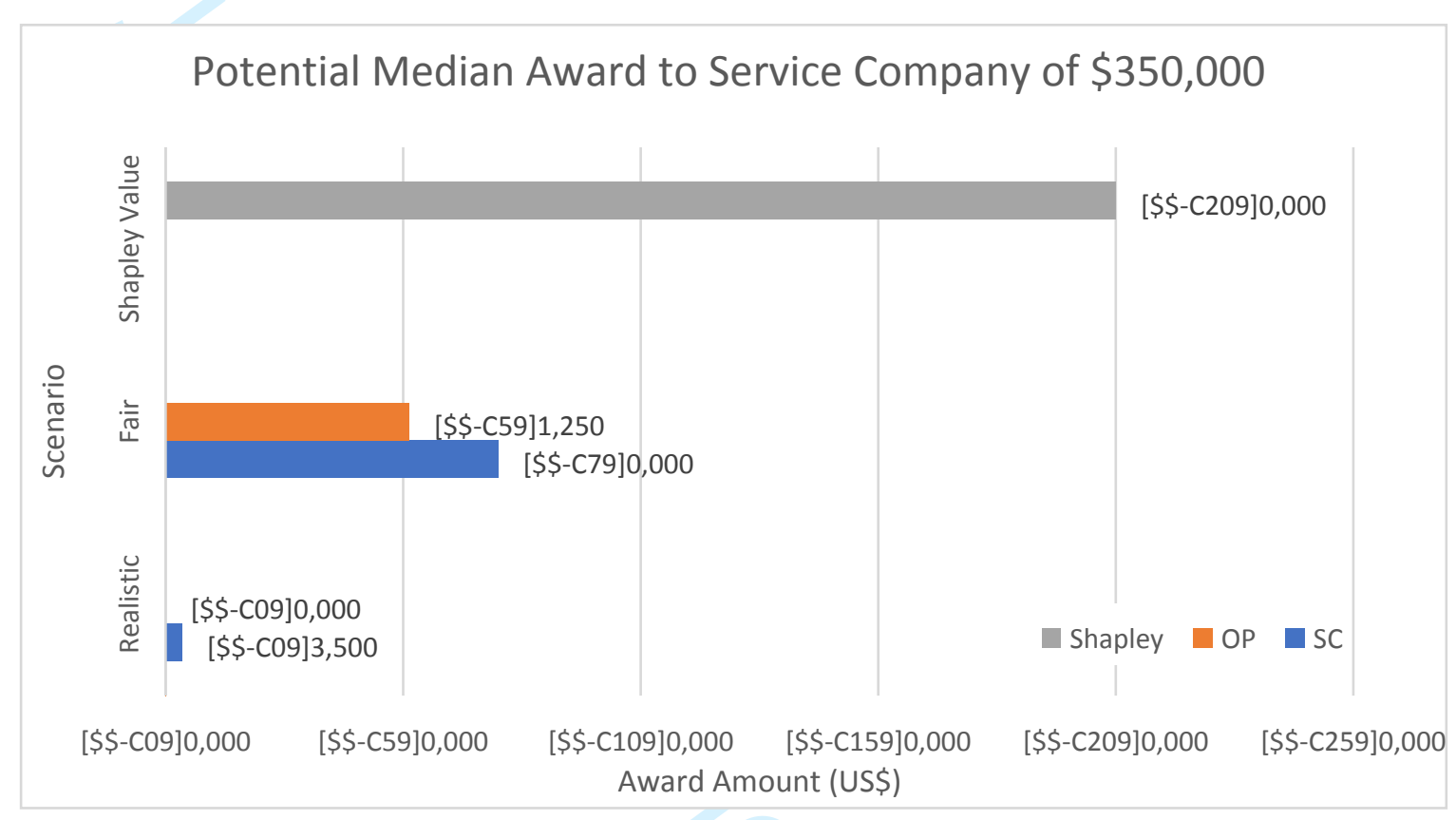

Graph 2: Median award to $S C$ when value $=\$ 350,000 . n=24$

Graph 2 shows that there is also a significant difference between all the proposed rewards and the Shapley value, even for a lesser reward. T-tests, see Table III below, were carried out which show that the difference between SC fair and realistic values were statistically significantly different $(\mathrm{p}<0.001)$. Similarly, the OP fair and realistic values were statistically significantly different $(\mathrm{p}=0.008)$. Referring to Figure 4 , we can determine that, again, all parties were not working cooperatively, and all parties were cognisant of this.

***Insert Table III here***

The servitization levels, as perceived by the respondents, within each organisation were also collected and it was found that the median servitization level claimed by OP employees was 5.0 , or intermediate, with an IQR of 1.5. However, the SCs claimed a median servitization level of 6.5 which is slightly above intermediate, with an IQR of 5.0. The OP has a small IQR which indicates that there is general agreement amongst this group that the servitization level is 5.0. However, the larger IQR of the SC would seem to indicate that there is less agreement within the group on servitization level.

\subsection{A Deeper Understanding of the Situation}

Table IV shows the final coding framework developed in this research. Themes and subthemes are listed, and the references attributed to each are shown in parentheses. The 
emergent themes are identified by an asterisk (*). Appendix 1 provides a list and explanation of all themes and sub-themes.

*** Insert Table IV here****

The interview sessions were designed to deepen the understanding of the findings of the fairness analysis, which found that the relationship is knowingly unfair but acceptable to both SC and OP. One significant finding effect noted was the economic downturn in the oil industry, this lead to tightening of contractual terms and budget constraints and increased the likelihood of adversarial relationships. Many of the interviewees also noted that they had experience of organisations where advanced servitization levels created a more cooperative environment. Several senior SC and OP managers from various locations reported that organisations with higher levels of servitization were more cooperative, and vice versa.

\subsubsection{The Relationship Between Servitization and Cooperation}

The interviewees reported many examples of the necessity of collaboration between all actors for advanced levels of servitization (supporting Story et al., 2017; Polova and Thomas, 2020). For example:

A senior SC Middle East account manager who identifies that greater levels of cooperation (servitization) will lead to more cooperative relationships:

To build a relationship with your client and to maintain that, you've got to service a client and he's got to service you as well. Once you build up trust and respect, the business will just continue to grow.

Likewise, a SC product champion in the US also states that greater levels of collaboration (servitization) create a balance of benefits for both parties compared to non-cooperative behaviour:

The collaborative environment makes a huge difference, ... work[ing] together to explain ... the benefits of both rather than thinking ... you're going to squeeze more money out of me. So instead of this...more collaborative and open discussions..., interactions and collaborations help the situation to be a win-win; ... is very essential... high servitization is a win-win ... there has to be a very good balance from both sides.

Finally, the quote below from a senior OP confirms that cooperation and trust lead to successful business relationships and win-win outcomes for both parties:

If you have ... trust and partnership ..., it will almost always result in a winwin .. the operator then goes out of their way [to] find other ways to compensate you ... I've experienced that in multiple locations around the world. 
The three quotes above not only confirm that collaboration is required for servitization, but also indicate that this collaboration is a universal requirement. The three individuals quoted come from manufacturers (SC), customers (OP) and represent different cultural and geographical regions.

\subsubsection{Resistance to Change and Industry Norms.}

The influence of organisational culture was brought up extensively during the semi-structured interviews. Additionally, resistance to change was found to be universal, which indicates this is likely to be an 'industry norm' rather than a geographic or social cultural effect (Gordon, 1991). The oil industry is notorious for having a culture of change resistance as highlighted in their continued resistance to gender diversity (Miller, 2004). The example below, from a sales manager in the US confirms that there is an industry-wide culture of resistance to change impeding the application of servitization:

The organisational culture barrier... some organisations which are culturally very... laggard in a sense where they just don't like changes.

A similar observation was made by an OP manager in the Middle East, but this time referring to individuals exhibiting resistance to change and that this was a result of the effect of an industry norm:

The biggest barrier is people and the mindset and opening up organisations to work collaboratively. So there's still a lot of resistance. There's still a lot of 'them and us' in oil ... and that's probably the biggest thing which is holding people back.

During the semi-structured interviews, a number of interviewees attributed the resistance to change and adversarial attitude to an East-West cultural difference. However, these reports were inconsistent, even between interviewees with experience of working in multiple cultures. An East-West cultural difference would conflict with literature on this subject (Salacuse, 1998), therefore, we posit that this is not a social or geographical cultural difference but a result of an industry norm. An example of such a quote gathered during the semi-structured interviews by a SC Country Manager in the Middle East is presented below:

If you're talking low-cost areas invariably they're [Middle East] just looking at the price and they may have old fashioned attitudes in terms of service companies... it's definitely the old fashioned attitude that wins.

As discussed above an adversarial business culture was identified in many interviews. This was reported universally, from $\mathrm{OP}, \mathrm{SC}$ and different regions. The quotation below serves as an example taken from a SC country manager who explains that there is a high occurrence of a win/lose culture and employees who naturally prefer to play a win/lose strategy: 
People who've got certain chips on their shoulders and think they're better than other people at their jobs when they're clearly not. And the jumping to rash decisions.

These findings provide evidence that the oil industry has a universal industry norm, which cuts across geographical cultures, and instils an industry norm that encourages an aversion to change. The evidence also suggests that the same industry norm promotes an adversarial working relationship between all parties.

\subsubsection{Servitization Planning and Resources}

There were many observations on the effect of servitization strategy on the implementation of servitization, both from an organisational and personal perspective. The findings suggest that such planning is ubiquitously absent from all of the organizations represented in this research, instead, they rely upon a process of organic growth or, as Ruis-Alba et al., (2019, p.629) phrase it, "flying blind". Lack of planning can starve the servitization process of resources and the necessary management support required for the lengthy and difficult servitization process (Baines and Lightfoot, 2013). In addition to this it is recognised that some organisations may be unaware of the benefits of servitization, preferring to "buy hardware instead of outcomes" (Kohtamäki et al., 2019, p. 381). This point is made by an account manager in the US who describes how companies are unwilling to undertake new strategies, such as servitization:
It was getting better but then again with the downturn, it has also gone down significantly.... Deep down they probably are aware, but they're missing out on the opportunity and at the same time justifying with the fact that what they're doing is already working so let's not change with bigger promises which may not even happen.

\subsubsection{Environmental Influences}

During the semi-structured interviews, the impact of the recent oil price decline and general environment within the oil industry was expressed as a potential cause for the problems in implementing servitization. The interviews provided support to show that there are significant internal (strict application of contractual and financial terms) and external influences which prevent the formation of mutually beneficial relationships between the relevant actors. The inhibition of these natural business relationships hinders the introduction of servitization within the oil industry. This point is made by a senior OP engineer from the Middle-East:

I just think in the last three to five years with the ... there's been a huge culling of specialty service staff. It was pretty brutal the way people had careers ripped away from them, and forced redundancies, ... in that environment you can't afford to have much leeway... the working relationships are far more brutal.

This observation was echoed by a SC engineer, also in the Middle East: 
The base problem is the people that control the money make the biggest decisions. And it's all based on cost and reducing costs, whereas they don't look at the big picture, the value of it.

These findings compliment the findings of the game theory analysis and together provide a robust set of data which can be used to interpret the observable and underlying motivations of the strategies towards the observed inter and intra company relationships. Strong evidence has been provided relating to the stagnation of servitization and deservitization within the oil industry.

\section{Discussion}

The quantitative analysis has shown, with a high degree of statistical significance, that both the OP and SC are using an adversarial or non-cooperative strategy in their interactions. This finding was also confirmed in the interviews. Furthermore, the interviews revealed that the relationships appear to be becoming more adversarial and suggest that a cost-cutting environment, brought about by a prolonged industry downturn, may be responsible. Thus, illustrating how business relationships impact upon servitization strategies and outcomes; this finding is congruent with Kowalkowski et al., (2015). Interestingly, this finding illustrates the complexity of the relationship that exists in a servitization ecosystem where goals and strategies are not always shared equally and value creation is not distributed fairly (Kohtamäki et al., 2019; Lusch and Nambisan, 2015; Opresnik and Taisch, 2015; Sklyar et al., 2019; Story et al., 2020).

The use of game theory and the test administered allowed the underlying nature of the relationship to be observed and could, therefore, differentiate between intent and action. When comparing the proposed awards from the test, the findings show that both parties were cognisant that their behaviour was unfair and non-cooperative, or adversarial. One could therefore suggest that not only a base, but an intermediate level of servitization is likely to create an environment where an adversarial relationship is prominent, see Figure 5 below. This finding is congruent with a form of mimetic isomorphism as described in institutional theory where the actors within the oil industry change or have changed their behaviour to become increasingly similar to each other (Haveman, 1993); in this case their preference for a non-cooperative strategy. Generally, the assumption of Institutional Theory and specifically isomorphism is that the process elevates these organisations to a more harmonious sameness (Martínez-Ferrero and García-Sánchez, 2017). However, in this research the isomorphism takes a darker form of a common, or shared, noncooperative sameness.

All parties expressed that they had experienced greater levels of cooperation in organisations with higher levels of servitization. Similarly, they also stated that they had experienced more adversarial behaviour when working for organisations with low levels of servitization within the oil industry. It was suggested that taking steps to increase or decrease servitization could therefore influence the development of an adversarial relationship into a cooperative relationship and vice versa. This shows that the servitization process is dynamic, complex and is not always one-directional (Valtakoski, 2017) and affected by the relationships of the 
actors involved, i.e., actors are both impacted by and influence the relationships they are involved in (Håkansson and Ford, 2002).

Figure 5 below shows the revised relationship between servitization level and game type. In the initial conceptualisation (see Figure 2) intermediate servitization was connected to a variable strategy which eventually led to a complex relationship. However, the findings of this research have shown that an intermediate level of servitization does not lead to a variable strategy, but instead leads to a non-cooperative strategy, as seen below in Figure 5. Therefore, the findings of this research indicate that both base and intermediate servitization levels result in an adversarial relationship and a win-lose strategy.

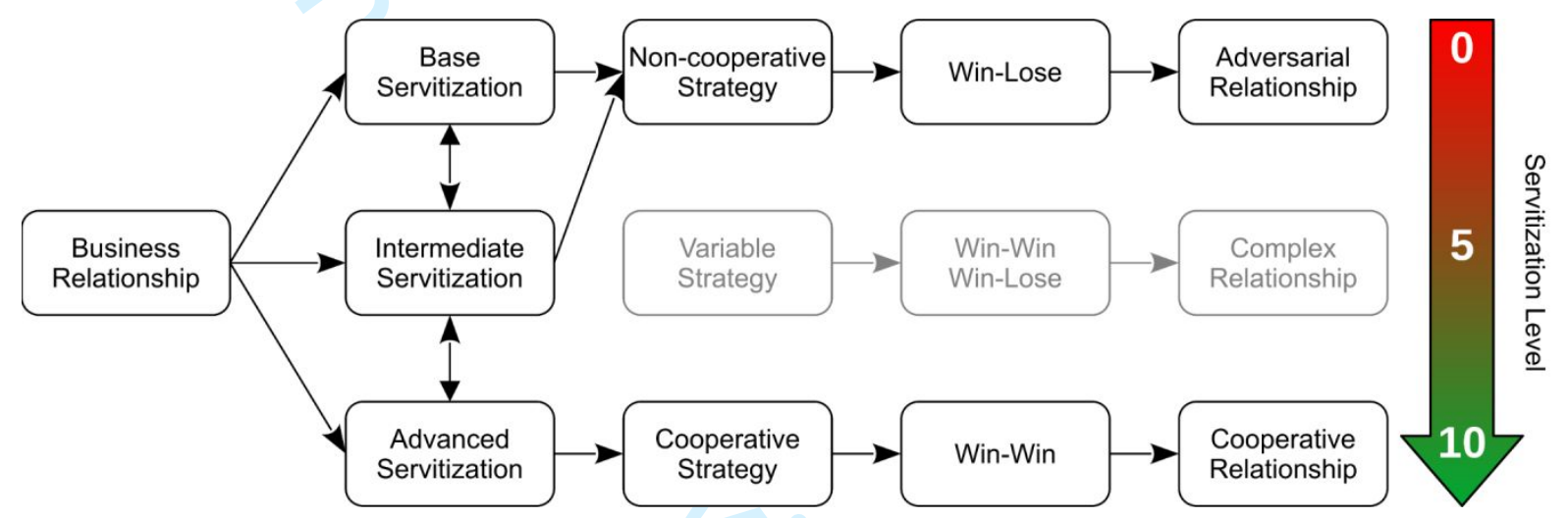

Figure 5: Proposed relationship between servitization level and game type

The findings have indicated that servitization at a base or intermediate level can produce the same outcome, i.e., a win-lose adversarial relationship. In order for servitization to become a game-changer it, therefore, needs to be implemented at an advanced level. However, given the difficult and often non-linear progression of the servitization process and the absence of results on its progression through the basic and intermediate phases, it is questionable if it will receive the required management support and allocation of resources to reach the advanced level and provide a return on the investment. This may explain the apparent stagnation of the servitization process observed in the oil industry and similar organisations and industries observed in the academic literature (Andrews et al., 2018; Raddats et al., 2019).

\section{Conclusion}

\subsection{Theoretical Contributions}

Little literature exists on the use of game theory and servitization (Zhong, 2014). Therefore, this research provides an opportunity to make a methodological contribution. In this section we identify three theoretical contributions to existing servitization theory derived from this research.

The first theoretical contribution shows that whilst there is acknowledgement that servitization is a dynamic process (Andrews et al., 2018; Raddats et al., 2019) and subject to deservitization (Brax, 2005), by using game theory we can add to existing theory by showing that cooperative relationships are only achievable in this context when advanced services are 
involved. This contribution was made possible by combining the methods used within this research and opens a new area of theoretical interest and research opportunities. This finding challenges the tacit assumption that the benefits of servitization improve linearly with an increase in servitization level, instead suggesting that there may be a parabolic relationship, as shown in Figure 6 below.

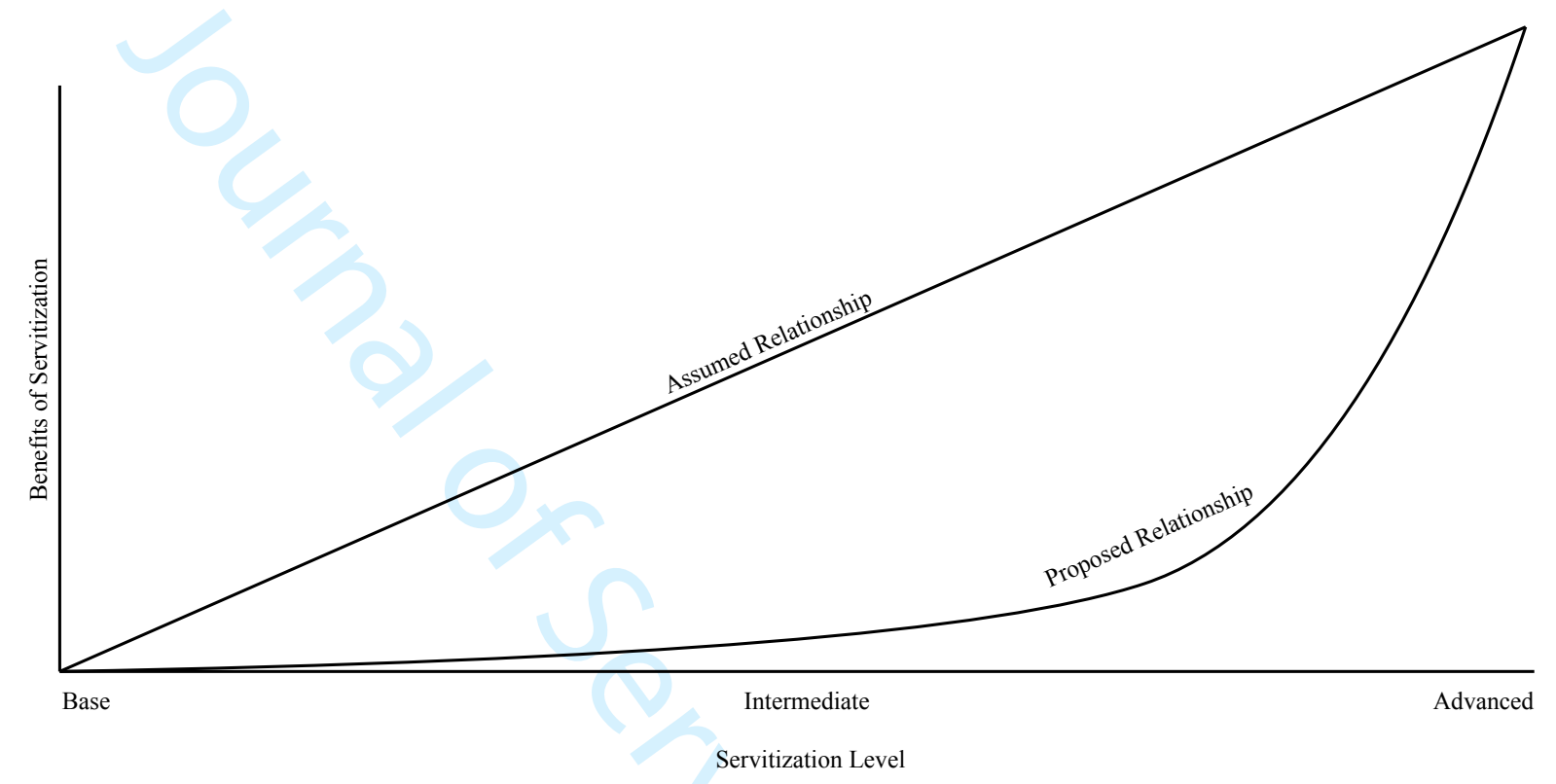

Figure 6: Sketch Showing Assumed and Proposed Relationship Between Servitization Level and Servitization Benefits

Secondly, our research shows how both industry and macro-level factors influence servitization strategies. A darker side of mimetic isomorphism (Haveman, 1993) appeared with respect to how employees of each organisation type were behaving in their business dealings. The research identified that this unfair behaviour was a conscious decision that both sides were aware of and, in the case of many of the SC, self-imposed. By exploring this from a multi-actor perspective, this extends understanding of the darker side of servitization. Finally, the link proposed by many of the interviewees between servitization, deservitization, and the economic environment reminds us that servitization is impacted by macroenvironmental factors. Specifically, that an economic downturn may increase strict adherence to contractual terms and in so doing reduce the ability of employees to form cooperative relationships, and inevitably impedes the servitization process. These findings illustrate the insight that arises from adopting a relational lens for servitization research and how it provides additional insight into the theoretical understanding of servitization and the servitization paradox process.

\subsection{Management and Practical Implications}

This research provides practical insights for management teams wishing to implement a servitization strategy within their organisation. These relate to:

- The nonlinear application and return of servitization

- Criticality of management strategy and the effect of downturns 
- The role of individual, organisational and geographical culture

- The motivators for management to implement servitization and reflection on unilateral application within networks

It has been suggested that the application of servitization is not a linear process (Andrews $e t$ al., 2018; Raddats et al., 2019). This research supports this position and goes further to propose that the return on servitization, especially in the interim stages of servitization, are also not linear. Specifically, that the cooperative relationships derived from servitization may not become evident until advanced levels of servitization have been achieved. Therefore, if an organisation wishes to take advantage of increased cooperation and the benefits of closer working relationships, the management team and organisational structure needs to be committed to achieving advanced levels of servitization.

The transition to servitization is a difficult and prolonged process, requiring management commitment to change within an organisation (Raddats et al., 2018; Ulaga and Reinartz, 2011) and provision of suitable resources (Baines and Lightfoot, 2013; Lenka et al., 2018). A lack of management commitment was mentioned by the interviewees as a significant factor in the failure of the servitization process to reach advanced levels. Therefore, this research advocates that management should prioritise the preparation of a robust servitization strategy. Failure to prepare such a strategy may incur the detrimental effects of deservitization and failure to achieve the rewards if servitization is abandoned or stalled before advanced levels are achieved (Benedettini et al., 2015). Management commitment is especially important during the many industry specific downturns, such as the ongoing oil price crash of 2014 (England, 2020), and the more widespread global economic recessions. This research has shown that there is a tendency for management to reduce costs by strict enforcement contracts or introducing tighter constraints within new contracts, and it is not uncommon for servitization to stall or revert to an earlier incarnation due to these restrictions, an observation also made by Andrews et al. (2018).

This research has shown that there is a resistance to change both at an organizational and individual levels within both OP and SC, which may slow the implementation of servitization. Both the $\mathrm{OP}$ and $\mathrm{SC}$ are aware that an adversarial relationship exists within the oil industry. It has been shown in this research that there is a propensity for a win-lose culture. However, this may be more a factor of industry norms (Blake and Mouton, 1961; Bülow and Kumar, 2011) than East-West cultural differences (Salacuse, 1998). Failure to address these aspects within the servitization strategy may slow or completely derail the servitization process.

The findings suggest that increasing servitization to advanced levels increases the likelihood of cooperation and in turn increases value co-creation. Similarly, reducing or maintaining servitization levels at a base or even intermediate levels is likely to result in adversarial relationships and reduce the likelihood of value co-creation. Therefore, one can posit that management should endeavour to increase servitization levels in order to maximise the potential value co-creation possibilities. However, it must be recognised that these 
organisations exist within a highly complex service ecosystem and a unilateral change is unlikely to be successful. Therefore, a paradigm change within the entire ecosystem may be required (potentially requiring political or regulatory action) to realise the financial and environmental advantages that servitization can access from value co-creation and the efficient use of existing and new resources.

This research is of importance to many stakeholders as it may reduce the need to develop new oil reserves by increasing efficient use of existing reserves. It should therefore benefit the natural environment and economic and political stability of the nations which hold these reserves.

\subsection{Limitations and Future Research}

This research was undertaken in the oil industry and, therefore, further research is needed to explore if the findings are generalisable to other contexts. However, there is no reason to suspect that advanced servitization may not promote cooperative relationships in other industries. Game theory provides an avenue to explore this further and also to investigate if there are other factors that impact on the level of servitization achieved.

The test taken by the participants was relevant to their industry and factored in elements such as the size of award, however, there is a possibility that the subjects could have responded differently to a different scenario or group of scenarios. Therefore, it would be prudent to confirm these findings with a greater range of tests across a wider range of industries. Due to the inherently complex and sometimes counterintuitive nature of game theory, the format of the test in this research was somewhat complex, especially for those not familiar with game theory. This complexity required an explanation of the test scenario and an opportunity for the person being tested to ask questions and seek clarification, removing the option of a selfadministered electronic survey. This personal interaction limited the number of tests taken due to time constraints and other logistical issues. In order to increase the quantity of responses and apply this test to other industries, perhaps a version of the test could be administered simultaneously to a larger group with individual responses collected on paper or some form of electronic voting system. Such an approach could also work for a range of tests and applied to other industries, where the subject matter could be modified, but the underlying concept remained intact.

The research has identified that there is a statistically significant difference in servitization level within the SC when compared with the OP. It may be beneficial to perform additional research, perhaps with a larger sample group and using a more advanced method of assessing servitization level, to understand the reasons for this discrepancy and if this has any influence on the servitization process.

It has been mentioned that industry downturn appears to increase the likelihood for adversarial relationships, and the findings seem to suggest that cost cutting, and strict contract enforcement may be, at least in part, responsible for this. However, focusing on this financial and contractual aspect is warranted to identify the causal link between cost cutting, contractual enforcement and its impact on the servitization process. Furthermore, the 
acceptance of adversarial relationships by both SC and OP at the expense of servitization and value co-creation warrants further investigation.

Future game theory research could be conducted via researcher collaboration with practitioners. A servitizing company with a relatively large number of customers could offer two levels of new service value sharing with two separate groups of randomly allocated customers: low and high. The value created and volume of service activities could then be measured over time to identify the potential impact of different applied servitization strategies. 


\section{References}

Algaba, E., Fragnelli, V. and Sánchez-Soriano, J. (Eds.). (2019), Handbook of the Shapley Value, 1st ed., Chapman \& Hall, Boca Raton.

Alvarado, V. and Manrique, E. (2010), "Enhanced Oil Recovery: An Update Review", Energies, Vol. 3 No. 9, pp. 1529-1575.

Åm, K. and Heiberg, S. (2014), "Public-private partnership for improved hydrocarbon recovery - Lessons from Norway's major development programs”, Energy Strategy Reviews, Vol. 3, pp. 30-48.

Andrews, D., Dmitrijeva, J., Bigdeli, A.Z. and Baines, T. (2018), "Snakes and Ladders in Servitization: Using a Game to Capture Inhibitors and Enablers of Transformation", Research-Technology Management, Vol. 61 No. 6, pp. 37-47.

Baines, T., Bigdeli, A.Z., Sousa, R. \& Schroeder, A. 2020. Framing the servitization transformation process: A model to understand and facilitate the servitization journey. International Journal of Production Economics, 221, 107463, pp 1-16.

Baines, T. and Lightfoot, H. (2013), Made to Serve, 1st ed., John Wiley \& Sons, Inc., Chichester, available at:https://doi.org/10.1002/9781119207955.

Baines, T.S., Lightfoot, H.W., Benedettini, O. and Kay, J.M. (2009), "The servitization of manufacturing”, Journal of Manufacturing Technology Management, Vol. 20 No. 5, pp. 547567.

Bandinelli, R. and Gamberi, V. (2011), "Servitization in oil and gas sector: outcomes of a case study research", Journal of Manufacturing Technology Management, Vol. 23 No. 1, pp. 87-102.

Benedettini, O., Neely, A. and Swink, M. (2015), "Why do servitized firms fail? A risk-based explanation", International Journal of Operations \& Production Management, Vol. 35 No. 6, pp. 946-979.

Bentley, R.W. (2002), "Global oil \& gas depletion: an overview”, Energy Policy, Vol. 30 No. 3, pp. 189-205.

Blake, R.R. and Mouton, J.S. (1961), "Reactions to Intergroup Competition under Win-Lose Conditions", Management Science, INFORMS, Vol. 7 No. 4, pp. 420-435.

Brax, S. (2005), "A manufacturer becoming service provider - challenges and a paradox", edited by Gustafsson, A.Managing Service Quality: An International Journal, Vol. 15 No. 2, pp. 142-155.

Brewer, J. and Hunter, A. (1989), Multimethod Research: A Synthesis of Styles., 1st ed., Sage, Thousand Oaks.

Bryman, A. (2012), Social Research Methods, 4th ed., Oxford University Press, Oxford.

Bülow, A.M. and Kumar, R. (2011), "Culture and Negotiation", International Negotiation, Vol. 16 No. 3, pp. 349-359.

Burton, J., Story, V.M., Raddats, C. and Zolkiewski, J. (2017), “Overcoming the challenges that hinder new service development by manufacturers with diverse services strategies", International Journal of Production Economics, Vol. 192 No. October 2017, pp. 29-39. 
Burton, J., Story, V., Zolkiewski, J., Raddats, C., Baines, T.S. and Medway, D (2016) " Identifying Tensions in the Servitized Value Chain", Research-Technology Management, Vol. 59, No. 5; pp. 38-47.

Calleja, P. and Llerena, F. (2020), "Consistency, weak fairness, and the Shapley value", Mathematical Social Sciences, Vol. 105, pp. 28-33.

Chatterjee, K. and Samuelson, W. (2014), Game Theory and Business Applications, 2nd ed., Springer, Boston.

Corley, K.G. and Gioia, D.A. (2004), "Identity Ambiguity and Change in the Wake of a Corporate Spin-off”, Administrative Science Quarterly, Vol. 49 No. 2, pp. 173-208.

Creswell, J.W., Plano Clark, V.L., Gutmann, M., and Hanson, W. (2003), Advanced mixed methods research designs. In A. Tashakkori \& C. Teddlie (Eds.), Handbook of mixed methods in social and behavioral research (pp. 209-240). Thousand Oaks, CA: Sage.

Crowley, E., Burton, J. and Zolkiewski, J. (2018), "Servitization intent as a factor in the servitization process", Journal of Business \& Industrial Marketing, Vol. 33 Issue: 8, pp.11251140 .

Denzin, N.K. (1978), The Research Act, 1st ed., Aldine, Chicago.

Dixit, A.K. and Nalebuff, B.J. (2010), The Art of Strategy: A Game Theorist's Guide to Success in Business and Life, 1st ed., W. W. Norton \& Company, London.

Dubois, A. and Gadde, L.-E. (2002), "Systematic combining: an abductive approach to case research", Journal of Business Research, Vol. 55 No. 7, pp. 553-560.

Dyer, J.H. and Nobeoka, K. (2000), "Creating and Managing a High-Performance Knowledge-Sharing Network: The Toyota Case", Strategic Management Journal, Vol. 21 No. 3, pp. 345-367.

Easterby-Smith, M., Horpe, R. and Jackson, P.R. (2012), Management Research, 4th ed., SAGE, London.

Elkind, E. and Rothe, J. (2016), "Cooperative Game Theory", Economics and Computation: An Introduction to Algorithmic Game Theory, Computational Social Choice, and Fair Division, Springer, Berlin, Heidelberg, pp. 135-193.

England, J. (2020), "Lower for Longer and the Risk of Oil and Gas Underinvestment", Deloitte United States, available at: https://www2.deloitte.com/us/en/pages/energy-andresources/articles/lower-for-longer-risk-oil-gas-underinvestment.html (accessed $2 \mathrm{March}$ 2020).

Fang, E. (Er), Palmatier, R.W. and Steenkamp, J.-B.E.M. (2008), "Effect of Service Transition Strategies on Firm Value", Journal of Marketing, Vol. 72 No. 5, pp. 1-14.

Ferreira, F.N.H., Proença, J.F., Spencer, R. and Cova, B. (2013), "The transition from products to solutions: External business model fit and dynamics", Industrial Marketing Management, Vol. 42 No. 7, pp. 1093-1101.

Finne, M. and Holmström, J. (2013) 'A manufacturer moving upstream: triadic collaboration for service delivery', Supply Chain Management: An International Journal, 18(1), pp. 21-33. Flick, U. (2009), An Introduction to Qualitative Reaearch, 4th ed., SAGE, Los Angeles.

Galvin, R. (2015), "How many interviews are enough? Do qualitative interviews in building energy consumption research produce reliable knowledge?", Journal of Building Engineering, Vol. 1, pp. 2-12. 
Gao, L. (2019), "Evolutionary game analysis of servitization transformation in manufacturing enterprises", presented at the 2019 5th International Conference on Green Power, Materials and Manufacturing Technology and Applications (GPMMTA 2019), Taiyuan, China, pp. 16.

Gebauer, H., Fleisch, E. and Friedli, T. (2005) " Overcoming the service paradox in manufacturing companies", European Management Journal, Vol. 23, No. 1, pp. 14-26.

Gebauer, H. and Kowalkowski, C. (2012), "Customer-focused and service-focused orientation in organizational structures", Journal of Business \& Industrial Marketing, Vol. 27 No. 7, pp. 527-537.

Gioia, D.A., Corley, K.G. and Hamilton, A.L. (2013), "Seeking Qualitative Rigor in Inductive Research”, Organizational Research Methods, Vol. 16 No. 1, pp. 15-31.

Gordon, G. G. (1991) 'Industry Determinants of Organizational Culture', The Academy of Management Review, 16(2), pp. 396-415.

Håkansson, H. and Ford, D. (2002) "How Should Companies Interact in Business Networks?", Journal of Business Research, Vol. 55, No. 2, pp. 133-139.

Håkansson, H. and Snehota, I. (eds.) (2017), No Business Is An Island: Making Sense of the Interactive Business World, Emerald Publishing Ltd., Bingley, UK

Hammoudi, A. (2018), Game Theory Approach to Managerial Strategies and Value Creation, 1st ed., Vol. 3, John Wiley and Sons Inc, Hoboken.

Harrison, R. L., Reilly, T. M. and Creswell, J. W. (2020) 'Methodological Rigor in Mixed Methods: An Application in Management Studies', Journal of Mixed Methods Research, 14(4), pp. 473-495

Hartwig, F.P., Smith, G.D., Schmidt, A.F., Sterne, J.A.C., Higgins, J.P.T. and Bowden, J. (2020), "The median and the mode as robust meta-analysis estimators in the presence of small-study effects and outliers", Research Synthesis Methods, Vol. 11 No. 3, pp. 397-412.

Haveman, H.A. (1993), "Follow the Leader: Mimetic Isomorphism and Entry Into New Markets”, Administrative Science Quarterly, Vol. 38 No. 4, pp. 593-627.

Hezarkhani, B. (2017), "Optimal design of uptime-guarantee contracts under IGFR valuations and convex costs", European Journal of Operational Research, Vol. 256 No. 2, pp. 556-566.

Homburg, C., Hoyer, W.D. and Fassnacht, M. (2002), "Service Orientation of a Retailer's Business Strategy: Dimensions, Antecedents, and Performance Outcomes", Journal of Marketing, Vol. 66 No. 4, pp. 86-101.

Huikkola, T., Rabetino, R., Kohtamäki, M. and Gebauer, H. (2020) " Firm boundaries in servitization: Interplay and repositioning practices", Industrial Marketing Management, Vol. 90, pp. 90-105.

Johnson, R.B, Onwuegbuzie, A.J. and Turner, L.A. (2007), "Towards a definition of mixed methods research", Journal of Mixed Methods Research, Vol. 1, No.2, pp. 112-133.

Kamalaldin, A. Linde, L., Sjödin, D. and Parida, V. (2020) "Transforming provider-customer relationships in digital servitization: A relational view on digitalization", Industrial Marketing Management, Vol. 89, pp. 306-325.

Kamp, B. and Parry, G. (2017), "Servitization and advanced business services as levers for competitiveness", Industrial Marketing Management, Vol. 60, pp. 11-16. 
Kemp, A.G. and Stephen, L. (1999), "Risk:reward sharing contracts in the oil industry: the effects of bonus:penalty schemes", Energy Policy, Vol. 27 No. 2, pp. 111-120.

Kesicki, F. (2010), “The third oil price surge - What's different this time?", Energy Policy, Vol. 38 No. 3, pp. 1596-1606.

King, Nigel., Horrocks, C. and Brooks, J. (2010), Interviews in Qualitative Research, 2nd ed., Sage Publications Ltd, Los Angeles.

Kohtamäki, M., Einola, S. and Rabetino, R. (2020), "Exploring servitization through the paradox lens: Coping practices in servitization", International Journal of Production Economics, Vol. 226, 107619, pp.1-15.

Kohtamäki, M., Parida, V., Oghazi, P., Gebauer, H. and Baines, T. (2019), "Digital servitization business models in ecosystems: A theory of the firm", Journal of Business Research, Vol. 104, pp. 380-392.

Koivisto, J. and Hamari, J. (2019), "The rise of motivational information systems: A review of gamification research", International Journal of Information Management, Vol. 45, pp. 191-210.

Korstjens, I. and Moser, A. (2017) 'Series: Practical guidance to qualitative research. Part 2: Context, research questions and designs', European Journal of General Practice, 23(1), pp. 274-279. doi: 10.1080/13814788.2017.1375090.

Kowalkowski, C., Gebauer, H., Kamp B. and Parry, G. (2017) "Servitization and deservitization: Overview, concepts, and definitions", Industrial Marketing Management, Vol. 60 (January), pp. 4-10.

Kowalkowski, C., Windahl, C., Kindström, D. and Gebauer, H. (2015), “What service transition? Rethinking established assumptions about manufacturers' service-led growth strategies", Industrial Marketing Management, Vol. 45 No. 1, pp. 59-69.

Kremer, D., Seregni, M., Canepa, A., Zanetti, C. and Gusmeroli, S. (2016), “The Focusactivity Framework for Evaluating PSS Cooperation Readiness of Manufacturing Firms", Procedia CIRP, Vol. 47, pp. 132-137.

Kumar, R. and Markeset, T. (2007), "Development of performance-based service strategies for the oil and gas industry: a case study", Journal of Business \& Industrial Marketing, Vol. 22 No. 4, pp. 272-280.

Lee, S., Yoo, S. and Kim, D. (2016), "When is servitization a profitable competitive strategy?", International Journal of Production Economics, Vol. 173, pp. 43-53.

Lenka, S., Parida, V., Sjödin, D.R. and Wincent, J. (2018), “Towards a multi-level servitization framework", International Journal of Operations \& Production Management, Vol. 38 No. 3, pp. 810-827.

Lexutt, E. (2020), "Different roads to servitization success - A configurational analysis of financial and non-financial service performance", Industrial Marketing Management, Vol., 84, pp.105-125.

Lima, B.B. de, Câmara, S.F., Mota, T.L.N. da G., Silva, A.L. e and Padilha, P. (2018), "Management of Innovation Networks: a choice for collaboration considering the game theory", Business and Management Studies, Vol. 4 No. 2, p. 24.

Lusch, R. F. and Nambisan, S. (2015) 'Service Innovation: A Service-Dominant Logic Perspective', MIS Quarterly, 39(1), pp. 155-175. 
Ma R., Feng C., Jiang L. (2020) "Evolutionary Game Analysis of Service Outsourcing Strategy for Manufacturing Enterprises Based on Servitization", In: Zhang J., Dresner M., Zhang R., Hua G., Shang X. (eds) LISS2019. Springer, Singapore.

https://doi.org/10.1007/978-981-15-5682-1_19

Martínez-Ferrero, J. and García-Sánchez, I.-M. (2017), “Coercive, normative and mimetic isomorphism as determinants of the voluntary assurance of sustainability reports", International Business Review, Vol. 26 No. 1, pp. 102-118.

Miller, G. E. (2004) 'Frontier Masculinity in the Oil Industry: The Experience of Women Engineers', Gender, Work \& Organization, 11(1), pp. 47-73.

“Mission, Vision, Values". (2020), Halliburton, available at: https://www.halliburton.com/en-US/about-us/corporate-profile/mission-visionvalues.html?node-id=ijzrw073 (accessed 5 November 2020).

Morgan, R.M. and Hunt, S.D. (1994), "The Commitment-Trust Theory Of Relationship Marketing", Journal of Marketing, Vol. 58 (July 1994), pp. 20 -38.

Murphy, M.K., Black, N.A., Lamping, D.L., McKee, C.M., Sanderson, C.F., Askham, J. and Marteau, T. (1998), "Consensus development methods, and their use in clinical guideline development.", Health Technology Assessment, Vol. 2 No. 3, pp. 1-88.

Ng, I., Parry, G., Smith, L., Maull, R. and Briscoe, G. (2012), “Transitioning from a goods-dominant to a service-dominant logic: Visualising the value proposition of Rolls-Royce”, Journal of Service Management, Vol. 23 No. 3, pp. 416-439.

Opresnik, D. and Taisch, M. (2015) 'The value of Big Data in servitization', International Journal of Production Economics, 165, pp. 174-184.

Parra, F. (2004), Oil Politics - A Modern History of Petroleum, Vol. 25, L. B. Tauris \& Co. Ltd., New York, available at:https://doi.org/10.2307/41323035.

Peillon, S. and Dubruc, N. (2019), "Barriers to digital servitization in French manufacturing SMEs", Procedia CIRP, Vol. 83, pp. 146-150.

Peleckis, K. (2015), "The Use of Game Theory for Making Rational Decisions in Business Negations: A Conceptual Model”, Entrepreneurial Business and Economics Review, Vol. 3 No. 4, pp. 105-121.

Peleg, B. and Sudhölter, P. (2007), Introduction to the Theory of Cooperative Games, 2nd ed., Springer, Berlin, available at:https://doi.org/10.1007/978-3-540-72945-7.

Polova, O. and Thomas, C. (2020) 'How to perform collaborative servitization innovation projects: the role of servitization maturity', Industrial Marketing Management, 90, pp. 231251.

Raddats, C., Burton, J. and Ashman, R. (2015), "Resource configurations for services success in manufacturing companies", Journal of Service Management, Vol. 26 No. 1, pp. 97-116.

Raddats, C., Burton, J., Zolkiewski, J. and Story, V. (2018), "Overcoming the Challenges of Servitisation: Aligning Responses to Service Strategy", Practices and Tools for Servitization, Springer International Publishing, Cham, pp. 171-184.

Raddats, C. and Kowalkowski, C. (2014) "A Reconceptualization of Manufacturers' Service Strategies", Journal of Business-to-Business Marketing, Vol. 21, No. 1, pp. 19-34. 
Raddats, C., Kowalkowski, C., Benedettini, O., Burton, J. and Gebauer, H. (2019), "Servitization: A contemporary thematic review of four major research streams", Industrial Marketing Management, Vol. 83, pp. 207-223.

Raddats, C., Zolkiewski, J., Story, V. M., Burton, J., Baines, T. and Ziaee Bigdeli, A. (2017) 'Interactively developed capabilities: evidence from dyadic servitization relationships', International Journal of Operations \& Production Management, 37(3), pp. 382-400.

Reim, W., Sjödin, D.R. and Parida, V. (2019) "Servitization of global service network actorsA contingency framework for matching challenges and strategies in service transition", Journal of Business Research, 104, pp.461-471.

Ross, D. (2019), “Game Theory”, The Stanford Encyclopedia of Philosophy, Metaphysics Research Lab, Stanford University.

Ruiz-Alba, J. L., Soares, A., Rodríguez-Molina, M. A. and Frías-Jamilena, D. M. (2019) 'Servitization strategies from customers' perspective: the moderating role of co-creation', Journal of Business \& Industrial Marketing, 34(3), pp. 628-642.

Salacuse, J.W. (1998), "Ten Ways that Culture Affects Negotiating Style: Some Survey Results", Negotiation Journal, Vol. 14 No. 3, pp. 221-240.

Salonen, A., Saglam, O. and Hacklin, F. (2017), "Servitization as reinforcement, not transformation", Journal of Service Management, Vol. 28,reim

No. 4, pp. 662-686.

Shapley, L.S. (1953), “A value for n-person games”, Contributions to the Theory of Games II, 1st ed., Princeton University Press, Princeton, pp. 307-317.

Shi, V.G., Baines, T., Baldwin, J., Ridgway, K., Petridis, P., Bigdeli, A.Z., Uren, V., et al. (2017), "Using gamification to transform the adoption of servitization", Industrial Marketing Management, Vol. 63, pp. 82-91.

Shi, V.G., Baldwin, J., Ridgway, K. and Scott, R. (2013), "Gamification for servitization a conceptual paper", Frameworks and Analysis, p. 114.

Sklyar, A., Kowalkowski, C., Tronvoll, B. and Sörhammar, D. (2019) 'Organizing for digital servitization: A service ecosystem perspective', Journal of Business Research, 104, pp. 450460.

Story, V.M., Raddats, C., Burton, J., Zolkiewski, J. and Baines, T. (2017), “Capabilities for advanced services: A multi-actor perspective", Industrial Marketing Management, Vol. 60 No. May, pp. 54-68.

Story, V., Zolkiewski, J., Verleye, K., Nazifi, A., Hannibal, C., Grimes, A. and Abboud, L. (2020) 'Stepping out of the shadows: Supporting actors' strategies for managing end-user experiences in service ecosystems', Journal of Business Research, 116, pp. 401-411.

Süße, T. and Wilkens, U. (2014), "Preparing Individuals for the Demands of PSS Work Environments through a Game-based Community Approach - Design and Evaluation of a Learning Scenario", Procedia CIRP, Vol. 16, pp. 271-276.

Tadelis, S. (2013), Game Theory: An Introduction, 1st ed., Princeton University Press, Oxford.

Tronvoll, B., Sklyar, A., Sörhammar, D. and Kowalkowski, C. (2020), "Transformational shifts through digital servitization”, Industrial Marketing Management, Vol. 89, pp. 293-305. 
Ulaga, W. and Reinartz, W.J. (2011), "Hybrid Offerings: How Manufacturing Firms Combine Goods and Services Successfully", Journal of Marketing, Vol. 75 No. 6, pp. 5-23.

Valtakoski, A. (2017) "Explaining servitization failure and deservitization: A knowledgebased perspective", Industrial Marketing Management, Vol. 60, January, pp. 138-150.

Welbers, K., Konijn, E.A., Burgers, C., de Vaate, A.B., Eden, A. and Brugman, B.C. (2019), "Gamification as a tool for engaging student learning: A field experiment with a gamified app", E-Learning and Digital Media, Vol. 16 No. 2, pp. 92-109.

"Who We Are". (2020), Schlumberger, available at: https://www.slb.com/who-we-are (accessed 11 April 2020).

Winter, E. (2002), “The shapley value”, Handbook of Game Theory with Economic Applications, Vol. 3, Elsevier, London, pp. 2025-2054.

Zhong, H. (2014), "Game analysis of product-service integration”, Journal of Industrial Engineering and Management, Vol. 7 No. 5, pp. 1447-1467.

Zitha, P., Felder, R., Zornes, D., Brown, K. and Mohanty, K. (2008), “Increasing Hydrocarbon Recovery Factors”, Society of Petroleum Engineers, pp. 1-9. 


\section{Appendix 1}

\begin{tabular}{|c|c|c|}
\hline Theme & Sub-theme & Description \\
\hline \multirow[t]{7}{*}{$\begin{array}{l}\text { Oilfield dilemma } \\
\text { discussion }\end{array}$} & \multicolumn{2}{|c|}{$\begin{array}{c}\text { The level of awareness of both personal and organisational attitudes } \\
\text { to servitization. }\end{array}$} \\
\hline & Offer reward in Ideal World & $\begin{array}{l}\text { Expectation of a reward in an ideal } \\
\text { world scenario and what is a fair } \\
\text { reward }\end{array}$ \\
\hline & Offer reward in Real World & $\begin{array}{l}\text { Expectation of a reward in a real-world } \\
\text { scenario and what is a realistic reward }\end{array}$ \\
\hline & Offer Tool & $\begin{array}{l}\text { Attitudes of } S C \text { and } O P \text { to win-lose } \\
\text { relationships and if these relationships } \\
\text { are common within the setting }\end{array}$ \\
\hline & Long term relationship & $\begin{array}{l}\text { How the intention to maintain long } \\
\text { term relationships influences business } \\
\text { decisions }\end{array}$ \\
\hline & Expected service & $\begin{array}{l}\text { How the expectation of service is } \\
\text { expressed as a business differentiator }\end{array}$ \\
\hline & $\begin{array}{l}\text { Contractual or procurement } \\
\text { block }\end{array}$ & $\begin{array}{l}\text { The impact of contractual or } \\
\text { procurement restrictions on the ability } \\
\text { to participate in a win-win scenario }\end{array}$ \\
\hline \multirow{5}{*}{$\begin{array}{l}\text { Servitization } \\
\text { Level }\end{array}$} & \multicolumn{2}{|c|}{ Perceptions of levels of servitization } \\
\hline & Level & $\begin{array}{l}\text { Servitization level of different } \\
\text { organisations and what constitutes the } \\
\text { level }\end{array}$ \\
\hline & $\begin{array}{l}\text { High servitization }= \\
\text { increased chance of win/win }\end{array}$ & $\begin{array}{l}\text { Advanced levels of servitization and its } \\
\text { contribution to a win/win culture. }\end{array}$ \\
\hline & $\begin{array}{l}\text { Low servitization }=\text { reduced } \\
\text { chance of win/win }\end{array}$ & $\begin{array}{l}\text { Base levels of servitization and its } \\
\text { influence on a win/win culture }\end{array}$ \\
\hline & Contracts and procurement & $\begin{array}{l}\text { Contracts and procurement procedures } \\
\text { removing the ability to form close } \\
\text { relationships with their business } \\
\text { partners }\end{array}$ \\
\hline \multirow{6}{*}{$\begin{array}{l}\text { Servitization } \\
\text { Application }\end{array}$} & \multicolumn{2}{|c|}{ How servitization impacts the health of a business } \\
\hline & $\begin{array}{l}\text { Opportunities lost due to } \\
\text { lack of servitization }\end{array}$ & $\begin{array}{l}\text { Lost/sacrificed servitization } \\
\text { opportunities }\end{array}$ \\
\hline & $\begin{array}{l}\text { Awareness of opportunities } \\
\text { lost due to lack of } \\
\text { servitization }\end{array}$ & $\begin{array}{l}\text { Awareness of lost servitization } \\
\text { opportunities }\end{array}$ \\
\hline & Power & $\begin{array}{l}\text { Interorganisational power and its } \\
\text { impact on servitization and/or } \\
\text { cooperation strategy. }\end{array}$ \\
\hline & Organisation size & $\begin{array}{l}\text { How the size of the organisation, with } \\
\text { respect to its counterparts or } \\
\text { irrespective of its counterparts' size } \\
\text { impact servitization }\end{array}$ \\
\hline & Culture & $\begin{array}{l}\text { How organisational culture impacts } \\
\text { servitization }\end{array}$ \\
\hline
\end{tabular}




\begin{tabular}{|c|c|c|}
\hline Theme & Sub-theme & Description \\
\hline & Fading service levels & $\begin{array}{l}\text { Impact of diminishing levels of service } \\
\text { on the business relationship and the } \\
\text { servitization process }\end{array}$ \\
\hline & $\begin{array}{l}\text { Inter-organisational } \\
\text { administration block }\end{array}$ & $\begin{array}{l}\text { Barriers to servitization caused by the } \\
\text { rigidity of intracompany administration }\end{array}$ \\
\hline \multirow{7}{*}{$\begin{array}{l}\text { Antecedent } \\
\text { Factors }\end{array}$} & \multicolumn{2}{|c|}{ Antecedents to servitization } \\
\hline & Culture & $\begin{array}{l}\text { Culture in the context of personal } \\
\text { attitudes to relationships }\end{array}$ \\
\hline & $\begin{array}{l}\text { Industry downturn and } \\
\text { environment }\end{array}$ & $\begin{array}{l}\text { Impact of wider environmental factors } \\
\text { on the servitization process }\end{array}$ \\
\hline & Trend & $\begin{array}{l}\text { Trends with respect to servitization and } \\
\text { relationship type }\end{array}$ \\
\hline & Revenue and budget driven & $\begin{array}{l}\text { Impact of resource availability on the } \\
\text { application of servitization }\end{array}$ \\
\hline & Management Commitment & $\begin{array}{l}\text { Differences in managerial intent, e.g., } \\
\text { where senior managers appear to be } \\
\text { more committed to servitization than } \\
\text { less senior managers }\end{array}$ \\
\hline & $\begin{array}{l}\text { Internal administration } \\
\text { block }\end{array}$ & $\begin{array}{l}\text { Business practices of organisations } \\
\text { which restrict the implementation of } \\
\text { servitization }\end{array}$ \\
\hline \multirow{5}{*}{$\begin{array}{l}\text { Servitization as a } \\
\text { solution }\end{array}$} & \multicolumn{2}{|c|}{ Perceptions of different levels of servitization } \\
\hline & $\begin{array}{l}\text { Increasing servitization }= \\
\text { win/win }\end{array}$ & $\begin{array}{l}\text { How increasing servitization results in } \\
\text { a win/win outcome }\end{array}$ \\
\hline & $\begin{array}{l}\text { Increasing servitization } \neq \\
\text { win/win }\end{array}$ & $\begin{array}{l}\text { How increasing servitization does not } \\
\text { result in a win/win outcome }\end{array}$ \\
\hline & $\begin{array}{l}\text { Decreasing servitization }= \\
\text { win/win }\end{array}$ & $\begin{array}{l}\text { How decreasing servitization results in } \\
\text { an increased possibility of a win/win } \\
\text { outcome }\end{array}$ \\
\hline & $\begin{array}{l}\text { Decreasing servitization } \neq \\
\text { win/win }\end{array}$ & $\begin{array}{l}\text { How decreasing servitization decreases } \\
\text { the possibility of a win/win outcome }\end{array}$ \\
\hline East/West divide & & $\begin{array}{l}\text { Differences between Eastern and } \\
\text { Western cultures }\end{array}$ \\
\hline $\begin{array}{l}\text { Short term } \\
\text { planning }\end{array}$ & & $\begin{array}{l}\text { Management commitment not being } \\
\text { forward looking enough to see a } \\
\text { servitization plan through to fruition }\end{array}$ \\
\hline
\end{tabular}




\begin{tabular}{|l|l|l|l|}
\hline \multicolumn{1}{|c}{ Type } & \multicolumn{1}{c}{ Defined by } \\
\hline $\begin{array}{l}\text { Base } \\
\text { services }\end{array}$ & $\begin{array}{l}\text { An outcome focused } \\
\text { on product provision }\end{array}$ & $\begin{array}{l}\text { Based on the execution of } \\
\text { production competence (i.e. we } \\
\text { know how to build it) }\end{array}$ & $\begin{array}{l}\text { Product/equipment provision, } \\
\text { spare part provision, warranty }\end{array}$ \\
\hline $\begin{array}{l}\text { Intermediate } \\
\text { services }\end{array}$ & $\begin{array}{l}\text { An outcome focused } \\
\text { on maintenance of } \\
\text { product condition }\end{array}$ & $\begin{array}{l}\text { Based on exploitation of } \\
\text { production competences to also } \\
\text { maintain the condition of } \\
\text { products (i.e. because we know } \\
\text { how to build it, we know how to } \\
\text { repair it) }\end{array}$ & $\begin{array}{l}\text { Scheduled maintenance, } \\
\text { technical helpdesk, repair, } \\
\text { overhaul, delivery to site, } \\
\text { installation, operator training, } \\
\text { operator certification, condition } \\
\text { monitoring, in-field service }\end{array}$ \\
\hline $\begin{array}{l}\text { Advanced } \\
\text { services }\end{array}$ & $\begin{array}{l}\text { An outcome focused } \\
\text { on capability } \\
\text { delivered through } \\
\text { performance of the } \\
\text { product }\end{array}$ & $\begin{array}{l}\text { Based on translation of } \\
\text { production competences to also } \\
\text { manage the product's } \\
\text { performance (i.e. because we } \\
\text { know how to build it, we know } \\
\text { how to keep it operational) }\end{array}$ & $\begin{array}{l}\text { Customer support agreement, } \\
\text { risk and reward sharing contract, } \\
\text { revenue-through-use contract, } \\
\text { rental agreement }\end{array}$ \\
\hline
\end{tabular}




\begin{tabular}{|c|c|c|}
\hline & Qualitative & Quantitative \\
\hline High reward test: $\underline{\text { Service Company (HS) }}$ & \multirow{4}{*}{13 Participants } & 12 Participants \\
\hline High reward test: $\underline{\text { Operator }(\mathrm{HO})}$ & & 12 Participants \\
\hline Low reward test: $\underline{\text { Service Company (LS) }}$ & & 12 Participants \\
\hline Low reward test: $\underline{\text { Operator (LO) }}$ & & 12 Participants \\
\hline Totals $(n)$ & 13 & 48 \\
\hline
\end{tabular}

Table II: Research Group Classification and Distribution 


\begin{tabular}{|c|c|c|c|c|c|c|c|c|c|c|}
\hline & & & $\mathbf{n}$ & Mean \% & Mean \$ & SD & $\mathbf{t}$ & df & p & Power \\
\hline \multirow{4}{*}{ High } & \multirow{2}{*}{$\begin{array}{l}\text { Service } \\
\text { company }\end{array}$} & Fair world & \multirow{2}{*}{12} & 5.84 & 59,899 & 55,158 & \multirow{2}{*}{3.5615} & \multirow{2}{*}{11} & \multirow{2}{*}{0.004} & \multirow{2}{*}{0.899} \\
\hline & & Real world & & 0.22 & 2,242 & 7,758 & & & & \\
\hline & \multirow{2}{*}{ Operator } & Fair world & \multirow{2}{*}{12} & 23.95 & 245,521 & 144,780 & \multirow{2}{*}{5.7605} & \multirow{2}{*}{11} & \multirow{2}{*}{$<0.001$} & \multirow{2}{*}{0.999} \\
\hline & & Real world & & 0.31 & 3,203 & 8,868 & & & & \\
\hline \multirow{4}{*}{ DW } & \multirow{2}{*}{$\begin{array}{l}\text { Service } \\
\text { company }\end{array}$} & Fair world & \multirow{2}{*}{12} & 22.34 & 78,196 & 48,411 & \multirow{2}{*}{6.1814} & \multirow{2}{*}{11} & \multirow{2}{*}{$<0.001$} & \multirow{2}{*}{0.999} \\
\hline & & Real world & & 2.73 & 9,542 & 15,513 & & & & \\
\hline & \multirow{2}{*}{ Operator } & Fair world & \multirow{2}{*}{12} & 17.35 & 60,711 & 47,027 & \multirow{2}{*}{3.2594} & \multirow{2}{*}{11} & \multirow{2}{*}{0.008} & \multirow{2}{*}{0.842} \\
\hline & & Real world & & 3.67 & 12,833 & 22,943 & & & & \\
\hline
\end{tabular}




\begin{tabular}{|c|c|c|}
\hline Theme & Sub-theme (References) & $\begin{array}{l}\text { Sub-sub-theme } \\
\text { (References) }\end{array}$ \\
\hline \multirow{9}{*}{$\begin{array}{l}\text { Oilfield dilemma } \\
\text { discussion (62) }\end{array}$} & \multirow{2}{*}{ Offer Reward in Ideal World (16) } & No $(2)$ \\
\hline & & Yes (14) \\
\hline & \multirow{2}{*}{ Offer Reward in Real World (17) } & No (9) \\
\hline & & Yes (8) \\
\hline & \multirow{2}{*}{ Offer Tool (15) } & No $(6)$ \\
\hline & & Yes (9) \\
\hline & Long term relationship* $(7)$ & \\
\hline & Expected service* $(3)$ & \\
\hline & Contractual or procurement block* (4) & \\
\hline \multirow{8}{*}{ Servitization level (60) } & \multirow{3}{*}{ Level (17) } & Base $(0)$ \\
\hline & & Intermediate (15) \\
\hline & & Advanced (2) \\
\hline & \multirow{2}{*}{ High servitization $=$ increased chance of win/win (24) } & Agree (13) \\
\hline & & Disagree (2) \\
\hline & \multirow{2}{*}{ Low servitization $=$ reduced chance of win/win $(15)$} & Agree (12) \\
\hline & & Disagree (2) \\
\hline & Contracts and Procurement* (4) & \\
\hline \multirow{11}{*}{$\begin{array}{l}\text { Servitization application } \\
(186)\end{array}$} & Opportunities lost due to lack of servitization (22) & \\
\hline & \multirow{2}{*}{$\begin{array}{l}\text { Awareness of opportunities lost due to lack of } \\
\text { servitization (20) }\end{array}$} & Aware (18) \\
\hline & & Unaware (2) \\
\hline & \multirow{2}{*}{ Adversarial relationship (30) } & No $(6)$ \\
\hline & & Yes (23) \\
\hline & \multirow{2}{*}{ Power (25) } & Authority (13) \\
\hline & & Influence (12) \\
\hline & Organisation size* $(23)$ & \\
\hline & Culture* (22) & \\
\hline & Fading service levels* $(17)$ & \\
\hline & Inter-organisational administration block* (27) & \\
\hline \multirow{9}{*}{ Antecedent factors (121) } & \multirow[t]{3}{*}{ Culture (81) } & $\begin{array}{l}\text { Personal attitude to } \\
\text { adversarial } \\
\text { relationships (29) }\end{array}$ \\
\hline & & Win/lose people (35) \\
\hline & & Win/win people (13) \\
\hline & \multicolumn{2}{|l|}{ Industry Downturn and environment* (26) } \\
\hline & \multirow{2}{*}{ Trend* (16) } & Growing win/win (1) \\
\hline & & Reducing win/win (15) \\
\hline & Revenue and Budget driven* (49) & \\
\hline & Management commitment* (12) & \\
\hline & Internal administration block* (14) & \\
\hline \multirow{4}{*}{$\begin{array}{l}\text { Servitization as a solution } \\
(68)\end{array}$} & Increasing servitization $=$ win/win $(53)$ & \\
\hline & Decreasing servitization $\neq$ win/win $(14)$ & \\
\hline & Decreasing servitization $=$ win/win $(1)$ & \\
\hline & Increasing servitization $\neq$ win/win $(0)$ & \\
\hline \multicolumn{3}{|l|}{ East/West divide* (14) } \\
\hline Short term planning* $(21)$ & & \\
\hline
\end{tabular}

Table IV: Final thematic coding framework, $n=13$ 


\begin{tabular}{|c|c|c|c|}
\hline Type & Defined by & Organisational stretch & Examples of services offered \\
\hline $\begin{array}{l}\text { Base } \\
\text { services }\end{array}$ & $\begin{array}{l}\text { An outcome focused } \\
\text { on product provision }\end{array}$ & $\begin{array}{l}\text { Based on the execution of } \\
\text { production competence (i.e. we } \\
\text { know how to build it) }\end{array}$ & $\begin{array}{l}\text { Product/equipment provision, } \\
\text { spare part provision, warranty }\end{array}$ \\
\hline $\begin{array}{l}\text { Intermediate } \\
\text { services }\end{array}$ & $\begin{array}{l}\text { An outcome focused } \\
\text { on maintenance of } \\
\text { product condition }\end{array}$ & $\begin{array}{l}\text { Based on exploitation of } \\
\text { production competences to also } \\
\text { maintain the condition of } \\
\text { products (i.e. because we know } \\
\text { how to build it, we know how to } \\
\text { repair it) }\end{array}$ & $\begin{array}{l}\text { Scheduled maintenance, } \\
\text { technical helpdesk, repair, } \\
\text { overhaul, delivery to site, } \\
\text { installation, operator training, } \\
\text { operator certification, condition } \\
\text { monitoring, in-field service }\end{array}$ \\
\hline $\begin{array}{l}\text { Advanced } \\
\text { services }\end{array}$ & $\begin{array}{l}\text { An outcome focused } \\
\text { on capability } \\
\text { delivered through } \\
\text { performance of the } \\
\text { product }\end{array}$ & $\begin{array}{l}\text { Based on translation of } \\
\text { production competences to also } \\
\text { manage the product's } \\
\text { performance (i.e. because we } \\
\text { know how to build it, we know } \\
\text { how to keep it operational) }\end{array}$ & $\begin{array}{l}\text { Customer support agreement, } \\
\text { risk and reward sharing contract, } \\
\text { revenue-through-use contract, } \\
\text { rental agreement }\end{array}$ \\
\hline
\end{tabular}




\begin{tabular}{|c|c|c|}
\hline & Qualitative & Quantitative \\
\hline High reward test: $\underline{\text { Service Company (HS) }}$ & \multirow{4}{*}{13 Participants } & 12 Participants \\
\hline High reward test: Operator (HO) & & 12 Participants \\
\hline Low reward test: $\underline{\text { Service Company (LS) }}$ & & 12 Participants \\
\hline Low reward test: $\underline{\text { Operator (LO) }}$ & & 12 Participants \\
\hline Totals ( & 13 & 48 \\
\hline
\end{tabular}

Table II: Research Group Classification and Distribution 


\begin{tabular}{|c|c|c|c|c|c|c|c|c|c|c|}
\hline & & & $\mathbf{n}$ & Mean \% & Mean \$ & SD & $\mathbf{t}$ & df & $\mathbf{p}$ & Power \\
\hline \multirow{3}{*}{ High } & \multirow{2}{*}{$\begin{array}{l}\text { Service } \\
\text { company }\end{array}$} & Fair world & \multirow{2}{*}{12} & 5.84 & 59,899 & 55,158 & \multirow{2}{*}{3.5615} & \multirow{2}{*}{11} & \multirow{2}{*}{0.004} & \multirow{2}{*}{0.899} \\
\hline & & Real world & & 0.22 & 2,242 & 7,758 & & & & \\
\hline & \multirow{2}{*}{ Operator } & Fair world & \multirow{2}{*}{12} & 23.95 & 245,521 & 144,780 & \multirow{2}{*}{5.7605} & \multirow{2}{*}{11} & \multirow{2}{*}{$<0.001$} & \multirow{2}{*}{0.999} \\
\hline & & Real world & & 0.31 & 3,203 & 8,868 & & & & \\
\hline & \multirow{2}{*}{$\begin{array}{l}\text { Service } \\
\text { company }\end{array}$} & Fair world & \multirow{2}{*}{12} & 22.34 & 78,196 & 48,411 & \multirow{2}{*}{6.1814} & \multirow{2}{*}{11} & \multirow{2}{*}{$<0.001$} & \multirow{2}{*}{0.999} \\
\hline \multirow{3}{*}{ Low } & & Real world & & 2.73 & 9,542 & 15,513 & & & & \\
\hline & \multirow{2}{*}{ Operator } & Fair world & \multirow{2}{*}{12} & 17.35 & 60,711 & 47,027 & \multirow{2}{*}{3.2594} & \multirow{2}{*}{11} & \multirow{2}{*}{0.008} & \multirow{2}{*}{0.842} \\
\hline & & Real world & & 3.67 & 12,833 & 22,943 & & & & \\
\hline
\end{tabular}


Oilfield dilemma discussion (62)

\begin{tabular}{|c|c|c|}
\hline \multirow{9}{*}{$\begin{array}{l}\text { Oilfield dilemma } \\
\text { discussion (62) }\end{array}$} & \multirow{2}{*}{ Offer Reward in Ideal World (16) } & No $(2)$ \\
\hline & & Yes (14) \\
\hline & \multirow{2}{*}{ Offer Reward in Real World (17) } & No (9) \\
\hline & & Yes (8) \\
\hline & \multirow{2}{*}{ Offer Tool (15) } & No (6) \\
\hline & & Yes (9) \\
\hline & Long term relationship* (7) & \\
\hline & Expected service* $(3)$ & \\
\hline & Contractual or procurement block* (4) & \\
\hline \multirow{8}{*}{ Servitization level (60) } & \multirow{3}{*}{ Level (17) } & Base $(0)$ \\
\hline & & Intermediate (15) \\
\hline & & Advanced (2) \\
\hline & \multirow{2}{*}{ High servitization $=$ increased chance of win/win (24) } & Agree (13) \\
\hline & & Disagree (2) \\
\hline & \multirow{2}{*}{ Low servitization $=$ reduced chance of win/win $(15)$} & Agree (12) \\
\hline & & Disagree (2) \\
\hline & Contracts and Procurement* (4) & \\
\hline \multirow{11}{*}{$\begin{array}{l}\text { Servitization application } \\
(186)\end{array}$} & Opportunities lost due to lack of servitization (22) & \\
\hline & \multirow{2}{*}{$\begin{array}{l}\text { Awareness of opportunities lost due to lack of } \\
\text { servitization (20) }\end{array}$} & Aware (18) \\
\hline & & Unaware (2) \\
\hline & \multirow{2}{*}{ Adversarial relationship (30) } & No (6) \\
\hline & & Yes (23) \\
\hline & \multirow{2}{*}{ Power (25) } & Authority (13) \\
\hline & & Influence (12) \\
\hline & Organisation size* $(23)$ & \\
\hline & Culture* (22) & \\
\hline & Fading service levels* (17) & \\
\hline & Inter-organisational administration block* (27) & \\
\hline \multirow{9}{*}{ Antecedent factors (121) } & \multirow[t]{3}{*}{ Culture (81) } & $\begin{array}{l}\text { Personal attitude to } \\
\text { adversarial } \\
\text { relationships (29) }\end{array}$ \\
\hline & & Win/lose people (35) \\
\hline & & Win/win people (13) \\
\hline & \multicolumn{2}{|l|}{ Industry Downturn and environment* (26) } \\
\hline & \multirow{2}{*}{ Trend* (16) } & Growing win/win (1) \\
\hline & & Reducing win/win (15) \\
\hline & Revenue and Budget driven* (49) & \\
\hline & Management commitment* (12) & \\
\hline & Internal administration block* (14) & \\
\hline \multirow{4}{*}{$\begin{array}{l}\text { Servitization as a solution } \\
(68)\end{array}$} & Increasing servitization $=$ win/win (53) & \\
\hline & Decreasing servitization $\neq$ win/win (14) & \\
\hline & Decreasing servitization $=$ win/win $(1)$ & \\
\hline & Increasing servitization $\neq$ win/win $(0)$ & \\
\hline \multicolumn{3}{|l|}{ East/West divide* (14) } \\
\hline Short term planning* $(21)$ & & \\
\hline
\end{tabular}
(References)

Short term planning* (21)

Table IV: Final thematic coding framework, $n=13$ 


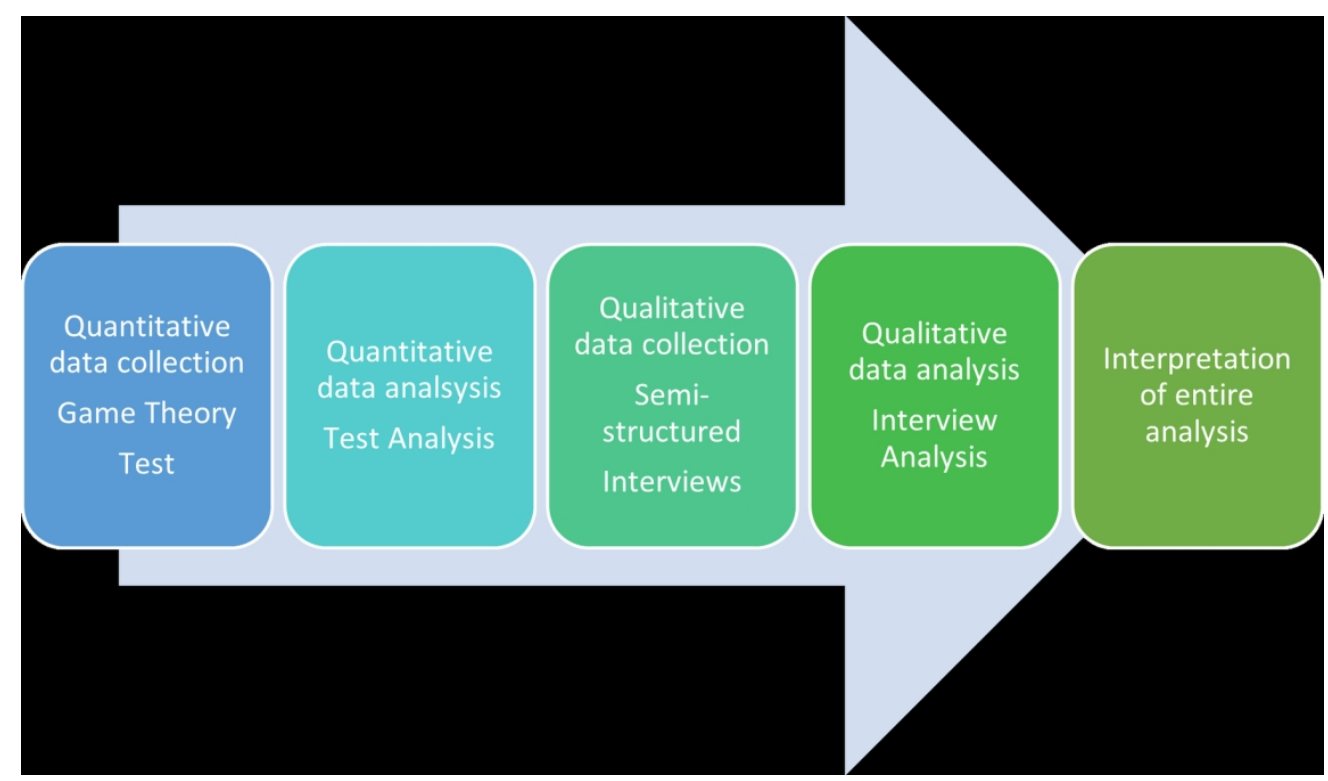

Figure 1 Sequential Explanatory Design, Adapted from Creswell et al., (2003, p. 180) $152 \times 88 \mathrm{~mm}(300 \times 300$ DPI $)$ 


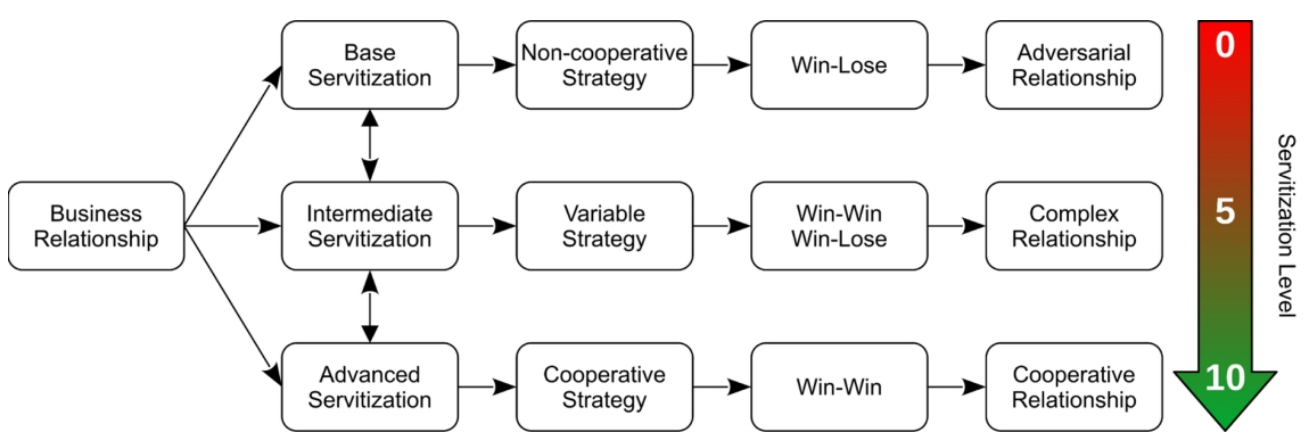

Figure 2 Hypothesised relationship between servitization level and game type $159 \times 50 \mathrm{~mm}(300 \times 300 \mathrm{DPI})$ 


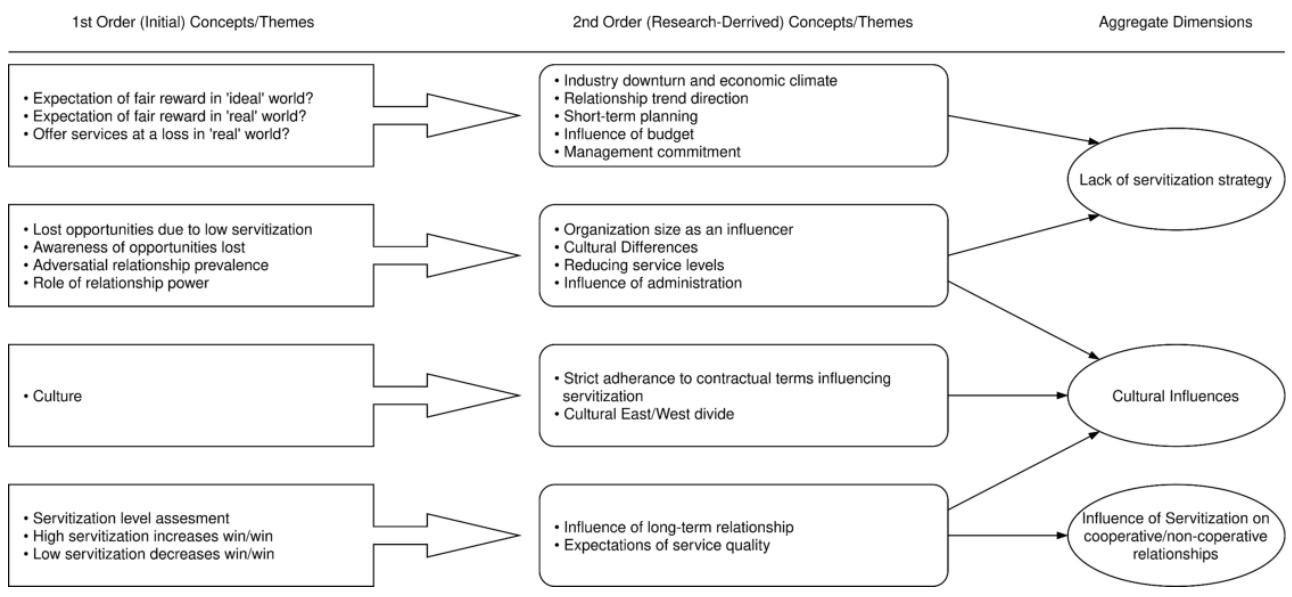

Figure 3: Data Structure, Adapted from Corley and Gioia (2004, p. 184) $158 \times 70 \mathrm{~mm}(600 \times 600 \mathrm{DPI})$ 


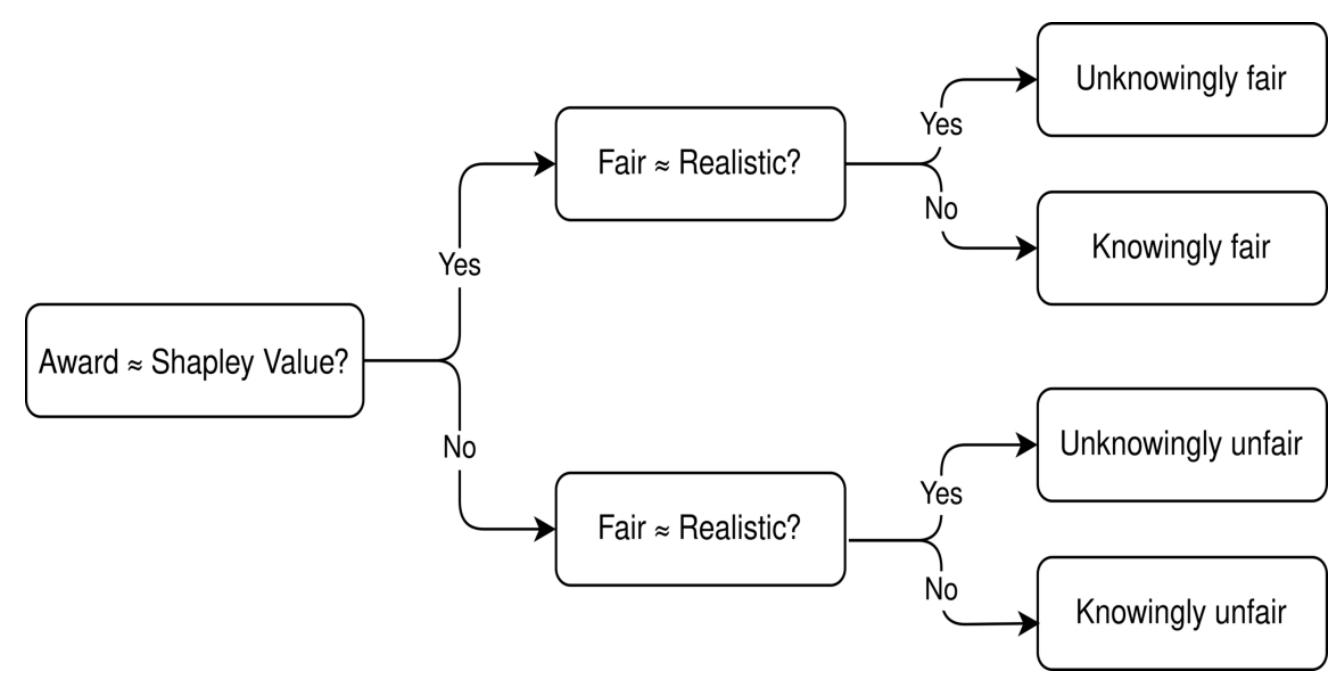

Figure 4: Fairness Analysis Flow Chart $136 \times 67 \mathrm{~mm}(600 \times 600 \mathrm{DPI})$ 


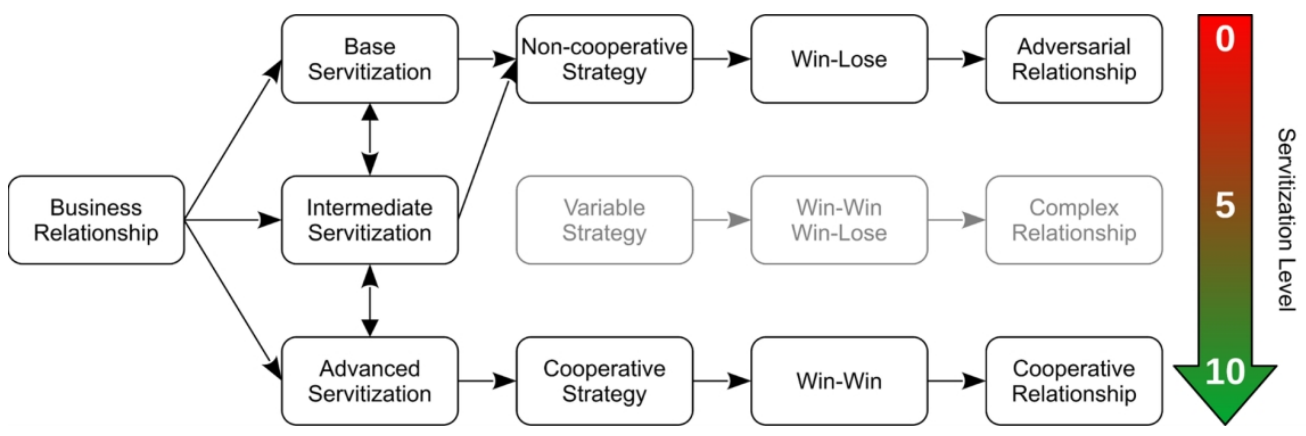

Figure 5: Proposed relationship between servitization level and game type

$159 \times 50 \mathrm{~mm}(300 \times 300$ DPI $)$ 
Figure 6: Sketch Showing Assumed and Proposed Relationship Between Servitization Level and Servitization Benefits

$273 \times 135 \mathrm{~mm}(96 \times 96$ DPI) 


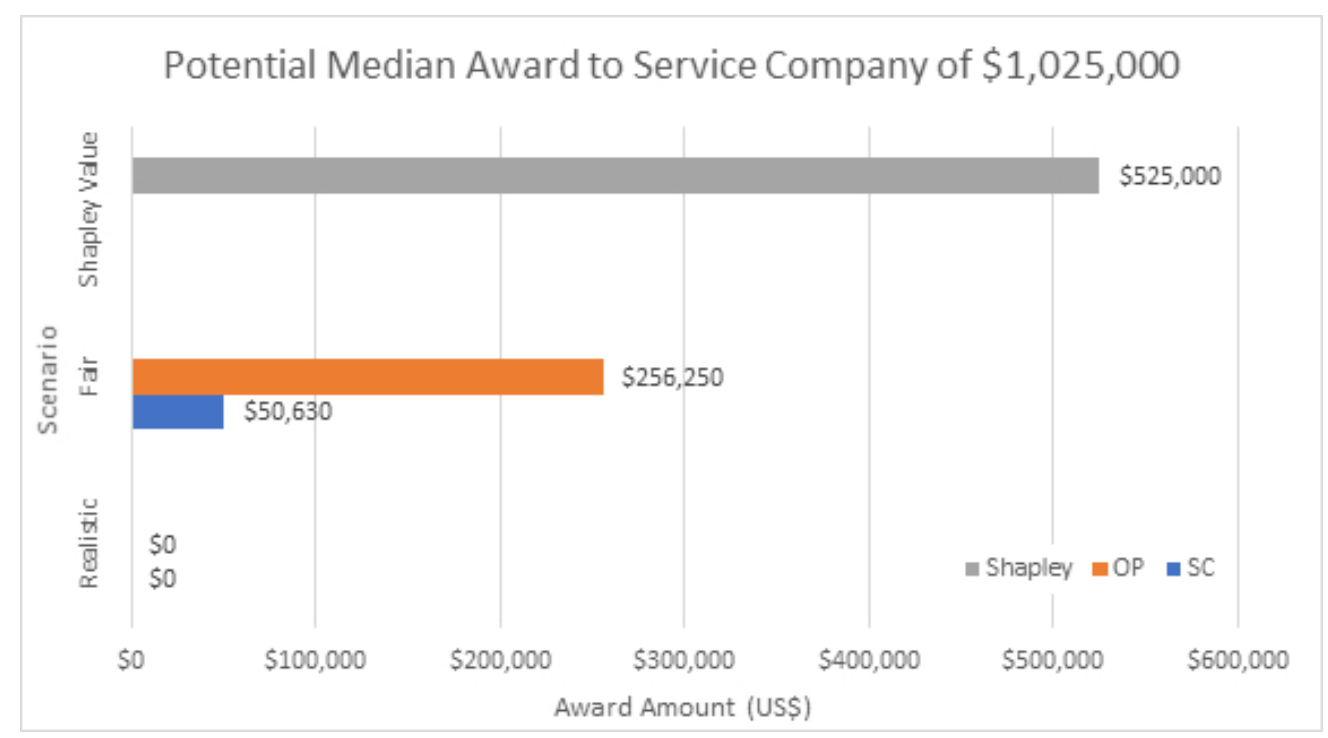

Graph 1: Median award to SC when value $=\$ 1,025,000 . n=24$

$152 \times 83 \mathrm{~mm}(96 \times 96 \mathrm{DPI})$ 


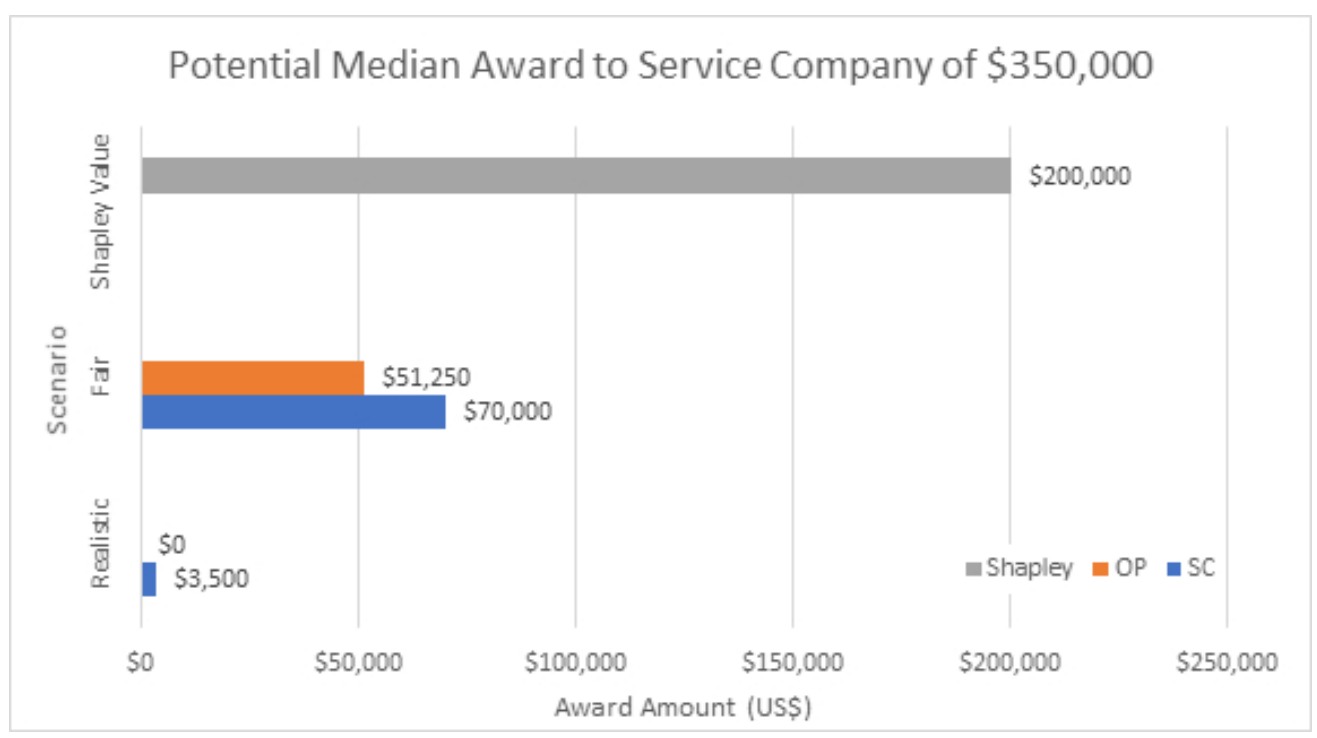

Graph 2: Median award to SC when value $=\$ 350,000 . n=24$

$152 \times 83 \mathrm{~mm}(96 \times 96 \mathrm{DPI})$ 